\title{
THE RECENT CARBONATE SEDIMENTS OF PALMYRA ATOLL, NORTHERN LINE ISLANDS, CENTRAL PACIFIC OCEAN
}

\author{
Oscar Clark
}

A thesis submitted to Victoria University of Wellington,

As partial fulfilment of the requirements for the degree of Master of Science in Geology

School of Geography, Environmental and Earth Sciences,

Victoria University of Wellington

2008 


\section{FRONTISPIECE}

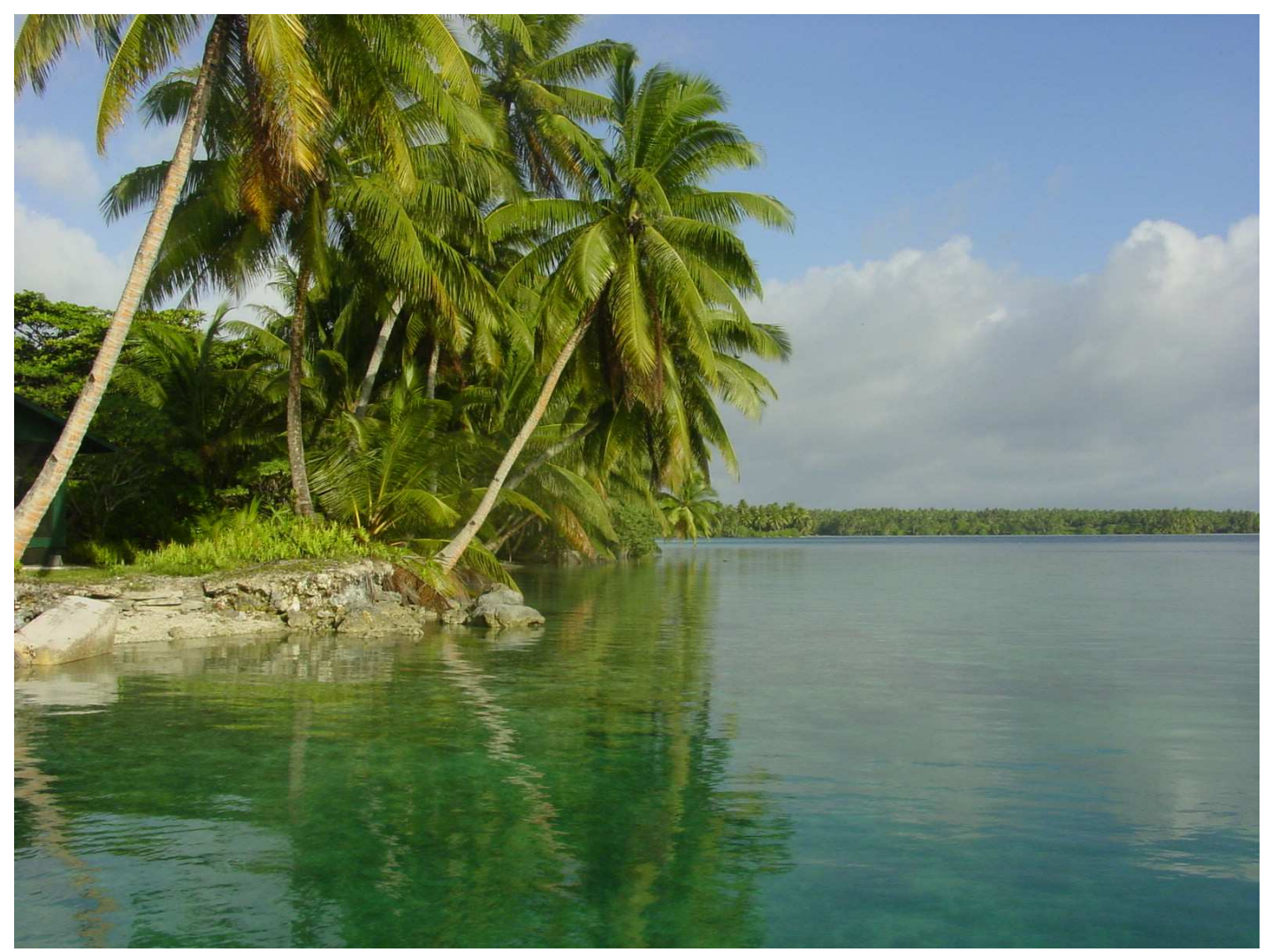

West Lagoon, Palmyra Atoll, Northern Line Islands 


\title{
The recent carbonate sediments of Palmyra Atoll, northern Line Islands, central Pacific Ocean.
}

Oscar Clark 2008

\begin{abstract}
Palmyra Atoll is an isolated carbonate reef system located approximately $1600 \mathrm{~km}$ south of Hawaii in the northern Line Islands, central Pacific Ocean. Sediment samples from the lagoons and tidal zones were analyzed for grainsize and composition, and the results used to compile detailed maps and interpret the environments and lithofacies present. A distinct grainsize distribution was observed forming concentric bands ranging from coarse gravel rubble on the outer reef through to finer material in the interior of the atoll in the deep lagoons, where peloidal muds prevail. Five lithologic facies have been identified and typical sediments are poorly sorted and near-symmetrical in their grainsize distribution. On average, sediments are medium sand. A distinct chlorozoan assemblage was observed with coral and calcareous red algal fragments forming half of the sediment, with varying amounts of molluscs, Halimeda and foraminifera being the lesser major constituents. Lagoonal and tidal sediments showed little variation in composition between locations and lacked clear compositional zonation, characteristic of other larger atolls of the Pacific. Palmyra Atoll is unique in that it has had little human intervention for the last sixty years and as a result uninhibited natural processes are occurring. It is also unique in that it displays relatively deep for its size $(<55 \mathrm{~m})$, steep-sided compartmentalized lagoons that have abundant fine material (upward of $70 \%$ silt or finer), a feature not commonly observed at other Pacific atolls. This fine material has been identified as a peloidal mud and its mode and rate of deposition may be partly controlled by the abundant zooplankton in the lagoons. Recent sediments of Palmyra Atoll are almost entirely carbonate, originating from reef organisms inhabiting the atoll. The only other material is small amounts of siliceous sponge skeletons.
\end{abstract}




\section{Acknowledgments}

There are many people whom I would like to extend my thanks to for their assistance in making this project possible. First, I would like to acknowledge the expertise, support and extensive assistance I have received from my supervisor, Dr. John Collen. The many hours he has spent to organize this project, the gruelling hours spent hauling the dredge rope under the searing hot Palmyra sun, and not forgetting the countless hours spent proofreading and editing. The nock at his door was always replied by a friendly “yip"!

I would like to thank everyone from TNC and U.S. Fish and Wildlife who without their support the trip to Palmyra would not have been possible. Many thanks to the wonderful hospitality I received upon the island from the Palmyra locals! Great food and great stories.

Thanks to the other members of the Victoria university staff and students who accompanied us to Palmyra in June 2007, James Allen, Jonathan Gardner, Laura wicks and Gareth Williams for making the trip so successful. Also to John Carter, John Paterson and Jill Ruthven who provided much assistance towards this project at university.

A special thank you to my parents, Jo-Anne and Glenn Clark, for always being there when I needed you, for all the funds, food and good advice along the way! Thanks to my little brother Dylan, my extended family and my good friends Cameron, Johann, Matt, Ivan, Jonathan, Kelly, Alice, William, Sandy, Melissa and many others for your comic relief and persistent methods of filling up all my spare time. A very special thank you to Regan Brash (and her family) for all the support and encouragement along the way, I don't know what I would have done without it.

Big props to my fellow Geology Brothers and Sisters! We made it after all! Thanks to Chris, Dhiresh Timmy, Joe, Matt, Andrew, Dave, Paul, Alex, Adian, Julene, Hannu, and everyone else from my graduating year and my many other friends of the rock. We've had some great times! I look forward to many more! 


\section{Table of Contents}

$\begin{array}{lll}\text { Frontispiece } & \text { II }\end{array}$

$\begin{array}{lll}\text { Abstract } & \text { III }\end{array}$

Acknowledgments

Table of contents $\quad$ V

List of figures $\quad \mathrm{X}$

List of tables $\quad$ XIII

$\begin{array}{ll}\text { Chapter One: Introduction } & 1\end{array}$

1.1 Introduction 1

1.2 Location of study area: Palmyra Atoll 1

1.3 Geological setting 4

1.3.1 Geochronological evidence for Palmyra Atoll volcanic formation 6

$\begin{array}{ll}1.4 \text { History of reef development, growth and subsidence } & 6\end{array}$

1.4.1 Controlling factors of reef development 9

$\begin{array}{ll}1.5 \text { Previous work } & 9\end{array}$

$\begin{array}{ll}\text { 1.6 Research at Palmyra Atoll } & 11\end{array}$

$\begin{array}{ll}1.7 \text { VUW research at Palmyra Atoll } & 12\end{array}$

$\begin{array}{lr}\text { Chapter Two: Environmental Setting } & 13\end{array}$

2.1 Geomorphology, atoll and lagoon bathymetry 13

$\begin{array}{ll}2.2 \text { Oceanography } & 13\end{array}$

2.2.1 Winds, waves, tides and currents 13

2.2.2 Salinity, dissolved oxygen, sea and lagoon temperature $\quad 14$

$\begin{array}{ll}\text { 2.2.3 Light penetration } & 19\end{array}$

$\begin{array}{ll}2.3 \text { Climate regime } & 19\end{array}$

2.3.1 Effect of El Nino Southern Oscillation (ENSO) 19

$\begin{array}{ll}\text { 2.3.2 Extreme events; tropical storms } & 21\end{array}$ 
2.4 Biology and ecology of Palmyra atoll 22

2.4.1 Dry land biota 22

2.4.2 Marine Biota 22

2.5 History of human settlement 23

2.5.1 History of human modification 26

2.5.2 Effects of modification $\quad 27$

2.6 Shoreline changes and sediment redistribution 31

Chapter 3: Sampling and methods $\quad 34$

3.1 Sampling $\quad 34$

3.2 Grain size analytical procedures and Processing 35

3.2.1 Process method 1 - Dominantly sand sized samples 35

3.2.2 Process method 2-Dominantly sand sized samples with removal of organic material 37

3.2.3 Process method 3 - Silt and clay samples 37

3.2.4 Process method 4 - Silt and clay samples 38

3.3 Problems encountered with grain size analysis and solutions utilized 38

3.3.1 Removal of organics 38

3.3.2 Disaggregation 39

3.4 Composition counts $\quad 39$

3.4.1 Binocular point counting $\quad 39$

3.4.2 Errors associated with compositional analysis $\quad 42$

3.5 Photography 42

3.6 Maps $\quad 42$

3.7 Conductivity, temperature and depth (CTD) casts 42

3.8 Total organic carbon 43

3.9 Errors and limitations 43 
4.1 Environmental zones found on Palmyra atoll 47

4.1.1 Fore reef and crest $\quad 48$

4.1.2 Eastern and western reef terraces $\quad 49$

4.1.3 Ocean outer reef flat $\quad 50$

4.1.3 a. Pavement $\quad 50$

4.1.3 b. Ocean-facing beach 51

4.1.4 Lagoon inner reef flat 53

4.1.4 a. Intertidal sand aprons and sheets 53

4.1.4 b. Inner beach 54

4.1.5 Lagoons $\quad 55$

4.1.5 a. Shallow lagoons $\quad 55$

4.1.5 b. Deep lagoons 55

4.1.5 c. Patch reefs / raised sand banks 56

4.1.5 d. Blue holes $\quad 58$

4.1.6 Reef islands $\quad 59$

4.2 Lithofacies descriptions: composition, texture and distribution 65

$\begin{array}{ll}\text { 4.2.1 Peloidal mud lithofacies } & 67\end{array}$

4.2.2 Muddy sand lithofacies $\quad 68$

$\begin{array}{ll}\text { 4.2.3 Coralalgal sand lithofacies } & 68\end{array}$

4.2.4 Rubble lithofacies $\quad 69$

4.2.5 Cemented pavement and beachrock lithofacies 71

$\begin{array}{ll}\text { 4.2.6 Living reef Lithofacies } & 73\end{array}$

$\begin{array}{lr}\text { Chapter 5: Sedimentology, processes and products } & \mathbf{7 8}\end{array}$

$\begin{array}{ll}\text { 5.1 Sediment composition } & 78\end{array}$

5.1.1 Coral and red algae fragments $\quad 80$

5.1.2 Molluscs $\quad 80$

$\begin{array}{ll}\text { 5.1.3 Calcareous green algae } & 81\end{array}$ 
5.1.4 Foraminifera $\quad 81$

5.1.5 Crustacea 86

5.1.6 Echinoids

$\begin{array}{ll}\text { 5.1.7 Other } & 87\end{array}$

5.1.8 Discussion of sediment composition $\quad 88$

5.1.9 Total organic carbon content $\quad 89$

$\begin{array}{ll}5.2 \text { Sediment source and erosion processes } & 91\end{array}$

5.2.1 Borers 93

5.2.2 Predators 94

5.2.3 Grazers 94

5.2.4 Browsers 95

5.2.5 Further effects of organisms on sediments; Encrustation and bioturbation 96

5.3 Grain size and sorting $\quad 97$

5.3.1 Measurement of average grain size $\quad 97$

$\begin{array}{ll}\text { 5.3.3 Sorting } & 98\end{array}$

5.3.4 Measures of Skewness $\quad 99$

5.3.5 Textural classification 101

$\begin{array}{ll}\text { 5.3.6 Depositional texture } & 101\end{array}$

$\begin{array}{ll}\text { 5.3.7 Roundness } & 101\end{array}$

$\begin{array}{ll}\text { 5.3.8 Discussion of grainsize characteristics } & 102\end{array}$

$\begin{array}{ll}5.4 \text { Sediment movement } & 103\end{array}$

5.4.1 Sedimentary structures and other evidence of sediment movement 106

$\begin{array}{ll}5.4 .2 \text { Image interpretation } & 109\end{array}$

$\begin{array}{ll}5.5 \text { Sedimentation rate } & 109\end{array}$

$\begin{array}{ll}\text { 5.6 Chemical alteration of sediment } & 110\end{array}$

$\begin{array}{ll}5.7 \text { Correlation analysis } & 110\end{array}$

$\begin{array}{ll}\text { Chapter Six: Discussion } & 111\end{array}$

6.1 Biological Control of control of sedimentation rate in deep lagoons 115 
6.1.2 Implications of pellet formation $\quad 122$

6.2 Controls on facies and environ distribution by antecedent topography 122

$\begin{array}{ll}6.3 \text { Comparison to other atolls and tropical carbonate systems } & 124\end{array}$

$\begin{array}{ll}\text { 6.4 Difficulties encountered and recommendations for future study } & 127\end{array}$

$\begin{array}{ll}6.5 \text { Summary and Conclusions } & 128\end{array}$

$\begin{array}{ll}\text { References } & 132\end{array}$

Appendices

A Summary of sample data

B Grain size data overview

C Grain size data and graphs for individual samples

D Composition data

E NOAA bathymetry map

F Ikonos satellite image with grid

G Environment maps (Enlarged copies)

$\mathrm{H} \quad$ Facies distribution maps (Enlarged copies)

I Textural classification Folk's maps (Enlarged copies)

J Depositional textures maps (Enlarged copies) 


\section{List of Figures}

1.1 Map of central Pacific Ocean showing location of the Line Islands and Palmyra atoll

1.2 Geographical Map of Palmyra Atoll showing labelled islands, lagoons and reefs

1.3 Satellite image of Palmyra Atoll 4

1.4 Major geological features of Central Pacific Ocean 5

1.5 Slope map from CRED/PIFSC with 50-m bathymetric contours for Palmyra Atoll

2.1 Examples of typical deeper water CTD profiles from (A) West Lagoon, (B) Center Lagoon, and (C) East Lagoon.

2.2 Map of Palmyra Atoll lagoon system showing sample sites, cross section lines, bathymetry and the distribution of anoxic and dysoxic zones for (A) West Lagoon, (B) Central Lagoon, (C) East Lagoon

2.3 Comparison of proxy climate records and external forcing during the last millennium, ENSO

2.4 Outline of Palmyra Atoll reef islands from 1974 to 2000

2.5 Time sequence diagrams showing hypothetical changes in water circulation patterns at Palmyra since 1939 and projected to 2039

2.6 Schematic diagram showing wave and current direction and sediment movement under north-easterly trade wind conditions

2.7 Shoreline changes around Strawn peninsula and Cooper-Meng Island $1945-2000$

2.8 Shoreline changes around the eastern coast of Palmyra atoll $1945-200033$

2.9 Shoreline changes around the southern areas of Palmyra atoll 1945-2000 33

3.1 Photo of dredge used to retrieve sediment from the lagoon substrate

3.2 Bathymetric basemap of Western Lagoon section showing sample

Locations

3.3 Bathymetric basemap of Central Lagoon section showing sample 
3.4 Bathymetric basemap of Eastern Lagoon section showing sample Locations

4.1 Cross section showing a generalized view and association of reef environments and their respective boundaries to each other.

4.2 Aerial view looking south across Strawn peninsular, West lagoon and then Paradise and home in the background in 1979

4.3 Typical pavement rock devoid of unconsolidated material

4.4 Looking west along ocean facing beach on the northern side of Strawn Peninsular

4.5 Looking west along accreting North Beach, northern side of Cooper-Meng Island

4.6 Inner reef flat Intertidal sand aprons and sheets, looking west from Paradise Island towards Home Island

4.7 Living patch reef between Barren Island and East Island called the Coral Gardens at low tide

4.8 Aerial view of northern part of N-S causeway between Central and Eastern Lagoons taken in 1979

4.9 Aerial view of Turtle Pool a blue hole located east of East Island in 197958

$\begin{array}{ll}4.10 & \text { North Fighter Strip eroding }\end{array}$

4.11 View north at low tide through the passage way between Quail and $\begin{array}{ll}\text { Aviation Islands towards the ocean } & 61\end{array}$

4.12 Environment zone map of West Lagoon 62

4.13 Environment zone map of Center Lagoon 63

4.14 Environment zone map of East Lagoon $\quad 64$

4.15 Folk’s (1974) textural classification with modifications by Blair et al. $\begin{array}{ll}\text { (1999) } & 67\end{array}$

4.16 Coralalgal sand facies from interior reef flat sand sheets 69

$\begin{array}{lll}4.17 & \text { Typical rubble facies material } & 70\end{array}$

$\begin{array}{lll}4.18 & \text { Weathered rubble facies showing clast dissolution }\end{array}$ 
4.19 Stratified seaward sloping beachrock, southern coast of Paradise Island 72

4.20 Typical Beachrock showing stratification, Southern coast of Paradise Island $\quad 73$

$\begin{array}{lll}4.21 & \text { Facies distribution map of West Lagoon } & 74\end{array}$

4.22 Facies distribution map of Center Lagoon 75

$\begin{array}{lll}4.23 & \text { Facies distribution map of East Lagoon } & 76\end{array}$

5.1 Proportion of the major sediemnt components identified in 22 samples $\begin{array}{ll}\text { from Palmyra Atoll } & 78\end{array}$

5.2 Molluscan composition percentage for 22 samples analysed 81

5.3 Percentage of species of total foraminifera counted from 22 samples $\begin{array}{ll}\text { on Palmyra Atoll } & 82\end{array}$

5.4 Foraminiferal composition for 22 samples analysed. Samples are arranged from east to west and in decreasing water depth for each lagoon $\quad 83$

$\begin{array}{ll}\text { Plate 5.1 Foraminifera } & 84\end{array}$

$\begin{array}{ll}\text { Plate 5.2 Foraminifera and other } & 85\end{array}$

5.5 Crustacean composition of 22 samples analysed 86

5.6 Contribution of echinoid clasts to the 22 samples analysed 87

5.7 Composition of the "Other" component for the 22 samples analysed 88

5.8 Summary representation of the average compositions of six major sediment components for 22 samples from the lagoons and interior tidal areas of Palmyra Atoll. A larger version of this figure is in Appendix D 89

5.9 Depth in m of sample recovery compared to percentage of loss from $\begin{array}{ll}\text { chemical organic removal process } & 91\end{array}$

5.10 Photo of Holothurians living behind small fighter strip on Palmyra Atoll 96

5.11 Graphic mean grain size of samples plotted against water depth $(n=51) 98$

5.12 Percentage diagram of sorting of 51 processed samples from Palmyra

Atoll interior

5.13 Percentage diagram of skewness of 51 processed samples from Palmyra Atoll interior

5.14 Generalized transect of Palmyra from crest to lagoon comparing gravel, 
sand, silt and finer sized sediments. Also showing environmental zones and facies 102 5.15 Storm ridge forming Barren Island

5.16 Photos (clockwise from top left) of mound approximately $40 \mathrm{~cm}$ in

diameter showing layering and groove caused by exhalant sand and water;

crab mound and depression landscape; and reef box crab (Calappa hepatica)

$\begin{array}{ll}\text { burrowing in to fine sand } & 108\end{array}$

5.17 Comparison of water depth against percentage of fines for 51 samples 110

6.1 Typical pellets found in deep lagoon Peloidal mud 116

$\begin{array}{lll}\text { 6.2 Photo of Creseis virgula constrica shells } & 117\end{array}$

6.3 Hypothetical vector diagram of three particle sizes (not drawn to scale) 121

6.4 Formation of atolls according to Purdy (1974), by Guilcher (1988) 123

\section{List of Tables}

3.1 Grain size scale for sediments, showing sieve size in millimetres and equivalent phi $(\Phi)$ units and Wentworth size class 36

3.2 Categories used for compositional counts 41

4.1 Classification of limestone according to depositional textures

(Dunham 1962 modified by Embry et al. 1972)

5.1 Compositional categories identified during counting of the gravel and sand-sized fractions for 22 sediment samples from the lagoons and interior tidal areas of Palmyra Atoll 79

5.2 Loss of weight recorded for organic removal process 90

5.3 Different types of bioeroders that affect tropical carbonates, categorised by their primary modes of erosion.

6.1 Summary of current meter data for June 2008 (J.P.A. Gardner pers. comm. 2008) 


\section{Chapter One: Introduction}

\subsection{Introduction}

This thesis is a study of the recent carbonate sediments of Palmyra Atoll in the northern Line Islands, central Pacific Ocean. The objective was to map, sample, analyse and describe for the first time the sediments of the lagoons and reef flats, and to discuss their origin and distribution, together with the sedimentary controls.

A variety of sedimentary techniques have been utilized and integrated with the present day environmental parameters, including the results of historical anthropogenic modifications to the atoll. The research complements other studies at Palmyra looking at shoreline change, coral health and settlement, the status of tridacnid clams, and related studies including the development of island management options as outlined by Gardner et al. 2007 (see section 1.7 VUW research at Palmyra Atoll).

Palmyra Atoll is a highly isolated location and as such there are many obstacles associated with visiting. The only transport to the island is by chartered private flights from Hawai'i. The atoll is one of only a handful of privately owned U.S territories and there are very specific guidelines and conditions for entering and working on the island. The geology and sediments of Palmyra present their own difficulties due to a lack of previous study and long term data, and often inaccessible environments.

\subsection{Location of study area: Palmyra Atoll topographic setting}

Palmyra Atoll (Fig 1.1, 1.2, 1.3) is a remote coral atoll island system in the northern Line Islands archipelago in the west-central Pacific Ocean, approximately 1,930 km (U.S. Dep of Interior 2006) to the southwest of Honolulu and $570 \mathrm{~km}$ north of the equator at $05^{\circ} 52^{\prime}$ North and $162^{\circ} 06$ West. Palmyra is the northernmost atoll of the 12 Line Islands, and only Kingman Reef lies further north. The atoll lies on the complex northwest - southeast 
trending Line Islands Submarine Ridge (Davis et al. 2002, Maragos et al. A 2008). Palmyra atoll consists of an elliptical reef $20 \mathrm{~km}$ in length in an east to west direction and $3.5 \mathrm{k} \mathrm{m}$ wide with elongated fore reef terraces extending $3-5 \mathrm{~km}$ off the eastern and western ends of the atoll from depths of 7 to $25 \mathrm{~m}$ (Fig 1.2). The reef flat of Palmyra appears tilted from west to east, with the western portion submerged. The submergence has apparently resulted from a long period of solution on the western side as growth has proceeded actively eastward (Dawson 1959). The central area of the atoll is encircled by shallow perimeter reefs that supported some 50 islets and three sub-lagoons separated by shallow north - south linear reefs before the Second World War. The atoll underwent a brief but substantial period of military modification to form a naval airbase between 1940 and 1945. This resulted in the islets of the atoll being connected, except for Sand Island in the west and Barren Island in the east. The largest island is Cooper-Meng Island in the north, followed by Kaula Island in the south. The northern rim of islets is formed by Strawn Island, Cooper-Meng Island, Aviation Island, Quail Island and Whippoorwill Island, followed along the east by Eastern Island, Papala Island, and Pelican Island, and to the south by Bird Island, Holei Island, Engineer Island, Tananger Island, Marine Island, Kaula Island, Paradise Island and Home Island (clockwise Fig 1.2). Palmyra Atoll has a combined total land area of 2.5 square $\mathrm{km}$ (Collen et al. 2009) and has an average land elevation of approximately 2 metres above sea level.

Palmyra atoll, its lagoons and accompanying coral reefs are a large structure and provide challenges in undertaking a detailed scientific geological study. The primary area of concern for this project was to investigate the three major lagoon sections, reef flats and shorelines located within the encompassing islet ring that makes up Palmyra atoll. These are known as West, Center and East lagoons (Fig 1.2). 


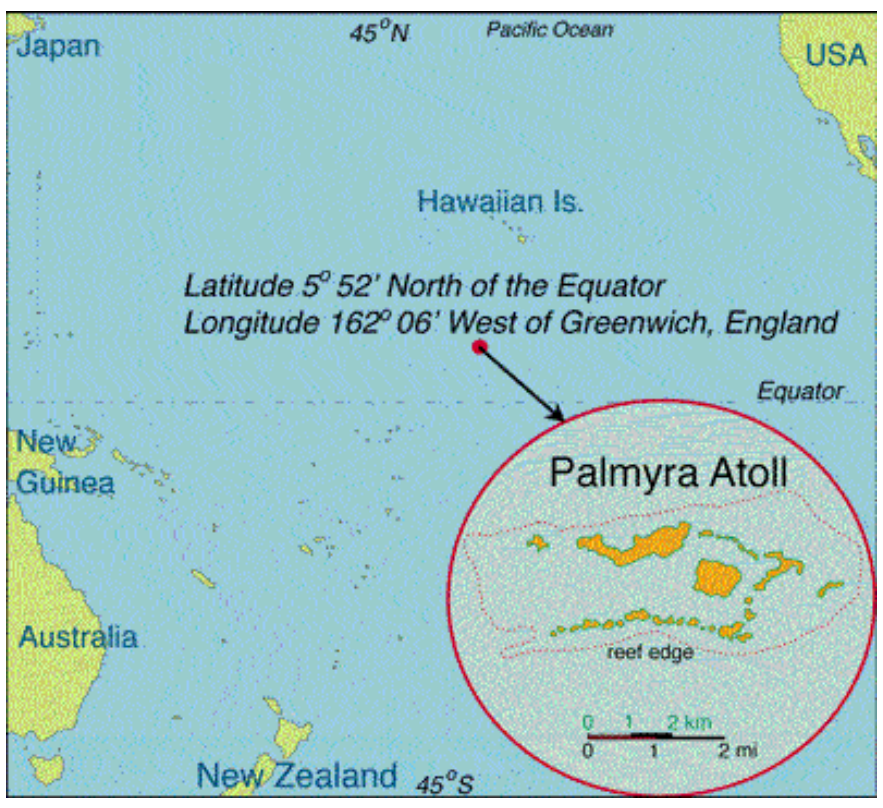

Fig 1.1 Map of central Pacific Ocean showing location of the Line Islands and Palmyra atoll.

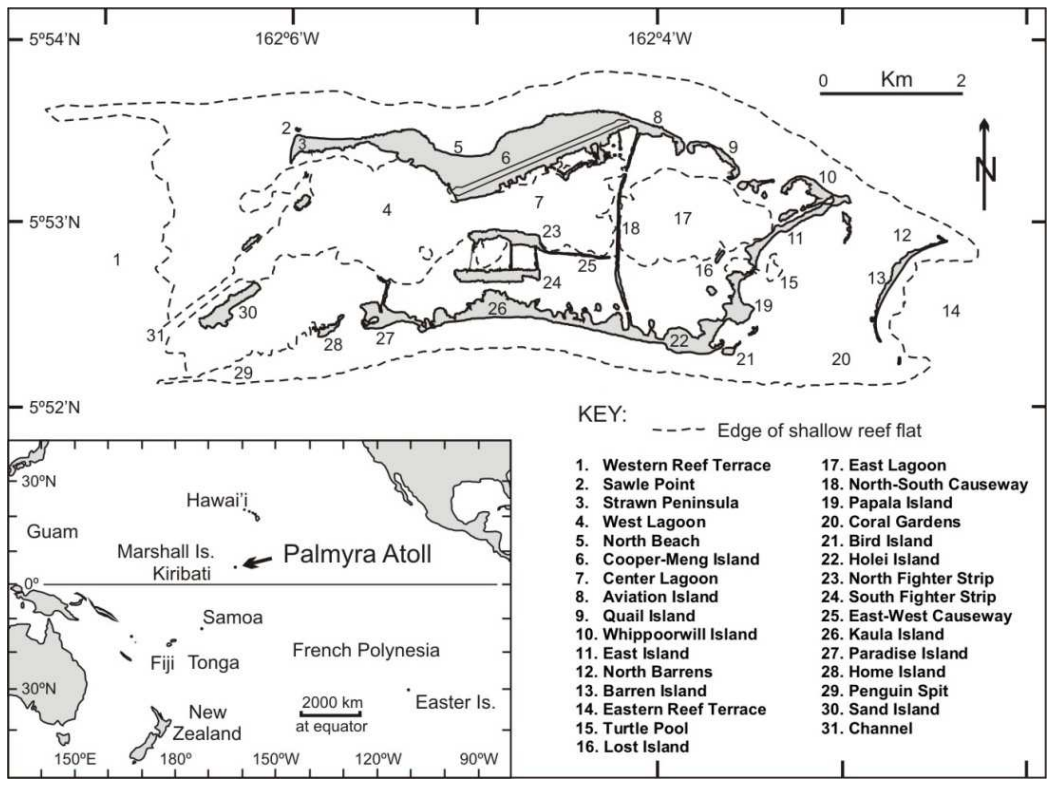

Fig 1.2 Geographical Map of Palmyra Atoll showing labelled islands, lagoons and reefs (from Collen et al. 2009) 


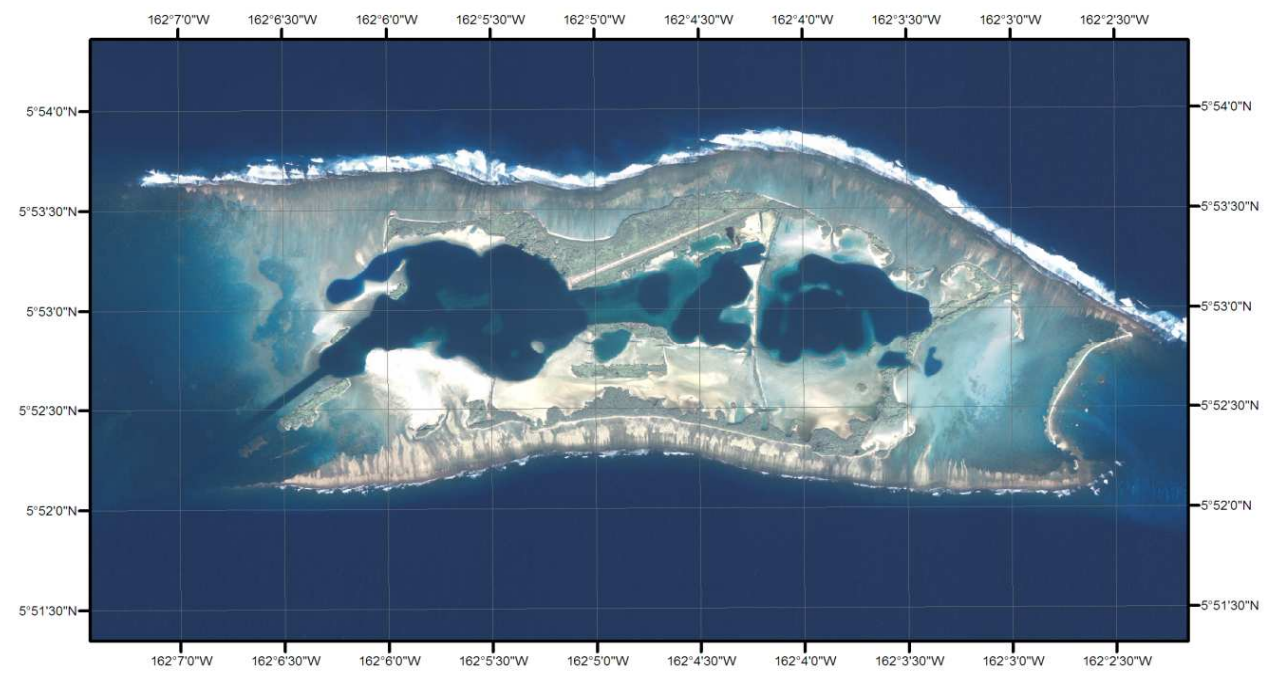

Fig 1.3 Ikonos satellite image (2000) of Palmyra Atoll, courtesy of the U.S. Fish and Wildlife Service and Space Imaging, Inc.

\subsection{Geological setting}

Palmyra Atoll is a remote atoll composed of thick carbonate deposits overlying a volcanic base, on the northwest - southeast trending Line Islands chain, a complex bathymetric chain of atolls, submarine ridges and seamounts in the central Pacific Ocean, southwest of Hawai'i. The $>4000 \mathrm{~km}$ long chain extends from the Mid-Pacific Mountains, at $20^{\circ} \mathrm{N}$, $170^{\circ} \mathrm{W}$, southeast to the north end of the Tuamotu Islands Submarine Ridge (Davis et al. 2002). In the vicinity of the Line Islands chain the central Pacific seafloor is a complex area and not well understood from a geological perspective (Maragos et al. A 2008). The Line Island chain lies within the Darwin Rise. This is an area of the Pacific Ocean that is between $200-700 \mathrm{~m}$ shallower than the surrounding oceanic lithosphere, and is magnetically "quiet" seafloor formed during the Cretaceous Normal Superchron (120 to $83 \mathrm{ma}$ ) (Atwater et al. 1993). The underlying seafloor along the Line Islands chain ranges from mid-Cretaceous (119 Ma) at the northern end to the late Cretaceous (83Ma) at the southern end (Davis et al. 2002) 
The volcanic structures of the Line Islands are diverse in shape, size, composition and morphology (Davis et al. 2002). The Line islands Ridge (Fig 1.4) has numerous parallel and NW-SE trending features and is intersected by three fracture zones: Molokai, Clarion and Clipperton (Maragos et al. A 2008). The Line Islands chain is divided into three geomorphic provinces, the Northern, Central and Southern provinces. Palmyra Atoll is located at the southern end of the Northern Province which extends from the mid Pacific mountains to a gap in the chain at $12^{\circ} \mathrm{N}$ latitude coinciding with a westwards extension of the Clarion Fracture Zone (Fig 1.4) (Davis et al. 2002).

"Owing to the remote location, complexity, and vast length of the Line Islands chain, it has not been thoroughly studied and only limited geological drilling and dredging has been done along the Line Islands submarine ridge (Schlanger et al. 1976; Schlanger et al. 1984; Garcia et al. 1993; Haggerty et al. 1982; Davis et al. 2002)" (Maragos et al. A 2008).

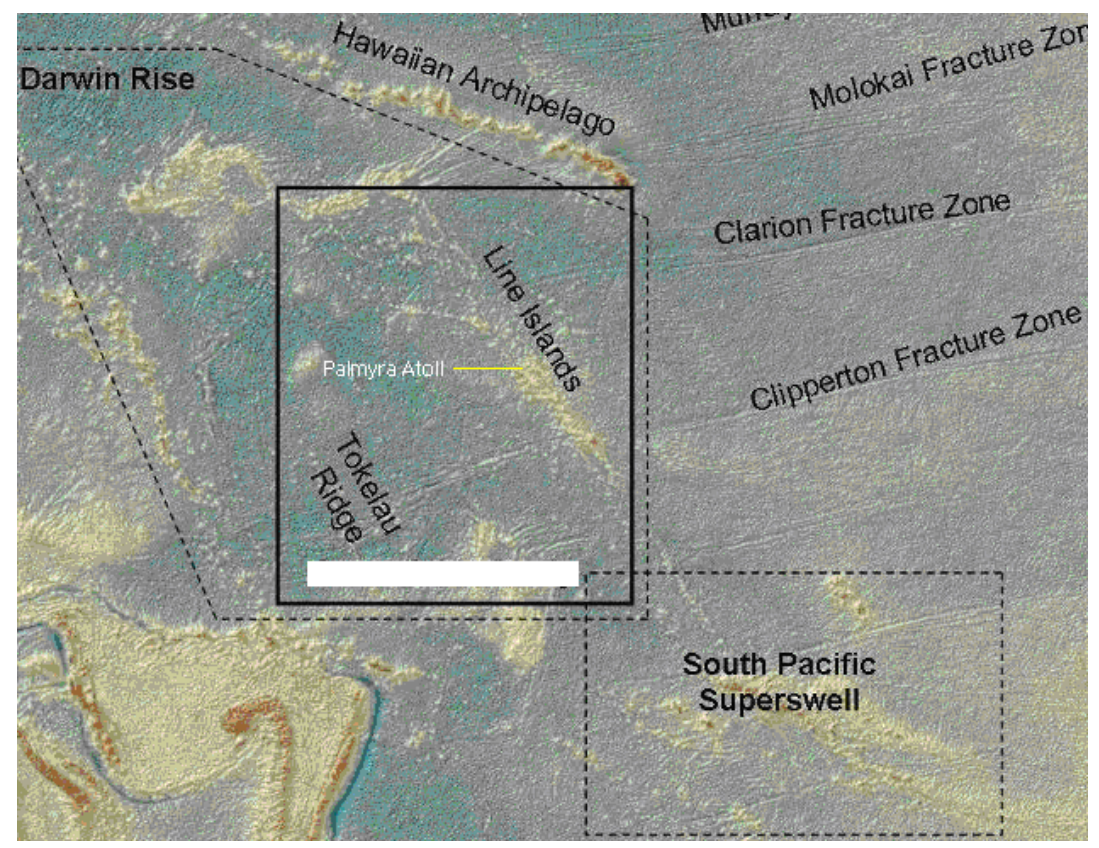

Figure 1.4: Major geological features of Central Pacific Ocean. Map modified from CRED/PIFSC with seafloor topography from Smith and Sandwell (1997). 


\subsubsection{Geochronological evidence for the origin of Palmyra Atoll}

Davis et al. (2002) presented new ${ }^{40} \mathrm{Ar} /{ }^{39} \mathrm{Ar}$ ages of 68 mineral separates and whole rock samples collected by dredging from nine volcanic edifices in the northern Line Islands region, between lat $20^{\prime} \mathrm{N}$ and $6^{\prime} \mathrm{N}$ depicting the formation of the Line Islands submarine ridge. Their results and other previously published ages suggest that the northern Line Islands are incompatible with single or multiple hot spot models; instead they suggest that there were two major episodes of volcanism. "Each episode of volcanism lasted $\sim 5 \mathrm{Ma}$ and was separated by $\sim 8$ Ma that occurred synchronously over long distances, not just along the main chain but also at non-aligned edifices. Volcanism during the older episode (81 - $86 \mathrm{Ma}$ ) extended over a distance of at least $1200 \mathrm{~km}$ along the eastern part of the complex seamount chain. Volcanism during the younger episode (68 - $73 \mathrm{Ma})$ was concentrated in the western part of the chain and may have extended over a distance of > 4000 km" (Davis et al.2002).

Davis et al. (2002) have analyzed three alkalic basalts from the Kingman Reef area, located $65 \mathrm{~km}$ northwest of Palmyra. The results show that the best age for Kingman Reef from the weighted means of the three ages determined is $70.0 \pm 0.5 \mathrm{Ma}$. This suggests that the Kingman structure initially formed during the younger of the two episodes of volcanism. No radiometric age determinations have ever been conducted for the formation of Palmyra Atoll. The Kingman Reef ages can be used as an estimate for Palmyra Atoll due to its proximity (65 km north) (Maragos et al. A 2008). Thus, Palmyra was probably also formed during the younger episode of volcanism between $68-73 \mathrm{Ma}$.

\subsection{History of reef development, growth and subsidence}

Reef growth, emergence, and subsidence on Palmyra Atoll since the Plio-Pleistocene have not been documented, and only a few studies exist for any of the Central Pacific reefs, reef islands, and atolls (Maragos et al. A 2008). Furthermore, the intensive dredging of the lagoon and the construction between 1940 and 1945 has modified the natural 
bathymetry and removed much evidence for the Holocene history of the atoll (Woodbury 1946, Dawson 1959, Maragos et al. A 2008, Collen et al. 2009).

Reef development in the area began when the volcanic foundations were still emergent islands in the late Cretaceous (Schlanger 1984), followed by volcanic subsidence and upward reef growth maintaining proximity to the sea surface during prolonged time periods. From studies of other Pacific atolls it is known that during glacio-eustatic drawdowns in global sea level by $120-125 \mathrm{~m}$, carbonate platforms of modern atoll provinces rose abruptly from the sea as clusters of subaerial limestone plateaus flanked by steep cliffs (Dickinson 2004). Slow subsidence coupled with karstic erosion of the emergent Palmyra Atoll during the last glaciation would have lowered the surfaces of the last-interglacial reef edifices and provided the base for later Holocene reef growth during postglacial eustatic sea level rise.

In comparison to work on other Holocene coral reef systems (Dickinson 2004, Purdy and Winterer 2001, Braithwaite et al. 2000) at the last glacial maximum, from 23 to about 19 ka BP, reefs only developed along what were to become the foreslopes of the present reefs, forming accumulations a few metres thick at vertical rates of up to $1 \mathrm{~mm}$ per year (Montaggioni 2005). The rapid postglacial rise in sea level, from about 19 to $6.5 \mathrm{ka}$, was accompanied by the formation of three successive reef generations within the periods 17.5 - $14.7 \mathrm{ka}, 13.8$ - $11.5 \mathrm{ka}$ and $10 \mathrm{ka}$ to the present (Braithwaite et al. 2000). Since the current stillstand which started around 4000 years ago, vertical reef development has slowed and in some cases ceased altogether, and lateral rather than vertical reef development has occurred causing a widening of the geographic extent of the reef structure. This is believed to be seen in the growth of both the eastern and western reef shelves. Multibeam mapping of Palmyra Atoll (Vroom et al. 2006, Ferguson et al. 2006) provides details of the morphology of the surrounding ocean and of the deeper parts of the lagoons (Fig 1.5). The multibeam data are limited due to operational and time constraints but results reveal that Palmyra Atoll is very low lying with little remaining subaerial evidence of previous sea stands (Maragos et al. A 2008). 
The depth below current sea level to the base of Holocene reef limestone that disconformably overlies Pleistocene limestone and the ages of the oldest Holocene limestones present are not known at present. Deep drilling and sample collection from the fore-reef for age determination would be required to provide a accurate reconstruction of the sea level records and reef growth the atoll. In comparison, other modern atoll reefs perched atop carbonate platforms which cap buried volcanic edifices in the Pacific Ocean are generally underlain by an average of 8 - $28 \mathrm{~m}$ of Holocene limestone overlying a substratum of last-Interglacial or older limestone (Dickinson 2004).

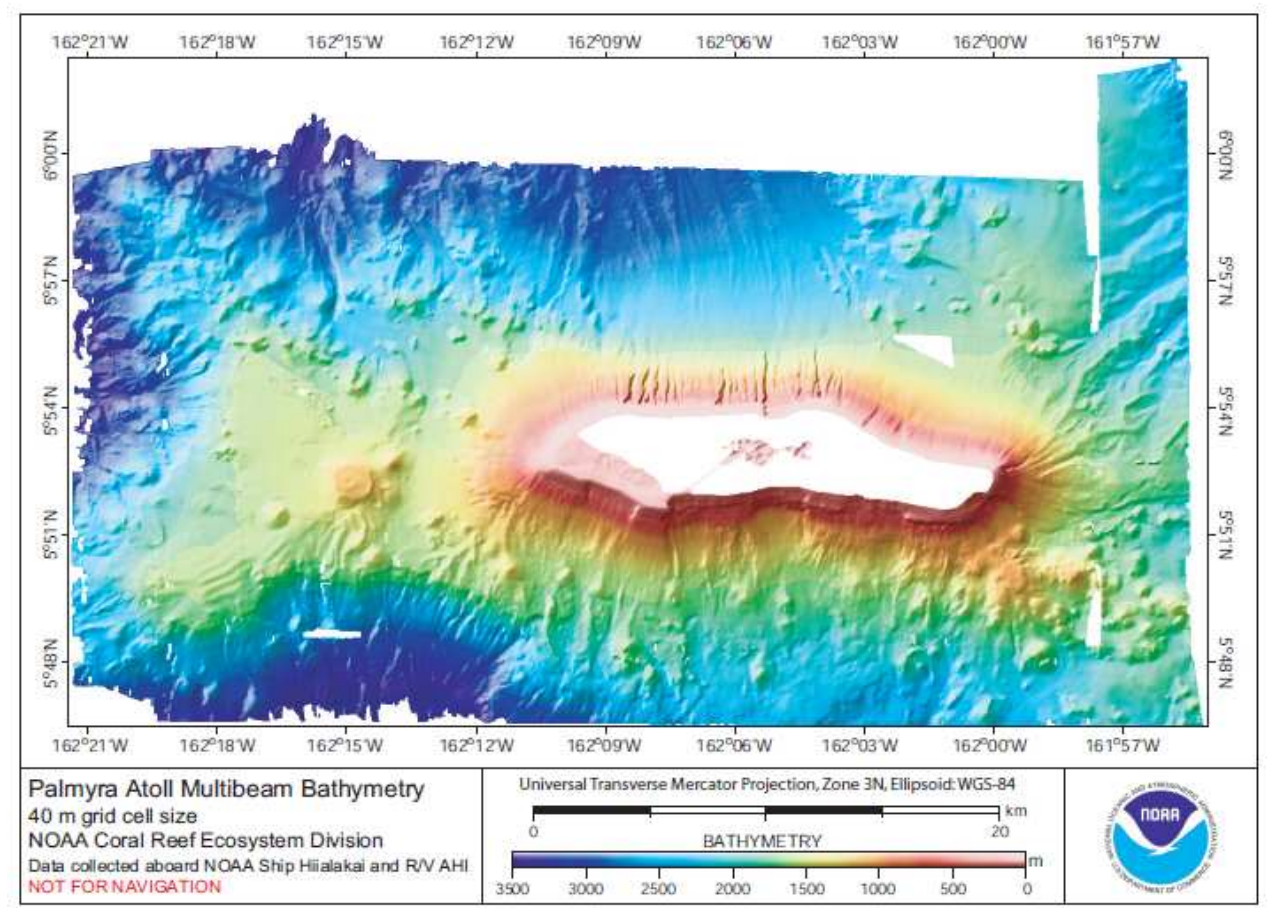

Figure 1.5: Slope map from CRED/PIFSC with 50-m bathymetric contours for Palmyra Atoll (NOAA, Vroom 2006, Ferguson 2006) 


\subsubsection{Controlling factors of reef development}

Tropical reef growth is dependent on several factors, with the two major environmental factors being sea water temperature and salinity.. Corals need to be within a fairly specific and narrow range for growth to occur, with water temperature in the range of $16-36^{\circ} \mathrm{C}$ with an optimum of $25-29^{\circ} \mathrm{C}$. Salinity tolerances range from $27-40 \%$ with an optimum of 36\%o (Tucker and Wright 1990). Nutrient levels and the amount of light that the coral receives are also important to reef development, as algal symbiots within coral need light for photosynthesis (Stoddart 1969, Tucker and Wright 1990, Guilcher 1988). Reef structure and development is also influenced by other oceanographic factors such as currents and wave energy, which in turn affect turbidity and circulation. Low turbidity and good circulation are optimum for reef growth. Sea level is a factor in reef growth as reefs are only able to grow as high as the current global sea level (accommodation space). It is also important to note that vertical accretion rates of reef frameworks are highly variable and are not directly dictated by coral growth habits (Montaggioni 2005).

\subsection{Previous work}

Early scientific research on Palmyra Atoll was focused on ecological studies of which botanical and seabird surveys were the most common. No previous geological work regarding the recent sediments of Palmyra Atoll has been produced, and in fact very limited geological studies of the Line Islands exist. This is partly due to the extreme isolation and great distances needed to travel between the locations and the time and cost that this entails.

In July, 1913, a scientific party from the Bishop Museum and College of Hawai'i, Honolulu, visited the atoll under the leadership of botanist Joseph Rock for the purpose of making a botanical survey of the area (Rock 1916). In the report on this work later prepared by Rock in 1916 it was said that the atoll originally consisted of approximately 52 islets, the largest of 46 acres and the smallest of .47 acres (19 and 0.2 Ha respectively). 
Rock prepared a chart of the island that has been used in the reconstruction of past sediment distribution and movements (Collen et al. 2009).

A popular book by David Woodbury entitled "Builders for battle, how the Pacific naval air bases were constructed" (Woodbury 1946) gives a detailed account of the activities involved in constructing the naval air facility at Palmyra Atoll in World War Two. His account also provides some insight into coral reef and human activity and how humans utilized the natural environment for their needs.

Yale Dawson in 1959 reported the changes in Palmyra vegetation due to human activities from 1913 to 1958 (Dawson 1959). The study was conducted as part of a long-term field exploratory program on poisonous fishes, and was a continuation and extension of earlier studies of the marine algae of Palmyra Atoll.

There was much early work done on the causes and effects of the outbreak of ciguatera fish poisoning on Palmyra by Dawson (1955), Randall (1958) and others due to its adverse affect on humans.

A preliminary environmental survey and assessment was prepared for the U.S. Departments of Sate and Energy, U.S. Army Corps of Engineers, Pacific Ocean division, Honolulu by J. E. Maragos in 1979 (Maragos 1979). This outlined the environmental impacts of naval construction and the state of the reef ecosystem.

The volcanic origins of the Line Islands chain have been examined using ${ }^{40} \mathrm{Ar} /{ }^{39} \mathrm{Ar}$ dating techniques from deep ocean basaltic sediments by Davis et al. (2002) and others. The results of this provide new geochronological evidence for two episodes of volcanism due to lithospheric extension during the Cretaceous.

A review of the regional geology and history of reef building in the Central Pacific has been compiled by Miller in Maragos et al. (2008). 
Information regarding the evolution of the shorelines of Palmyra Atoll post World War Two has been compiled by Collen et al. (2009).

Other key references (Emery et al. 1954, Emery 1956, Atkinson 1999, Kennedy and Woodroffe 2004, Hart and Kench 2007) come from comparison of similar studies of other carbonate reef systems from the Mediterranean, Central America and greater Pacific Ocean.

\subsection{Research at Palmyra Atoll}

Palmyra Atoll, its coral reefs, islands and lagoon represent one of the smallest natural laboratories in the oceans in which to study carbonate sediment production, movement, deposition and interaction with the ecophysical elements that make up a coral atoll. Palmyra is an ideal testing ground for sedimentological theory and currently serves as a laboratory for paleoclimatic and oceanographic reconstructions. For example, stable isotopes and geochemical tracers in coral skeletons have been used to identify previous El Nino- Southern Oscillation events by Cobb et al. (2003).

The island has never been permanently inhabited by a large population, although it was under military control for a brief period and was highly modified during this time. For the last 60 years of private ownership it had no long term resident human population or major exploitation of marine resources. In 2000 Palmyra Atoll was purchased by The Nature Conservancy (TNC) and the surrounding waters were transferred to the U.S. Fish and Wildlife Service and since 2001 it has been the Palmyra Atoll National Fish and Wildlife Refuge. The islands and their environs (out to 12 nautical miles) are thus now completely protected and there is no coastal preservation program in place. This offers an opportunity to study changes in the configuration of atoll reef islands and the movement of sediment along atoll reef rims without human restraint (Collen et al. 2009). Since 2005 there has been a small TNC base staff with parties of up to a dozen scientific researchers visiting the island as members of the Palmyra Atoll Research Consortium (PARC). PARC at present consists of nine research institutions; The American Museum of Natural History, 
California Academy of Sciences, Scripps Institution of Oceanography of the University of California (UC) at San Diego, Stanford University, UC at Irvine, UC at Santa Barbara, UC at Santa Cruz, University of Hawai'i, and Victoria University of Wellington.

\subsection{VUW research at Palmyra Atoll}

The aims of Victoria University of Wellington's research are to establish a long term research program at Palmyra to investigate the sources of carbonate production (inorganic versus organic), the movement of sediment into and through the lagoon, across the reef flat and off the atoll, and the likely impact of this on the ecophysiology of corals and tridacinid clams as part of Victoria University's commitments to PARC. Ongoing research will allow a better understanding of how water column properties (temperature, salinity, chlorophyll, turbidity) also change with time, and what these may mean to the structure and functioning of marine benthic communities in different areas of the atoll. Part of this is to determine how this may have differed in the past both before and after military construction. The slow, ongoing natural erosion of the North - South Causeway across the central lagoon will provide an opportunity to apply this knowledge to management of the atoll. This work at Palmyra will be complementary to the research group's ongoing projects of a similar nature at other south Pacific locations and will increase understanding of the geological and biological role that is played by carbonate production (Gardner et al. 2007.) 


\section{Chapter Two: Environmental Setting}

\subsection{Geomorphology, atoll and lagoon bathymetry}

Palmyra Atoll has a maximum relief of $3 \mathrm{~m}$ above sea level, and is surrounded by $61 \mathrm{~km}^{2}$ of submerged reefs. The atoll has a steep slope around it, with depths increasing from sea level to more than $1000 \mathrm{~m}$ over the short horizontal distance of approximately $2 \mathrm{~km}$, from 1000 to $2000 \mathrm{~m}$ depth over of the next $10 \mathrm{~km}$ and from 2000 to $4000 \mathrm{~m}$ by a distance of approximately $45 \mathrm{~km}$ from the atoll. $4000 \mathrm{~m}$ is the typical depth of the submarine ridge between the Line Islands (Hamann et al. 2004).

The interior of the atoll has not been well studied. However, a bathymetric chart of the seafloor and surround was produced by NOAA in 1944 (Appendix E) as well as a partial swath map by NOAA, the results of which have been published by Vroon et al. (2006), and these show that the lagoons are deep, up to $55 \mathrm{~m}$, steep sided in places and are compartmentalized (Fig 1.2).

\subsection{Oceanography}

\subsubsection{Winds, waves, tides and currents}

The tropical area of ocean encompassing the Line Islands is dominated by the easterly trade winds and the doldrums, and by a complex system of four major surface and nearsurface ocean currents. These are the North and South Equatorial currents, which flow westward, and the Counter-current and Equatorial Undercurrent, which flow to the east (Barkley 1962). Oceanographic conditions in the equatorial Pacific display a prominent seasonal cycle.

During easterly trade-wind conditions and the presence of the North Equatorial Current (NEC), north of $5^{\circ} \mathrm{N}$, Palmyra's eastern reefs receive wind and ocean swells from the east 
and northeast that refract around both the elongated north and south sides of the atoll, generating alongshore currents that move westward. Palmyra is also affected by the eastward-flowing North Equatorial Counter Current (NECC) and possibly the westwardflowing South Equatorial Current (SEC), depending on the position of the Intertropical Convergence Zone (ITCZ) (Maragos et al. A 2008, Cobb et al. 2003). No detailed and long term information is yet available for conditions specifically at the atoll (Collen et al. 2009).

A steep drop off from the reef crest means that deep water swells and waves are uninterrupted until they are within a few metres of the outer reef crest. This causes them to quickly steepen, curl and then break very suddenly with large amounts of force onto the outer reef rim (Fig 1.5, Appendix E).

Lagoons are affected by a semi-diurnal tidal pattern, the size and period of which still require quantifying. Strong currents were observed at choke points in causeways and natural channels between lagoons and between open ocean and lagoons (Table 6.1). Under normal conditions wave setup across the lagoons is controlled by the limited fetch of the lagoons and the strength of the prevailing winds and ocean swell plays only a very minor role of wave forcing in the lagoons in places where there are gaps in the encircling perimeter reef. Under storm condition waves have been reported to flow strongly across the outer reef flat and in some cases over the islands (J. Collen pers. comm. 2008). It was observed that the lagoons can quickly become very choppy in times of frequent passing squalls.

\subsubsection{Salinity, dissolved oxygen, sea and lagoon temperature.}

Measurements made by the NOAA vessel Townsend Cromwell between 22 August and 17 September 1990 and between 18 February to 9 March 1992 showed that the ocean waters around Palmyra Atoll were characterized by a thick surface mixed layer of approximately $75-100 \mathrm{~m}$ depth with almost constant temperatures of $29^{\circ}$ and $28^{\circ} \mathrm{C}$ 
during the two trips respectfully and surface salinities of $34.0 \%$ in 1990, and average surface salinity of $34.79 \%$ in 1992 (Hamann 2004).

The following is a summary of work regarding water column profiles of Palmyra Atoll's lagoon system made during daylight hours and under varying tidal and weather conditions at the same time as this study in June 2007, using a conductivity, temperature and depth data logger (CTD) by RBR sensors custom-fitted with dissolved oxygen probes (Gardner et al. in prep). The results (Fig 2.1) of the 122 vertical casts showed temperature and salinity remained constant with increasing depth. At depths of $>30 \mathrm{~m}$ profound changes were observed in percent dissolved oxygen (DO). With increasing depths, DO decreased dramatically until it reached $\sim 10 \%$, at which point it then typically decreased further, but at a slower rate, until it approached $\sim 0 \%$ saturation. It was noted that turbidity remained constant with increasing depth until the depth at which DO started to approach anoxic values. This critical oxygen depth varied among the selected sites. All casts that went deeper than $30 \mathrm{~m}$ were characterized by the absence of stratification for temperature and salinity (and therefore density), and by reverse stratification for turbidity and pronounced DO stratification.

The uniformity of temperature and salinity with depth suggests a well mixed system; however, DO stratification is consistent with the absence of significant mixing of oxygensaturated surface water below $30 \mathrm{~m}$, and many areas are characterized by anoxia below this depth. The inverse stratification of turbidity is consistent with a long term increase in concentration of very fine suspended material at $>30 \mathrm{~m}$ depth. The hydrographical results of this study were interpreted in terms of surface flow through the lagoon system. Despite observed strong east to west wind-driven surface circulation and significant rainfall there is only shallow mixing and a stable water column below this.

In summary, the lagoon system at Palmyra atoll can be represented by a shallow, westward moving surface layer of water characterized by high DO and low turbidity values, and below that by a deep relatively static and temporally stable layer which is characterized by low to zero DO concentrations, and by elevated turbidity. This layering 
has been proven to be stable over at least a week (Gardener et al. in prep). Temperature data collected by Maragos in late 2003 suggest that lagoon water temperatures consistently increase from east to west and that these data are consistent with observations of current and tidal patterns operating (Maragos et al. A 2008).

Data from the CTD casts were used to produce maps and cross sections based on saturated (>80\%), normal (50-80\%), limited (10-50\%) and anoxic $(<10 \%)$ dissolved oxygen (DO) levels (Fig 2.2). In the three main lagoon compartments anoxia was recorded at depths of $>30 \mathrm{~m}$ in numerous locations, but was not found at all depths greater than $30 \mathrm{~m}$. It appeared to be found in areas of the lagoon basins that were compartmentalized and protected by underwater barriers. The anoxic condition was in almost all cases accompanied by high organic matter concentrations and a strong $\mathrm{H}_{2} \mathrm{~S}$ odour emitted from the sediment samples dredged for this thesis.

Salinity varies according to the amount of precipitation and evaporation occurring. Under normal conditions the salinity of sea water is approximately $35 \%$, but this can be significantly higher in areas where evaporation greatly exceeds precipitation (Rao 1996). The average salinities recorded from the three lagoons by Gardner et al. (in prep) show the lagoons salinities to be between 36 and $37 \%$, this reflects higher evaporation occurring within the lagoons compared to the surrounding ocean waters where Hamann (2004) found average surface salinities of $34.0 \%$ in 1990 and of $34.79 \%$ in 1992. The average water temperature for the lagoons was $28^{\circ} \mathrm{C}$ for June 2007. 

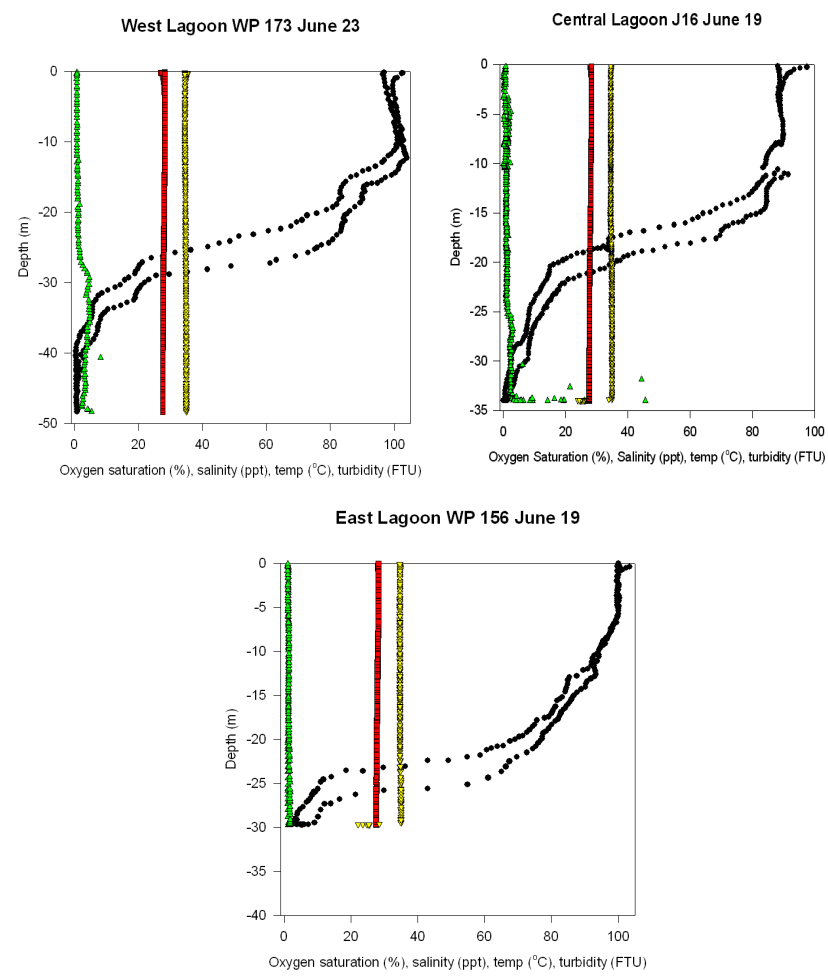

Fig 2.1 Examples of typical deeper water CTD profiles from (A) West Lagoon, (B) Central Lagoon, and (C) East Lagoon. Green symbols = turbidity $($ FTU $)$, red symbols = temperature $\left({ }^{\circ} \mathrm{C}\right)$, yellow symbols $=$ salinity $(\%)$, black symbols $=$ dissolved oxygen $(\%)$. The difference in the ascending and descending DO profiles reflects the delay in the equilibration of the oxygen sensor (from Gardner et al. in prep) 


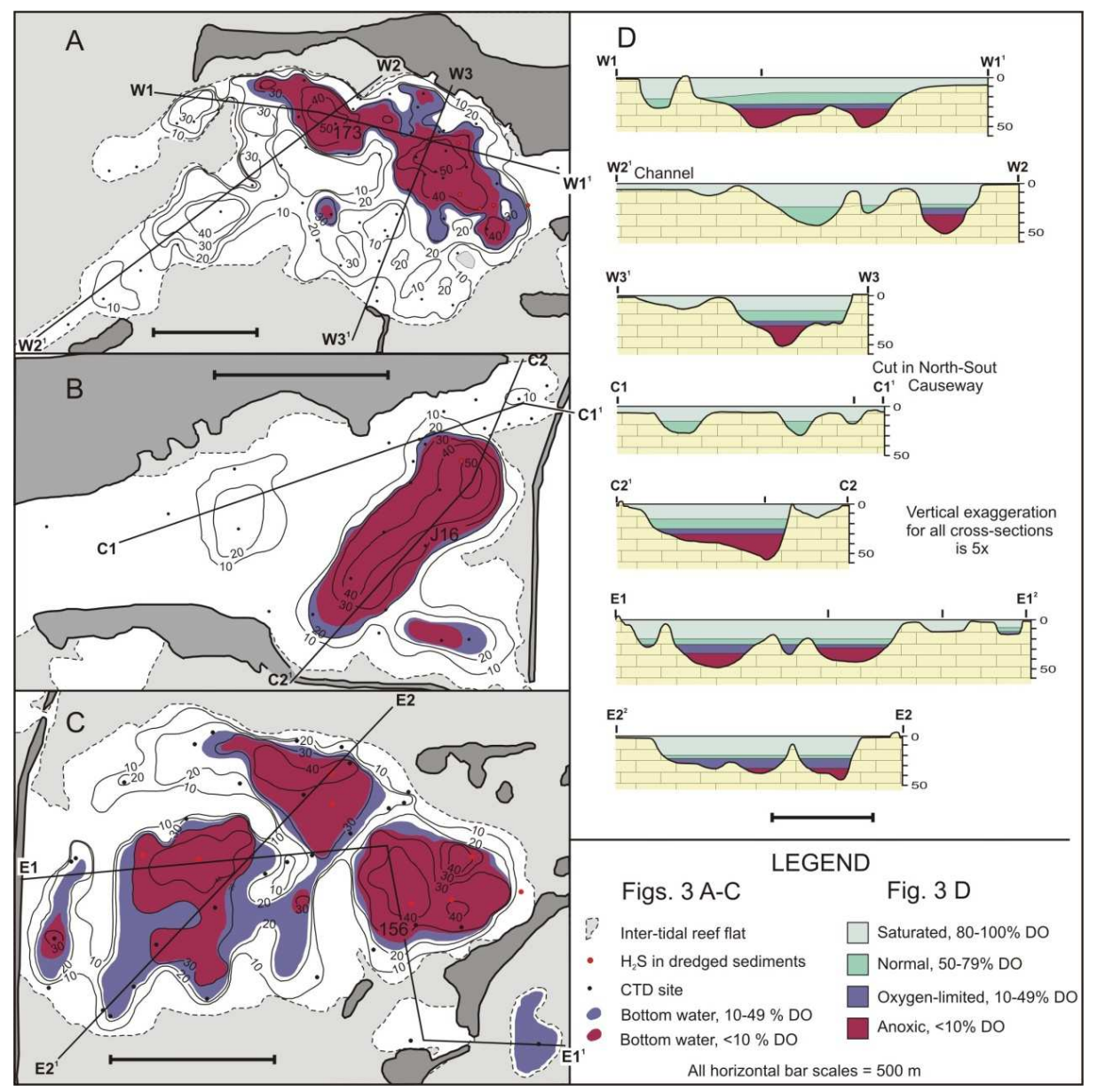

Fig 2.2 Map of Palmyra Atoll lagoon system showing sample sites, cross section lines, bathymetry and the distribution of anoxic and dysoxic zones for (A) West Lagoon, (B) Central Lagoon, (C) East Lagoon, and (D) cross sections for West Lagoon (W1, W2, W3), for Central Lagoon (C1, C2), and East Lagoon (E1, E2) showing dissolved oxygen zones. Locations of CTD profiles shown in Figure 2 are represented by 173 (West Lagoon), J16 (Center Lagoon) and 156 (East Lagoon) (from Gardner et al. in prep) 


\subsubsection{Light penetration}

Light is important to the growth of corals and other biota on Palmyra because of their reliance of it for the process of photosynthetically producing food, whether this be primary production or a symbiotic relationship to photosynthetic algae within the cells of the corals. Light penetration decreases with increasing water depth, meaning that the photic zone is limited to about $40 \mathrm{~m}$ (Hopley 1982, Guilcher 1988). Light penetration is also limited by water clarity, with high turbidity relating to the amount of sediment that is held in suspension. As wind waves and currents increase in strength so does the potential for increased turbidity.

Light penetration data are not available for Palmyra as yet. However, turbidity and amounts of suspended sediments were observed at all times in the deep lagoons of Palmyra. In contrast, the outer reef waters were always clear and the substrate was clearly visible. Visibility of upward of $30 \mathrm{~m}$ was observed while diving on the Western Reef Terraces, outside the interior of the atoll.

\subsection{Climate regime}

The climate is wet and humid. The pattern of precipitation is governed largely by the location and strength of the doldrums low-pressure trough (Barkley 1962). At Palmyra, trade winds from the northern and southern hemispheres meet, about 350 miles north of the equator. As the winds meet, they create the doldrums, with light winds and abundant rain. As a result, Palmyra receives an average of $440 \mathrm{~cm}$ of rain a year (The Nature Conservancy 2008).

\subsubsection{EI Nino Southern Oscillation (ENSO)}

Sea surface temperature (SST), ocean currents, precipitation, winds and biological production are highly variable in the vicinity of Palmyra Atoll on inter-annual time scales due to the El Nino Southern Oscillation (ENSO) (Cobb et al 2003, Maragos et al. A 
2008). Millennial-scale oscillation of ENSO has been present throughout the Holocene. The Holocene has been characterized by increasing ENSO frequency, reaching peak intensity 1200 years ago and declining until present day (Moy et al. 2002). ENSO has two distinct signatures, El Niño and La Niña, which are defined by sustained SST anomalies of magnitude greater than $0.5^{\circ} \mathrm{C}$ across the equatorial Pacific (Trenberth 1997).

During El Niño conditions, trade winds weaken and occasionally reverse, resulting in anomalously warm SSTs and wetter climate in the central Pacific, eastward surface transport occurs and a deepening of the thermocline (Yu and McPhaden, 1999, Cobb et al. 2003). Conversely, La Niña conditions are characterized by anomalously strong trade winds, cool SSTs, drier climate, enhanced westerly surface transport, a shallow thermocline, and a strong Equatorial Under-Current EUC (Cobb et al. 2003, Maragos et al. A 2008).

Cobb et al. (2003) using long-lived corals (Porites) from Palmyra atoll have generated multi-century, monthly resolved records of tropical Pacific climate variability over the last millennium by splicing together the overlapping fossil-coral records and modern coral records (multiple 30-150 year windows). Positive SST and rainfall anomalies that occur at Palmyra during an El Niño event result in lowered (more negative) coral $\mathrm{d}^{18} \mathrm{O}$, while the converse is true during a La Niña event. Thus Palmyra corals are sensitive recorders of regional-scale ENSO activity when dated using high precision U/Th dates (generally a +- 5-10 year error). The records (Fig 2.3) indicate mean climate conditions in the central tropical Pacific ranging from relatively cool and dry during the tenth century to increasingly warmer and wetter climate during in the twentieth century and document a broad range of ENSO behaviour. It was noted that ENSO activity in the seventeenth century sequence was not only stronger (in terms of variance), but more frequent than ENSO activity in the late twentieth century. Strong ENSO variance such as the El Niño event recorded in 1997 can have a major impact on coral growth and is associated with mass bleaching (die-off) events. 
It is theorized that strong El Niño events may cause a sudden surge of sediments to be supplied to Palmyra's sediment budget for those years or subsequent years affected. More detailed coring will be necessary to investigate historical sedimentation rates and the affects of ENSO on Palmyra Atoll.

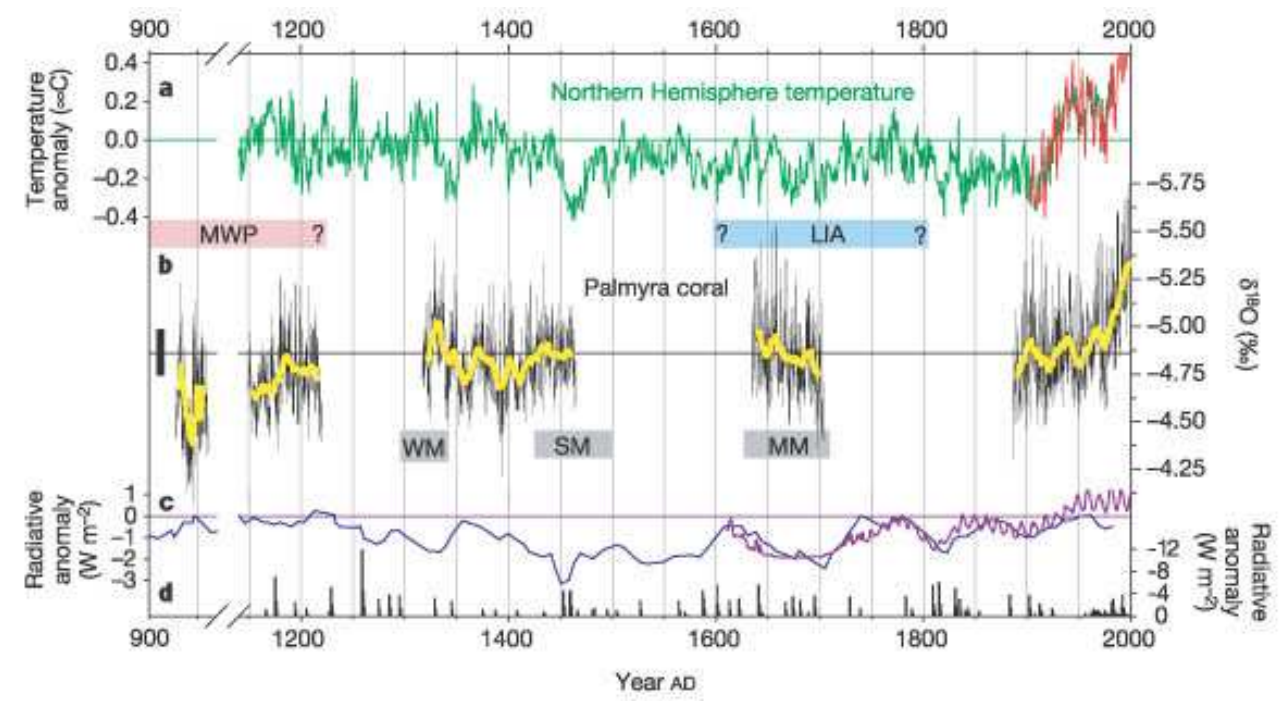

Fig 2.3 Comparison of monthly resolved $\mathrm{d}^{18} \mathrm{O}$ coral records from Palmyra (black line), shown with a 10 year running average (yellow line) and other proxy climate records and external forcing during the last millennium (Fig 5 from Cobb et al. 2003)

\subsubsection{Extreme events; tropical storms}

In general Palmyra receives very few tropical storm events. The atoll is located between the major eastern and western Pacific tropical storm centres, which are most active in late summer and early fall. Most storms that develop off the coast of Mexico and head west undergo cyclolysis (storm death) or spin off northwards before reaching the longitude of Palmyra. Cyclogenesis (storm formation) to the west and northwest of the Palmyra region produces tropical depressions and storms that head away from Palmyra toward the western Pacific. Additionally, due to Palmyra's proximity to the equator, the atoll is located out of the path of almost all tropical cyclones of any intensity. This is due to the insufficient coriolis effect for storm vortex to form at equatorial latitudes. Only three 
cyclones have been observed in the Kingman/Palmyra area. However, only one of these three, Ekeka in 1992, reached wind speeds in excess of 60 knots (Brainard 2008 in Maragos et al. A 2008).

\subsection{Biology and ecology of Palmyra atoll}

\subsubsection{Dry land biota}

Because of the warm wet climate, Palmyra, despite its small size, supports on almost all islets very dense tropical forests. This includes the rare Pisonia whose fibre is soft like balsa wood and which can grow up to 30 metres tall, with buttress trunks and tangled branches. On many Pacific islands people have used all the Pisonia for fire or shelter, or cleared it away for farming (National Geographic 2007, The Nature Conservancy 2008). The dense forests on Palmyra support tens of thousands of nesting seabirds and their young every spring. Palmyra is home to the world's second largest colony of Red-footed Boobies (Sula sula); other common species include around 750,000 Sooty Terns (Sterna fuscata) and large numbers of Masked Boobies (Sula dactylatra), Greater Frigate Birds (Fregata minor), Red Tailed Tropic Birds (Phaethon rubicauda), Brown Noddies (Anous stolidus), Black Noddies (Anous minutus), White Terns and highly endangered BristleThighed Curlews (Numenius tahitiensis). Large numbers of hermit crabs and other land crustaceans occur on all islets, including the world's largest land invertebrate, the coconut crab (Birgus latro). The coconut crab is considered a delicacy on other Pacific islands, and human consumption has decreased the numbers of the crabs dramatically through the rest of the Pacific. On Palmyra, where they are unmolested, they can live up to 50 years and grow to more than half a metre in size (U.S. Fish and Wildlife 2008)

\subsubsection{Marine Biota}

Palmyra Atoll has a diverse range of marine biota. This includes hundreds of tropical fish species, including mantra rays, mullets, fusiliers, snappers, humphead parrotfish, humphead wrasses, sharks, other rays, jacks, goat-fish, tuna, butterfly fish, damselfish, 
surgeonfish and world-class sportfishing populations of bonefish that occupy the shallow lagoon flats (Ault 2007). The atoll has numerous sea turtles, crustaceans and the giant clam Tridacna maxima (U.S Fish and Wildlife 2008).

The living reef framework consists of calcareous algae and both hard and soft corals; these exist in a variety of size, shape and colours. Palmyra's reefs support at least 130 species of hard stony coral, which is three times the number of coral species found in Hawai'i and the Caribbean, and five times the number of species found in the Florida Keys (The Nature Conservancy 2008, National Geographic 2007).

\subsection{History of human settlement}

Archaeological evidence at neighbouring islands and atolls in the Line and Phoenix Islands indicate that early Polynesians and Micronesians were likely the first visitors to Palmyra during the previous millennium, although brief archaeological surveys to date at Palmyra have not revealed any supporting evidence (Streck in Maragos et al. A 2008 ). Palmyra was uninhabited at the time of its discovery and visitation by European and American explorers, whalers and potential guano miners during the past two centuries some thought - it was uninhabited in 1800 but inhabited at the time of (Maragos et al. A 2008).

The atoll was believed to be first sighted, but not landed on, on the night of June $13^{\text {th }}$ 1798 by the American ship Betsy, under the command of Capt. Edmund Fanning. The atoll itself received its name from the American ship Palmyra, under the command of Captain Sawle who sought shelter and made landfall there on November $7^{\text {th }} 1802$ (Rock 1916). The atoll was also known for a time as "Samarang Island" after the visit from the ship Samarang, commanded by Captain Scott, on September 15 1840. Dr. Gerrit P. Judd of the vessel Josephine landed and laid claim to Palmyra on October the $19^{\text {th }} 1859$, for the American Guano Co., for which he was an agent, under the Guano Islands Act of 1856 (U.S. Fish and wildlife 2008). 
His Majesty Kamehameha IV (1834 - 1863) the fourth King of Hawai'i (1854 - 1863), on April the $15^{\text {th }} 1862$ issued a commission to Captain Zenas Bent and Mr. Johnson B. Wilkinson, both Hawaiian citizens, to sail to Palmyra and to take possession of the atoll in the king's name (U.S. Fish and Wildlife 2008, The nature conservancy 2008). Captain Bent and Mr. Wilkinson landed on Palmyra on April the $15^{\text {th }} 1862$ and took formal possession for the Hawai'ian government in accordance with the royal commission (U.S. Dep of Interior 2008). The rights to the island passed through a number of hands and eventual was claimed by Judge Henry Cooper on April the $30^{\text {th }} 1912$ after considerable legal proceedings (U.S. Dep of Interior 2008)

Commander Nichols of H.M.S. Cormorant formally annexed Palmyra to Great Britain on July the $7^{\text {th }} 1898$. Palmyra was specified as one of the islands included in the Joint Resolution of the $55^{\text {th }}$ U.S. Congress which annexed the archipelago Republic of Hawai'i to the United States and formal possession of the island was confirmed on February the $20^{\text {th }}-21^{\text {st }} 1912$ (U.S. Dep of Interior 2008 )

Judge Cooper sold 50 of the 52 original Palmyra atoll islands to Leslie and Ellen FullardLeo, of Honolulu on August the $19^{\text {th }} 1922$ (Woodbury 1946). After the death of Judge Cooper on May the $14^{\text {th }} 1929$ the title of the other two, known as the Home Islets was passed on to his heirs (The Nature conservancy 2008)

In preparation for possible war Palmyra was recommended strongly by the Hepburn Board as a scouting base to protect U.S. interests in the central Pacific and a reconnoitring expedition was sent there in 1938 (Woodbury 1946). The U.S. Navy attempted to lease or buy Palmyra from the Fullard-Leo family in 1938. The District Public Works office in Hawai'i discovered that only the fishing and copra rights had been granted to Judge Cooper by the Territorial Government, whereupon the U.S. Attorney in Honolulu brought the Fullard-Leos to court. The U.S. Government won and in 1939 the U.S. Congress authorized the immediate transferral of jurisdiction to the U.S. Navy and the construction of a naval base to be developed on Palmyra (Woodbury 1946, Maragos et al. A 2008). 
The U.S. Navy developed Palmyra into a four-million-dollar naval air base and up to 6000 servicemen occupied Palmyra atoll naval air station during the World War Two era (Dawson 1959). The islands were extensively modified during construction of the military facilities from 1940 - 1945 (Woodbury 1946, Dawson 1959, U.S. Dep of Interior 2008)

In 1947 the U.S. Supreme Court ruled in favour of the Fullard-Leo family, returning ownership of the atoll to the family. When in 1959 Hawai'i became the $50^{\text {th }}$ state of the United States of America, the statehood act specifically excluded Palmyra from the state of Hawai'i, thus making Palmyra the only privately owned territory in the U.S. (Nature Conservancy 2008). By this time all military occupation had ceased and all other federal presence at the atoll ended. Subsequently, the atoll remained abandoned except for resident caretakers supported by the Fullard-Leo family and the occasional ocean-going visitors and minor occupation by U.S. government officials.

In 2000, the Nature Conservancy (TNC) purchased Palmyra, and later the U.S. Department of the Interior bought all reefs and islands from TNC except for the main island (Cooper), its airfield and dock. On January 18, 2001, the atoll was established as a National Wildlife Reserve (NWR) under the administration of the United States Fish and Wildlife Service (USFWS). In 2005, TNC established the Palmyra Atoll Research Consortium (PARC) and built a field research station capable of housing up to 20 scientists and staff on Cooper Island which is now maintained by several caretakers. The PARC is operated by TNC and primarily funded by the Gordon and Betty Moore Foundation and the nine member research institutions mentioned previously (See section 1.6). From the initiation of PARC in 2005 until present Palmyra has been the staging ground for numerous scientific parties to undertake research on Palmyra, including the present project. Other studies included examining coral health (Williams et al. 2007, and others in prep), the biology and ecology of the flora and fauna both on land and on the reef, exploring climate shifts through the recent Holocene and the effects of climate change on these ecophysical systems to be used to interpret future anthropogenic changes (Knowlton et al. 2008, Sandin et al. 2008 and others ongoing). 


\subsubsection{History of human modification}

For much of this known history Palmyra Atoll has been largely uninhabited with little or no human connection. The first modification of the island by man was by the planting of 200 coconut trees on one of the islets by an employee of the Pacific Navigation Company in 1885 (Dawson 1959). One intense brief episode of human modification occurred when the U.S. Navy took control of Palmyra between 1940 and 1945 and built the Palmyra Naval Air Base (PNAB) as part of their Pacific defence network during World War Two. Before this time earliest charts and reports show that their were originally some 52 islets (Rock 1916) on extensive reef flats surrounding a three-part lagoon system up to $50 \mathrm{~m}$ deep (Collen et al. 2009). Although the positions of the reef islands varied from survey to survey, their areas remained similar until 1940, where upon the islands and lagoons were extensively modified during the construction of the military facilities until 1945. During this time a 60 metre wide ship channel was cut through the reef (Dawson 1959), new islands constructed, the areas of pre-existing ones increased by dredging and filling for the purpose of creating runways. Bunkers, gun emplacements, many pill boxes, seaplane ramps, hospitals, barracks, communications facilities and many other buildings were established on the extensive islands. The most dramatic modification of the atoll came was when all the major islands of the atoll ring except outlying Sand Island, Barren Island and Bird Island were joined by network of causeways and roads (Dawson 1959, Collen et al. 2009). These actions had considerable affect on lagoon circulation and ecosystem health (Dawson 1959, Maragos et al. b 2008, Collen et al. 2009) Fig 2.4 shows the modification to Palmyra through time, reconstructed from various historical charts and maps of the island. 


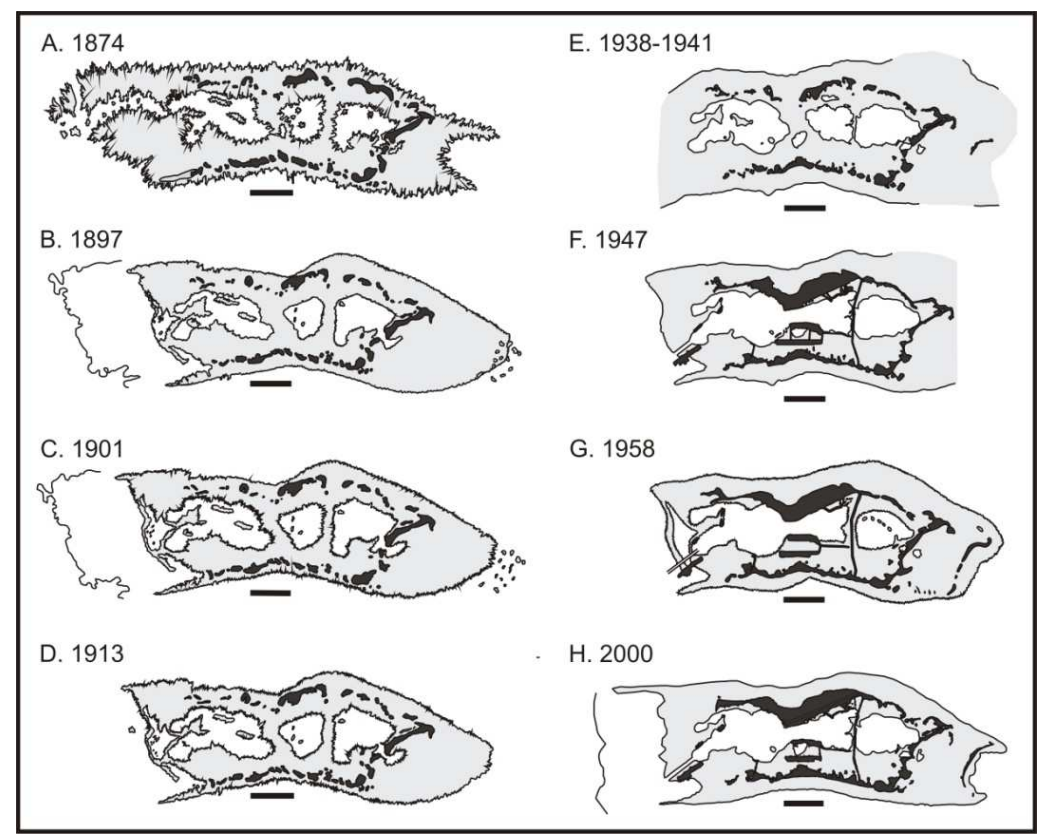

Fig 2.4 Outline of Palmyra Atoll reef islands from 1974 to 2000. The area including Barren Island to the east is not shown on the 1947 chart. Black areas represent islands, grey areas are shallow reef flats, and white areas are lagoons or the surrounding ocean. Scale bars represent $1 \mathrm{~km}$ and are taken from individual original maps (from Collen et al. 2009).

\subsubsection{Effects of modification}

Mechanical excavation and dredging during the construction of the Palmyra air base physically disturbed and removed the bottom substrate, deposited sediment on the substrate, suspended sediment in the water column, reduced light penetration, increased turbidity, changed circulation and was also thought to have reduced dissolved oxygen, and increased nutrient levels in the water column (Maragos et al. A 2008. The physical effects of the 1940-45 construction were to increase the area and volume of the islands, lower the water level in the lagoons, and restrict water and sediment flow into and 
through the lagoons (Dawson 1959, Maragos et al. A 2008, Collen et al. 2009). The effect of construction had a catastrophic effect on the ecosystems of Palmyra.

Dawson (1959) reported that the facilities could accommodate 6,000 military personal at its peak, with the consequent problem of sewage, other various toxic wastes and hazardous chemicals. After occupation of the island ended fuels, solvents, and numerous contaminants were abandoned. Barbed wire entanglements were strung out across all the reef flats and vegetation levelled to provide cross- firing ranges. These years of crowding the atoll with human beings greatly reduced the nesting bird population. The movement of personnel especially in and out of Hawai'i brought about the introduction and establishment of many weeds and also the deliberate planting of ornamental plants.

Woodbury (1946) reported for the year following directly after military occupation that the enormous modifications to the atoll by closing the natural circulation channels between the lagoons and between the lagoons and the vast eastern living patch reef zone and outer reef flats have left their mark on the life and conditions within the lagoons; which now remain murky throughout and essentially dead. Woodbury also reported that he observed no living coral of any consequence occurring on the inshore portions of the reef flat and that the only life present was quantities of Lyngbya majuscule a species of seaweed; a cyanobacterium that thrives in polluted, low oxygen environments and is one of the causes of the human skin irritation seaweed dermatitis. Furthermore he noted that the waters in general were filled with fine suspension of calcareous sediment and were in many areas so stagnant as to yield strong odours of hydrogen sulphide $\left(\mathrm{H}^{2} \mathrm{~S}\right)$ in the shallow flats (Woodbury 1946). A slow return of coral life to the lagoons for the past 30 years has been reported by Maragos (2008), and observations from this present study report there is abundant marine life within the lagoons, shallow water areas appear free of high amounts of fine suspended sediment and no H2S odours can be smelt.

It has been postulated by Maragos et al. (B 2008) that before military construction, wave forcing created currents over windward reefs which likely pushed cool oceanic waters between the islets from northeast to southwest into the lagoons; that the lagoons 
originally acted as a storage tanks with a one way valve, large waves from the east would pour millions of tons of water over the reef to the west. This kept the normal lagoon water level at least $30 \mathrm{~cm}$ (a foot) higher then the open ocean side. Woodbury (1946) notes that the opening by explosives and dredging of the boat channel gave rise to very strong currents flowing out of the lagoon. Measurements taken by J. Collen and D. Garton of exposed Porities microatoll patchreef heads in the Center Lagoon of up to $28 \mathrm{~cm}$ above the current water mark may provide evidence for such a theory, however precise dating of the coral heads is first needed. Under normal conditions coral heads grow to within a few centimetres of the low tide water mark.

Furthermore, Maragos et al. (B 2008) believed that originally the cooler oceanic waters flowing in would have likely descended into the east lagoon and displaced warmer waters upward that would have moved towards the Center lagoon, this process would then be repeated between the central and western lagoons, and finally with the warmest waters eventually spilling over the shallow southern and western perimeter reefs. Fig 2.5 shows this hypothetical original current regime, the resulting regime due to military modification and then its progress over the past 60 years and projected in to the future. 
16. Us Coral Roets in the Line

1939

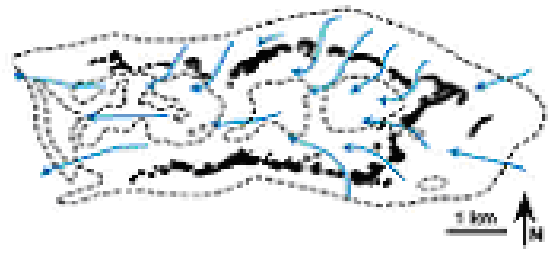

1946

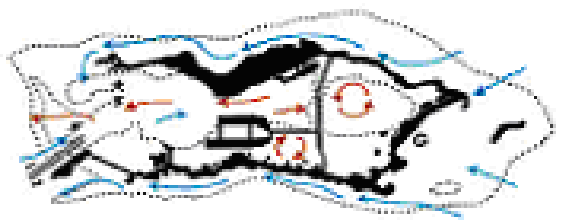

2000

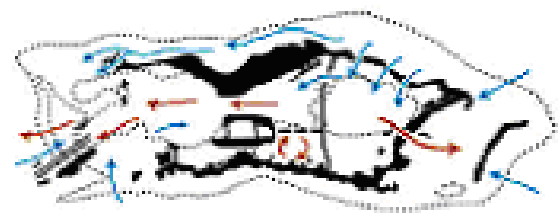

$2039 ?$

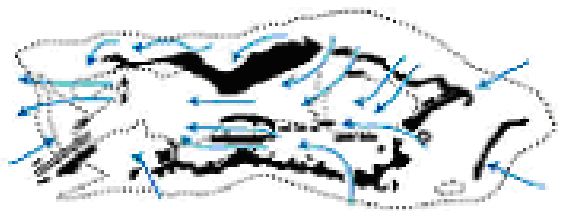

Fig 2.5 (Fig 16.2 from Maragos et al. B 2008) "Time sequence diagrams showing hypothetical changes in water circulation patterns at Palmyra since 1939 and projected to 2039. Solid black areas are islands and dashed lines are edges of shallow reefs. Blue arrows approximate net direction of cooler waters and the red arrows approximate net direction of warmer waters with suspended sediments. Constructed with the assistance of Phyllis Ha and John Collen from Woodbury (1946), Dawson (1959), Maragos (1993, unpublished observation), Ikonos 2000 image (Appendix F), and predictions for the 2039 scenario".

Wave set-up currents no longer entered the lagoon between windward islets after being blocked by the causeways. Instead ocean-side currents strengthened and moved westward and along the ocean shores of both the north and the south sides of the atoll (Maragos et 
al. B 2008). Collen et al. (2009) document the loss of islets and several WW2 concrete fortifications now well seaward of the shorelines of surviving islets.

Randall (1958) states that dredging, filling and other physical changes to habitats in the tropics have been implicated as causes for the increased incidence and outbreaks of ciguatera fish poisoning. The poisoning is caused by a toxic dinoflagellate, Gambierdiscus toxicus, which grows on microscopic algae that are eventually consumed by fish. The herbivores are eaten by carnivorous fish with the toxin passed up the food chain. Although mildly toxic to fish, ciguatera is much more toxic to mammals, including man. There is some circumstantial evidence for a relationship between ciguatera and construction at Palmyra (Dawson 1955, Randall 1958, Maragos 1993)

\subsection{Shoreline changes and sediment redistribution}

The following summarizes work by Collen et al. (2009), presenting research looking at shoreline changes and sediment redistribution at Palmyra atoll from pre-military modification to present (Fig 2.3, 2.4, 2.5, 2.6). After the departure of the military forces, natural physical processes began to modify the shorelines and causeways and this has since been continuing. Much evidence for erosion around the coast is seen on a variety of scales and shown by features such as coastal structures (especially gun emplacements) that are now below the high tide mark, undermined and collapsed structures, cliffing and erosion along the high tide level and exposed roots and fallen trees. Evidence for accretion around the coast is shown mainly by beach sediment accumulation and concentric zones of young vegetation. Shoreline movement was quantified by comparing the distance of old structures to the high tide line in the 1940's maps to their present day positions.

Overall sediment movement is from east to west. Islands were occasionally built up and united so as to increase their size. Sediment is also crossing the reef flats to infill the lagoons and areas such as the dredged boat channel and since 1945 there has been an overall smoothing of the coast lines (Fig 2.6, 2.7, 2.8, 2.9). 


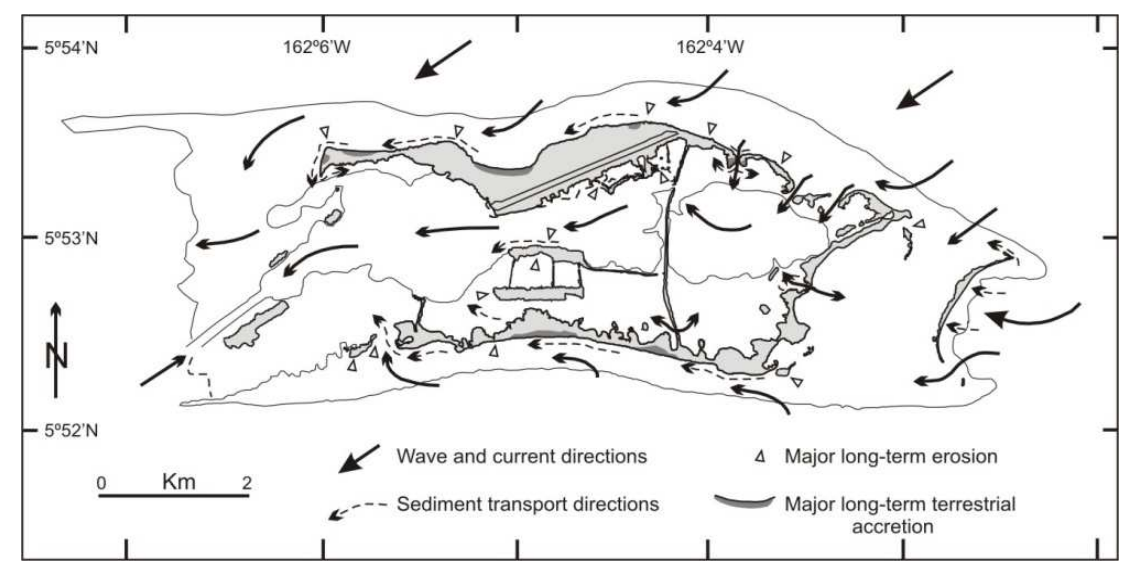

Fig 2.6 Schematic diagram showing wave and current direction and sediment movement under north-easterly trade wind conditions. Areas of major post-1945 terrestrial accretion and erosion are indicated. Water flow through the shipping channel is tidal. Flow inside the lagoons is after Maragos (Friedlander) et al. (B 2008). Diagram courtesy of Collen et al. (2009)

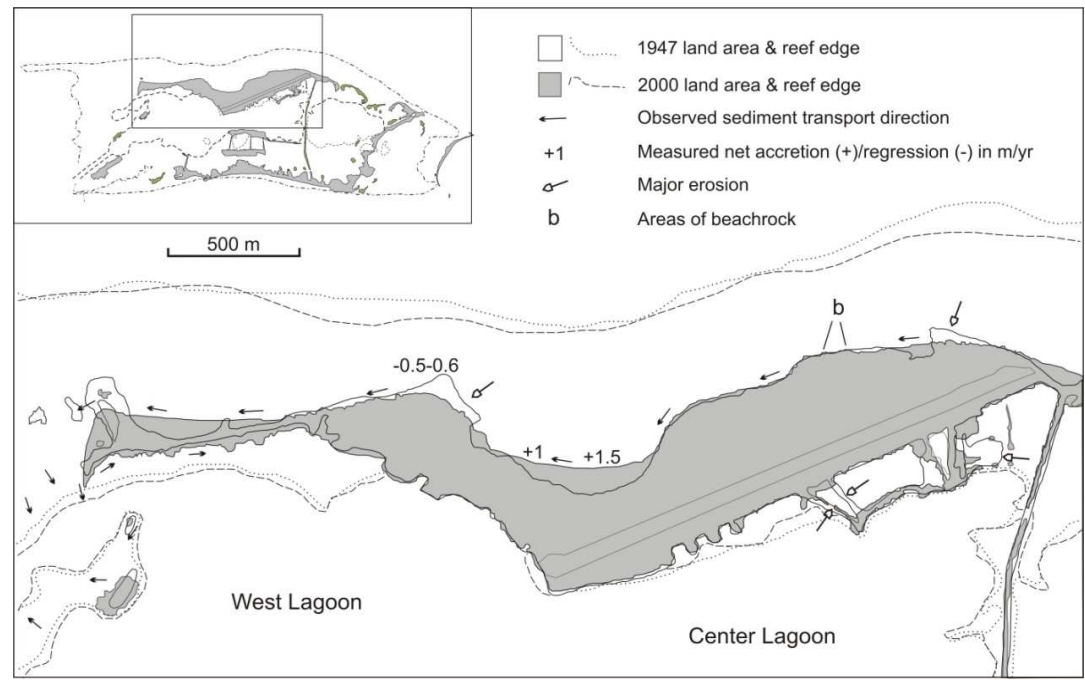

Fig 2.7 Shoreline changes around Strawn Peninsula and Cooper-Meng Island 1945-2000.

The single useable runway is now much narrower then when built and the second runway 
that ran northwest-southeast is completely overgrown and not shown here. Diagram courtesy of Collen et al. (2009)

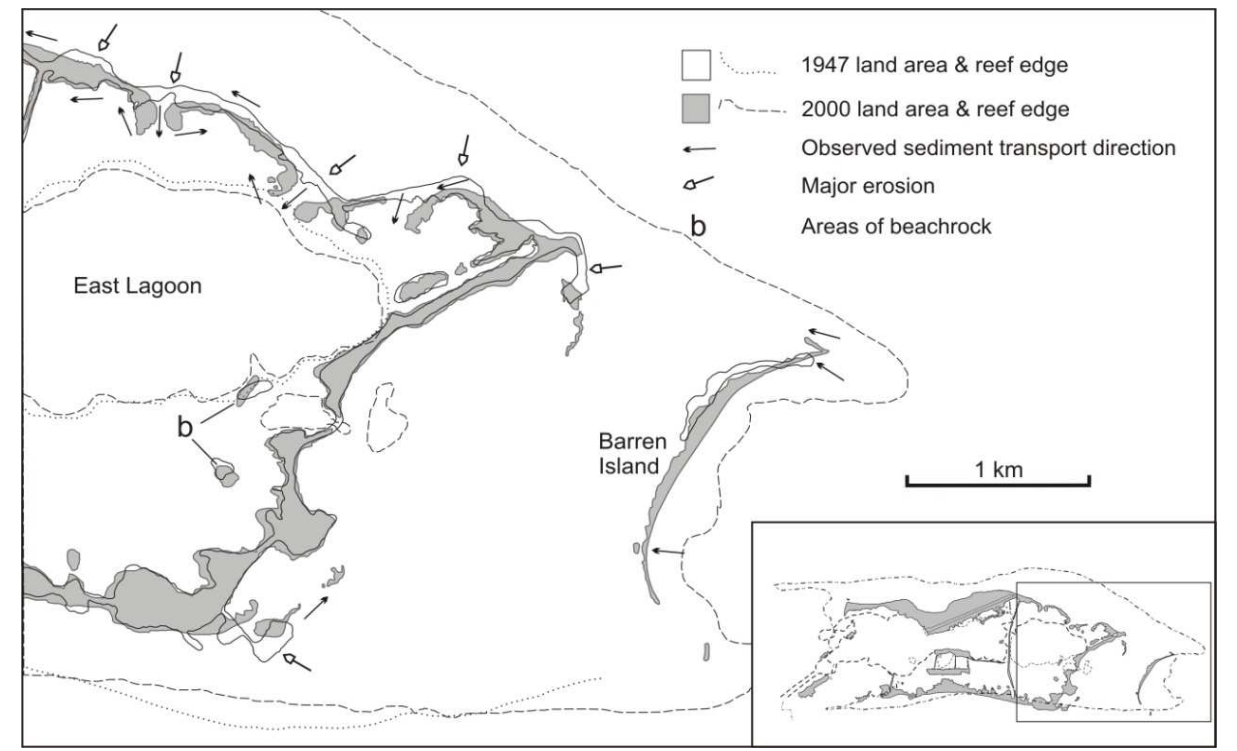

Fig 2.8 Shoreline changes around the eastern coast of Palmyra atoll 1945 -2000. Diagram courtesy of Collen et al. (2009)

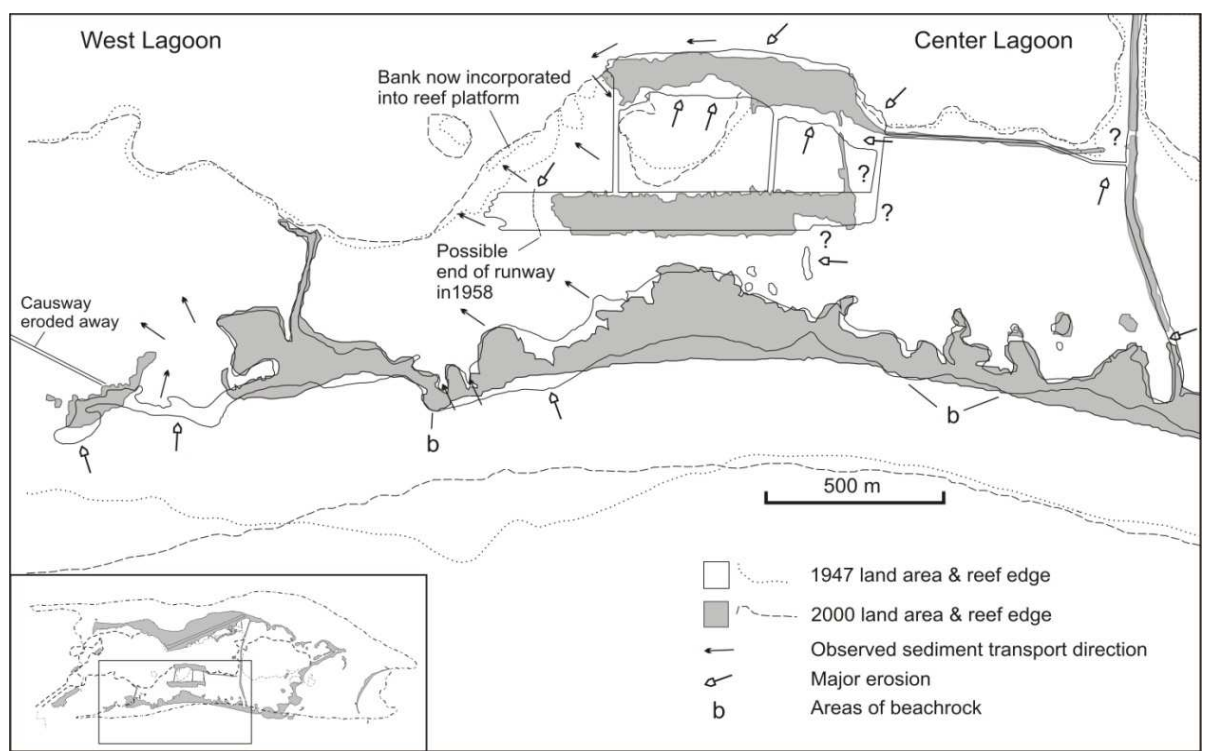

Fig 2.9 Shoreline changes around the southern areas of Palmyra atoll 1945-2000.

Diagram courtesy of Collen et al. (2009) 


\section{Chapter 3: Sampling and methods}

\subsection{Sampling}

Sampling was undertaken during an 18-day visit to Palmyra Atoll between the $10^{\text {th }}$ and $28^{\text {th }}$ of June, 2007. Sub-aerial environments were examined and a total of 124 sediment samples collected from shoreline, reef flat and lagoon bottom settings (Appendix B). Of these, 116 samples were collected by boat along a series of transects across the 3 main lagoons using a small hand operated dredge designed to sample the top $1 \mathrm{~cm}$ of the sediment (Fig. 3.1). Further samples onshore and offshore were collected by hand, using scuba equipment in deeper water, and by coring using $300 \mathrm{~cm}$ PVC tubes. Visual descriptions and photos of outcrops and substrate were made where sampling was not applicable. Sample positions were recorded using a handheld Garmin Etrex personal navigator GPS unit. For the purposes of this study a GPS error of $+-8 \mathrm{~m}$ was considered acceptable and GPS points matched well with grid positions on the Ikonos satellite image used as a basemap (Appendix F) without any further modification. Sample locations were plotted onto bathymetric basemaps (Fig 3.2, 3.3, 3.4) compiled from the Ikonos imagery and various previous bathymetric maps of Palmyra atoll (NOAA 1944), by Collen pers comm. (2008).

Sediment samples were taken at selected locations to give an even spread of data points in order to show sedimentological, environmental and bathymetric changes. Typically, 50 to 200 grams of surficial sediments were collected by dredging; however, in some locations this was much reduced especially where bottom topography was irregular or consisted of a hard surface. Samples were preserved in ethanol to satisfy the importation requirements of the New Zealand Ministry of Agriculture and Fisheries and then air dried for transport. 


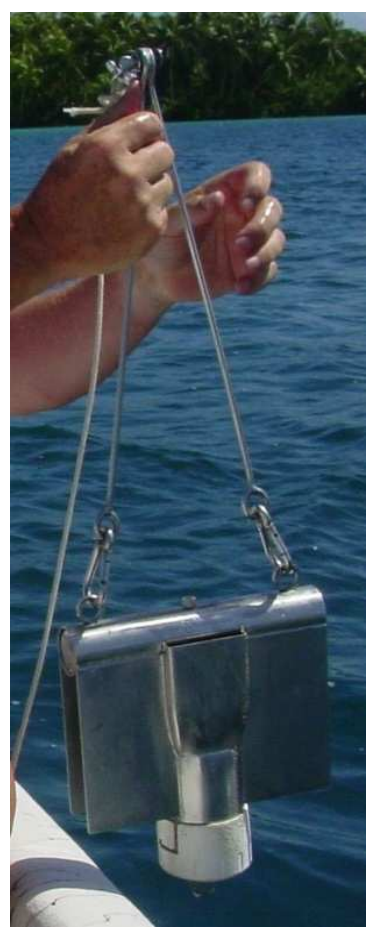

Fig 3.1 Photo of dredge used to retrieve sediment from the lagoon substrate. The $1 \mathrm{~cm}$ deep openings at the front collect only the surficial layer of sediment.

\subsection{Grain size analytical procedures and processing}

Fifty one samples were processed for grain size analysis using four different processes depending on sediment type, as follows:

\subsubsection{Process method 1 - Dominantly sand-sized samples}

Samples that were mainly of sand-sized sediment were dried in 1 litre stainless steel bowls in an oven at $60^{\circ} \mathrm{C}$ for 24 hours. Fourteen Samples were then split to approximately $30 \mathrm{~g}$ using a combination of Carver's (1980) spooning method and a micro splitter to obtain a valid representation of the original population. Samples were then dry sieved for 15 minutes into the following seven size fractions: coarser then -4 phi, $-3.5,-3,-2.5,-2.0$, 
$-1.5,-1.0,-0.5,0.0,0.5,1.0,1.5,2.0,2.5,3.0,3.5,4.0,4.5,5.0$ and finer than $5.0 \mathrm{phi}$ (pan) (Table 3.1).

\begin{tabular}{|c|c|c|c|c|}
\hline$\varphi$ scale & $\begin{array}{|ll|}\text { Size } & \text { range } \\
\text { (metric) } & \end{array}$ & $\begin{array}{|ll|}\text { Size } & \text { range } \\
\text { (approx. inches) } & \\
\end{array}$ & \begin{tabular}{|ll} 
Aggregate & name \\
(Wentworth Class) &
\end{tabular} & Other names \\
\hline$<-8$ & $>256 \mathrm{~mm}$ & $\mid>10.1 \mathrm{in}$ & Boulder & \\
\hline-6 to -8 & $64-256 \mathrm{~mm}$ & $2.5-10.1$ in & Cobble & \\
\hline-5 to -6 & $32-64 \mathrm{~mm}$ & || $1.26-2.5$ in & Very coarse gravel & ||Pebble \\
\hline-4 to -5 & $16-32 \mathrm{~mm}$ & $0.63-1.26$ in & Coarse gravel & Pebble \\
\hline-3 to -4 & $8-16 \mathrm{~mm}$ & $0.31-0.63$ in & ||Medium gravel & |Pebble \\
\hline-2 to -3 & $4-8 \mathrm{~mm}$ & $0.157-0.31$ in & Fine gravel & Pebble \\
\hline-1 to -2 & $2-4 \mathrm{~mm}$ & $0.079-0.157$ in & Very fine gravel & Granule \\
\hline 0 to -1 & $1-2 \mathrm{~mm}$ & | $0.039-0.079$ in & Very coarse sand & \\
\hline 1 to 0 & $0.5-1 \mathrm{~mm}$ & $0.020-0.039$ in & Coarse sand & \\
\hline 2 to 1 & $0.25-0.5 \mathrm{~mm}$ & $0.010-0.020$ in & Medium sand & \\
\hline 3 to 2 & $125-250 \mu \mathrm{m}$ & |0.0049-0.010 in & Fine sand & \\
\hline 4 to 3 & $62.5-125 \mu \mathrm{m}$ & $0.0025-0.0049$ in & Very fine sand & \\
\hline 8 to 4 & $3.90625-62.5 \mu \mathrm{m}$ & $0.00015-0.0025$ in & Silt & Mud \\
\hline$>8$ & $<3.90625 \mu \mathrm{m}$ & $<0.00015$ in & Clay & Mud \\
\hline$>10$ & $<1 \mu \mathrm{m}$ & $\|<0.000039$ in & Colloid & |Mud \\
\hline
\end{tabular}

Table 3.1 Grain size scale for sediments, showing sieve size in millimetres and equivalent phi (Ф) units and Wentworth size class (Boggs 2001).

Material finer than $62 \mu \mathrm{m}$ (4.0 phi) was collected as the pan, 5 and 4.5 fractions. These fractions had $40 \mathrm{mls}$ of $0.1 \%$ Calgon solution added, were disaggregated and then analyzed on a Micrometrics sedigraph 3 particle size analyser using the program 
Sedigraph 3 V1.01 by Micrometric Instrument Corporation. The following settings were used; Material / liquid: calcium carbonate / water. Measurement principle: X-Ray monitored gravity sedimentation. Calculation method: Stokes sedimentation and Beer's law of extinction.

The weight of each fraction was compiled, recorded and expressed as a percentage of the initial weight to show the overall grain size distribution for each analyzed sample. The results of this are recorded in Appendix B (Grain Size Data Overview).

\subsubsection{Process method 2 - Dominantly sand-sized samples with removal of organic material}

Twenty five samples were put through the same process as above but before sieving were washed with $20 \mathrm{mls}$ of hydrogen peroxide and distilled water and left in a $60^{\circ} \mathrm{C}$ waterbath to remove organic matter. The sample was then flushed with fresh distilled water to remove excess hydrogen peroxide, dried for 24 hours and then re-weighed to allow calculation of the weight of organic material removed.

\subsubsection{Process method 3 - Silt and clay samples}

Five mud samples were oven-dried in 1 litre stainless steel beakers at $60^{\circ} \mathrm{C}$ for 24 hours, weighed and then disaggregated using ultrasound for $15 \mathrm{~min}$ in a solution of $0.1 \%$ Calgon before being passed through a $62 \mu \mathrm{m}$ nylon mesh in a tube support in a funnel above a second beaker. The nylon mesh was first wetted before sediment passed through, and all material finer than $62 \mu \mathrm{m}$ was washed into the second beaker. The second beaker containing the finer material was then removed and the coarse material collected back into the original beaker by removing the tube support and turning it over.

Both the separated fine and coarse sediments were re-dried and re-weighed. The coarse material was then dry sieved using the same process used for sands without the hydrogen peroxide treatment above (process 1) and the fine fraction was re-disaggregated in $40 \mathrm{mls}$ 
of $0.1 \%$ Calgon before having Sedigraph analysis undertaken as for the finer fraction in method 1 .

\subsubsection{Process method 4 - Silt and clay samples}

Seven samples were split using the same method as above (method 3), but instead of redrying, re-weighing and re-disaggregating the finer fraction, the freshly washed fine fraction was run through the Sedigraph immediately.

\subsection{Problems encountered with grain size analysis and solutions utilized}

Several difficulties were encountered during the processing of the collected calcareous lagoon sediments. Especially problematic was the organic-rich finer grained material because of its ability to form hard aggregates that, once dried, resisted disaggregation in water. As a result multiple processing techniques were incorporated in an effort to find the best way of overcoming these.

\subsubsection{Removal of organic material}

Method 2 was originally selected as the primary method for grain size analysis of the dominantly sand fraction samples. However, a problem was encountered with the removal of organic material with hydrogen peroxide. The finer samples with abundant organic material would effervesce, cause aggregates to form on the sides of sample beakers and spill unless carefully watched and diluted with distilled water to slow the reaction. For this reason, method 1 was adopted in preference to method 2 half way through grain size processing. For the same reason, the collected coarse material from silt and clay methods 3 and 4 was not chemically washed and instead was sieved untreated.

The chemical removal of organic matter with hydrogen peroxide also led to colour bleaching which hindered subsequent compositional analyses. 


\subsubsection{Disaggregation}

Difficulties were encountered with the fine sediments using method 3, of re-drying, reweighing and then re-disaggregating the finer fraction material. The sample would not completely disaggregate again and formed aggregates larger then $62 \mu \mathrm{m}$ which blocked the sedigraph instrument and resulted in the analysis having to be aborted in order to unblock it.

The solution to this problem (Method 4) was to run the freshly split finer material without re-drying, weighing and re-disaggregating. No blockages of the sedigraph were encountered using this method and the weight of the finer samples was calculated by weighing the coarse material and subtracting the loss of weight from the original weighed material. An error in measurement of weight for the fine fraction could have been introduced with this method, but is believed to have been minimized as far as possible.

Problems with finer material not disaggregating were also encountered when dry sieving, as the finer material would cement into lumps and not sieve down to the correct grain size but when removed from sieve to be weighed would then later breakdown under the clearing of the sieve face with a brush, leading to a skewing of the grainsize data.

\subsection{Composition counts}

Two methods of obtaining the composition were trialed, a thin section and a binocular point counting method. The binocular method was found to be greatly superior to thin section examination as the large quantities of fine material within the sediment made visual recognition of these grain types very difficult.

\subsubsection{Binocular point counting}

Twenty two of the sediment samples processed for grain size analysis were selected for compositional analysis. Twelve of these were processed using method 1 and had not 
undergone organic removal, and the other 10 samples had been hydrogen peroxide treated to remove organics. The following combined weights were used in the analysis of composition: greater than $2 \mathrm{~mm}(-1 \Phi), 1 \mathrm{~mm}(0 \Phi), 0.50 \mathrm{~mm}(1 \Phi)$, and $0.25 \mathrm{~mm}(2 \Phi)$. All smaller fractions where omitted due to the difficulty of identifying such small grains using a binocular microscope. Selected fractions were point counted using a binocular microscope and, where possible; counts were made of 100 grains per size fraction. This was considered adequate because of the reasoning that if a particular grain is not present in the first 100 counted then that grain type represents less than $1 \%$ of the total. Grains were identified to one of 7 main categories and 28 sub-categories (Table 3.2). 
Table 3.2 Categories used for compositional counts

\begin{tabular}{|c|c|}
\hline & Composition \\
\hline \multirow[t]{9}{*}{ Foraminifera } & Amphistegina lessonii \\
\hline & Amphistegina lobifera \\
\hline & Textularia conica \\
\hline & Heterostegina depressa \\
\hline & Marginopora vertebralis \\
\hline & Other larger foraminifera \\
\hline & Other miliolids \\
\hline & Other textulariids \\
\hline & Other rotaliines \\
\hline Calcareous Algae & Halimeda spp. \\
\hline \multirow{2}{*}{ Coral and red algae } & Fragments \\
\hline & Sclerites \\
\hline \multirow[t]{2}{*}{ Crustacean } & Fragments \\
\hline & Ostracods \\
\hline \multirow[t]{2}{*}{ Echinoids } & Spines \\
\hline & Plates \\
\hline \multirow[t]{4}{*}{ Molluscs } & Bivalves \\
\hline & Gastropods \\
\hline & Gastropod operculae \\
\hline & Indeterminate \\
\hline \multirow[t]{7}{*}{ Other } & Rock fragments \\
\hline & Sponge spicules \\
\hline & Bryozoans \\
\hline & Wood \\
\hline & Worm tubes \\
\hline & Human Debris \\
\hline & Unidentifiable grains \\
\hline
\end{tabular}




\subsubsection{Errors associated with compositional analysis}

Composition analysis relies on the visual interpretation of a grain type, and this is not always clear. Difficulties were especially encountered when trying to distinguish red algae and coral, as the two may be very similar and are often intergrown; therefore the two were grouped together. The removal of organic material during preparation for grain size analysis can also make identification hard as it removes all pigmentation from the grains. This bleaching of the grains was clearly apparent when visually comparing raw unwashed samples to hydrogen peroxide treated ones.

\subsection{Photography}

Various individual components were separated during compositional analyses for the purpose of photographing and correctly identifying the various foraminifera present. Other non-foraminiferal components of significant interest were also selected to be photographed. The separated clasts were mounted on slides and then photographed (See section 5.1.4, Plate 5.1, 5.2).

\subsection{Maps}

Maps of lagoon and coastal sediments were completed in conjunction with bathymetric maps and high-resolution satellite imagery of the reef platform. The applicability of satellite imagery for studying shallow marine carbonate environments was tested by comparing sedimentary facies zones with recognizable environmental zones on the images.

\subsection{Conductivity, temperature and depth (CTD) casts}

Conductivity, temperature and depth (CTD) casts to measure water properties such as temperature, dissolved oxygen content, salinity and turbidity were made at the same time 
as this study. Selected data are used here where appropriate (Section 2.2.2) and full results will be presented elsewhere (see also Gardner et al. in prep).

\subsection{Total organic carbon}

An estimate of total organic carbon content was made for 25 sand samples. Results were obtained by using process method 2 (Section 3.2.2) for dominantly sand-sized samples with removal of organic material using a hydrogen peroxide wash. Results were calculated by subtracting the weight of hydrogen peroxide treated and re-dried samples from the initial dry weight of the same samples before processing began.

\subsection{Errors and limitations}

Some of the field observations, especially those in the centres of islands and along some shorelines, were limited by dense vegetation, access restrictions for wildlife and native plant protection and the presence of unexploded ordnance and hazardous chemicals. Errors may be associated with drifting away from the GPS location point while dredging for sediment, and also from dredging itself as the dredge only samples the top $1 \mathrm{~cm}$ of the sediment and any material coarser than this is not recovered. Retrieval of the dredge through the water column has the potential to cause the loss of finer material and some errors may also been introduced during the weighing and analysis processes. 
Fig 3.2 Bathymetric basemap of West Lagoon section showing sample locations

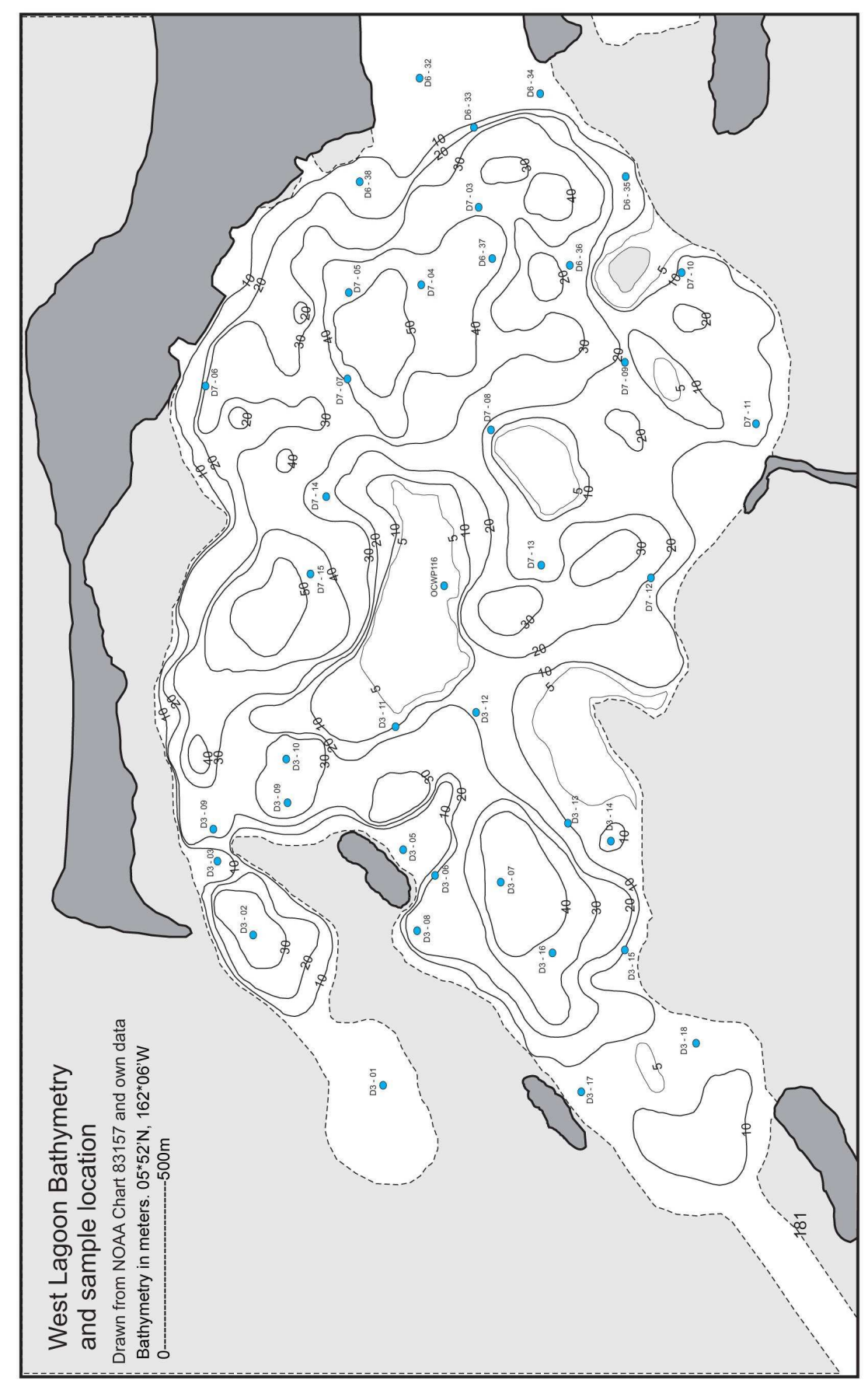


Fig 3.3 bathymetric basemap of Center Lagoon section showing sample locations

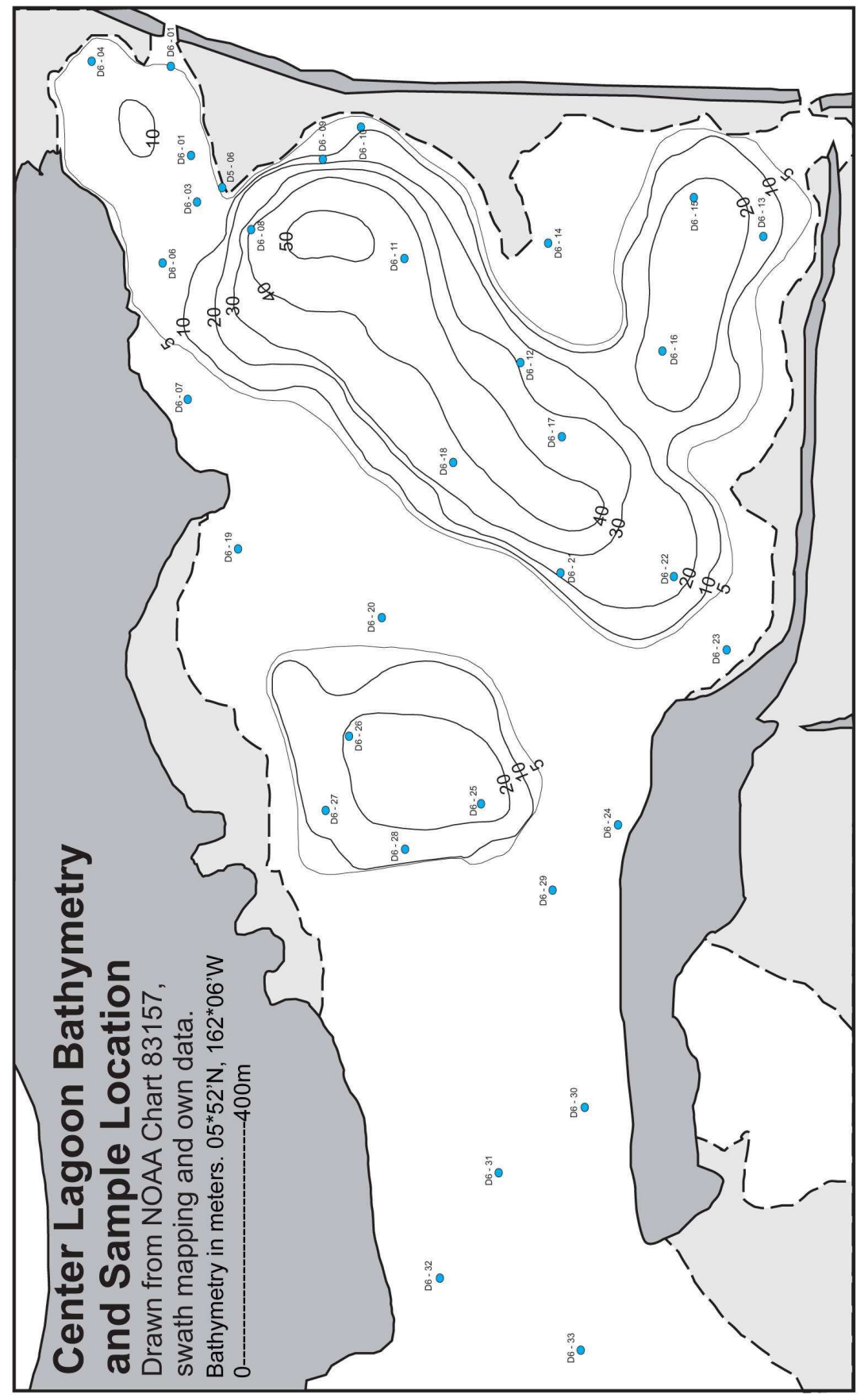


Fig 3.4 Bathymetric basemap of East Lagoon section showing sample locations

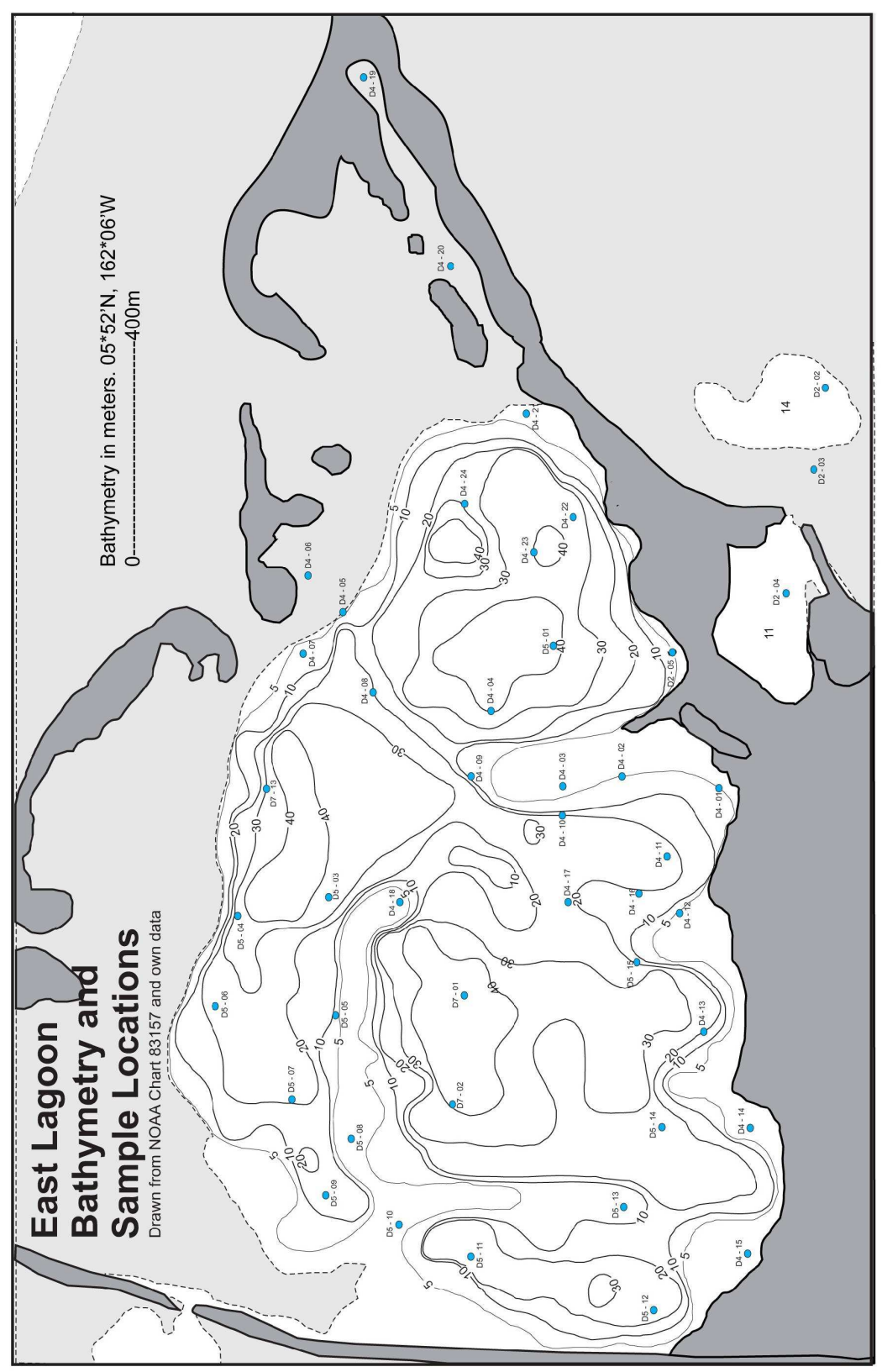




\title{
Chapter four: Physical environments and lithofacies on Palmyra Atoll
}

\author{
Tropical atolls show a complex mix of carbonate environments and associated \\ sedimentary facies. These environments and facies are inherently linked as the sediment \\ is entirely biologically derived, and hence similarities and controls exist between them. \\ This chapter describes the identified observed carbonate environmental zones and \\ sedimentary facies associated on Palmyra Atoll.
}

\subsection{Environmental zones found on Palmyra Atoll}

A number of distinctive carbonate environmental zones have been recognized for Palmyra Atoll. The following 6 zones and 8 sub-zones were identified and mapped (Fig 4.12, 4.13, 4.14, Appendix G) from distinctive topographic, lithologic and biological characteristics (Fig 4.1).

1. Fore reef and crest

2. Eastern and western reef terraces

3. Ocean outer reef flat:

3a. Pavement

3b. Ocean-facing Beach

4. Lagoon inner reef flat:

4a. Intertidal sand aprons and sheets

4b. lagoon beach

5. Lagoons:

5a. Shallow lagoons

5b. Deep lagoons

5c. Patch reefs / Sand Banks

5d. Blue holes / Ponds

6. Reef islands 
Fig 4.1 Cross section showing a generalized view and association of reef environments and their respective boundaries to each other.

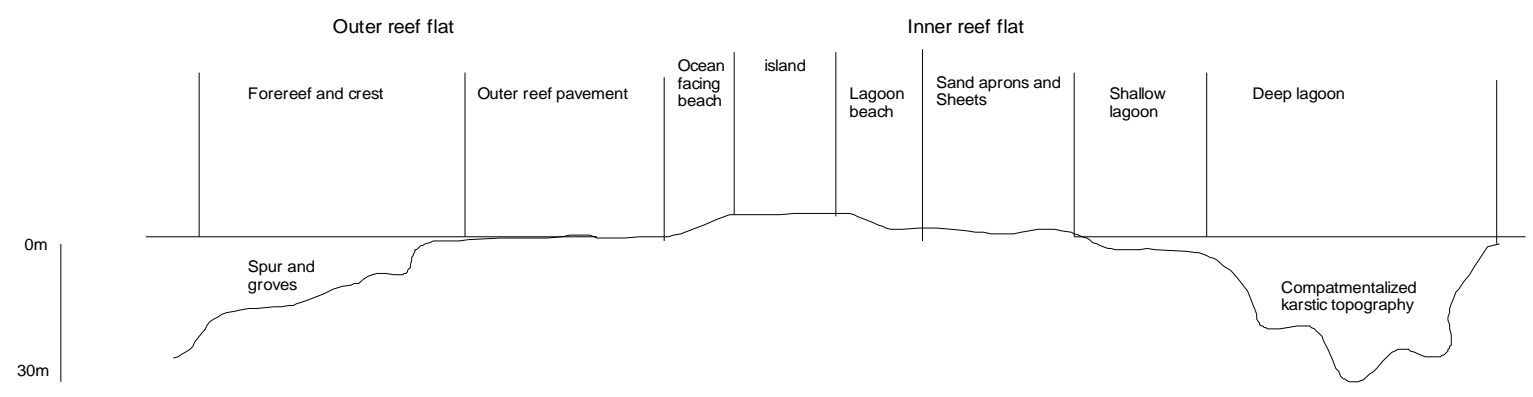

\subsubsection{Fore reef and crest}

The fore reef zone extends from the reef crest and dips seaward at between $10^{\circ}$ and $20^{\circ}$ into the deep $(70-100 \mathrm{~m})$ offshore area, below which little or no skeletal frame-building occurs (Tucker and Wright 1990). The reef crest zone is the highest, most exposed part of the reef and is a high energy regime. Here, ocean swells meet and break upon the reef crest and wash over the outer reef pavement zone, and resistant encrusting organisms dominate. The fore reef front and crest zones are characterized by a spur and groove system. The spurs and grooves are between 5 and 10 metres wide and spurs have several metres relief above the adjacent groove floor on the northern and southern limits of Palmyra (Fig 4.2). These zones were not studied in detail due to the strong surf, but appear to have little loose sediment accumulating. The spur and groves are thought to play a vital function of the outer reef rim as a breakwater (Wiens 1959). This breakwater is thought to have implications on the control of sedimentation observed on Palmyra on the ocean outer reef flat pavement. 


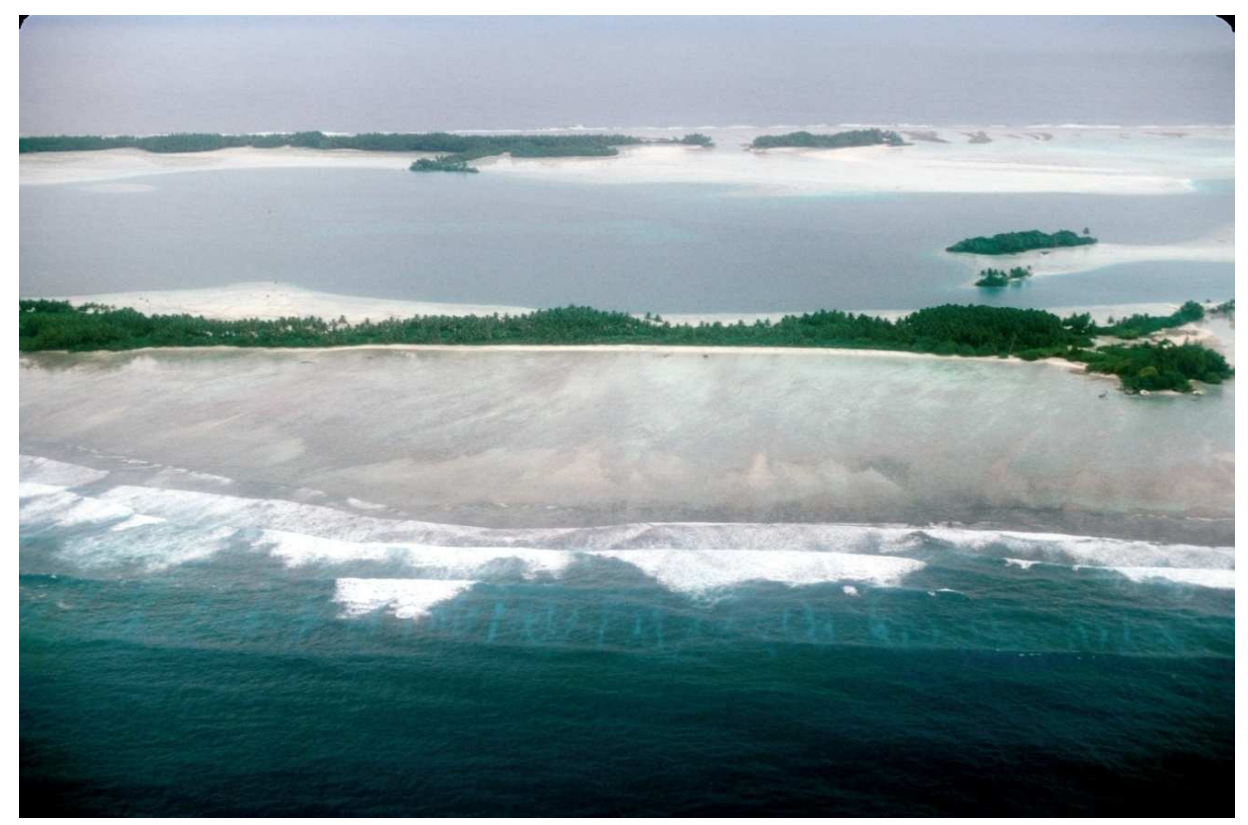

Fig 4.2 Aerial view to the south across Strawn Peninsula and West lagoon to Paradise and Home islands in the background, taken in 1979. Spur and groves appear as white veins just below the surf zone in the foreground. Above the surf zone is the outer reef pavement; the lighter areas here are lenses of unconsolidated material that approximately align with and are extensions of the spur and grove system operating on the fore reef and crest. Photograph courtesy of J. Maragos.

\subsubsection{Eastern and Western reef terraces}

Palmyra has elongated fore reef terraces extending for between 3 and $5 \mathrm{~km}$ off the western and eastern ends of the atoll at depths of 7-25 m. The reef terraces are areas of gently dipping, extensive abundant living coral and algal reef that supports a highly diverse range of aquatic biota. The reef terraces are characterized by low relief massive coral heads growing in the order of several metres to tens of metres high and wide with sparse pockets of thin, coarse grained sandy sediment composed of fragmented coral and Halimeda with lesser amounts of molluscan and crustacean clasts. 


\subsubsection{Ocean outer reef flat}

Palmyra has an almost continuous, surface-breaking reef crest rim enclosing the atoll on all sides. The outer reef flat area is behind and partially protected by this rim, and two sub-environments can be recognized here: the reef pavement and the ocean-facing beach.

\subsection{3 a. Pavement}

The reef pavement is immediately behind the reef crest rim zone and is partly protected by it. The outer reef flat is characterized by a hardened pavement cemented by crustose coralline algae and submarine cement that incorporates various detrital elements derived from the coral community, such as fragments of coral, Halimeda and molluscs, as well as entire foraminifera (Fig 4.3). The pavement is variable in width, from tens of metres to over a hundred metres. The water depth is typically only a few metres at high tide and much of the pavement is exposed at low tide. There are many pools of various sizes, often tens of centimetres deep, which provide habitats for soft algae, gastropods, echinoderms, starfish, eels, and small colonies of living coral. Unconsolidated sand and gravel formed from the branches of angular broken Acropora and algal debris derived from the reef crest and front occur in these pools. Much of the debris is encrusted by crustose coralline algae. The debris also forms larger thin mobile lenses of sand and gravel rubble that are strewn across the pavement. The lenses approximately represent extensions of the spurs and grooves of the fore reef and clearly show as light patches on aerial photographs (Fig 4.2). This implies that, as with the grooves, the lenses are controlled by wave dynamics. It is thought that there is a net balance over time in the total area covered by this unconsolidated material; whereby new material created balances the loss of material by cementation or transport off the pavement. Typical sediment deposits found here are bindstones and rudstones with lesser framestones. Channels and tidal passes occur as break through channels (hoas) in the islet supporting perimeter reef. Large, infrequent, storm-derived coral blocks occur on the pavement and outermost ocean-facing beaches; these are typically less bioeroded than material of the same type 
submerged in water. These blocks have been used to precisely date and record variability in ENSO over the last 1100 years by Cobb et al. (2003).

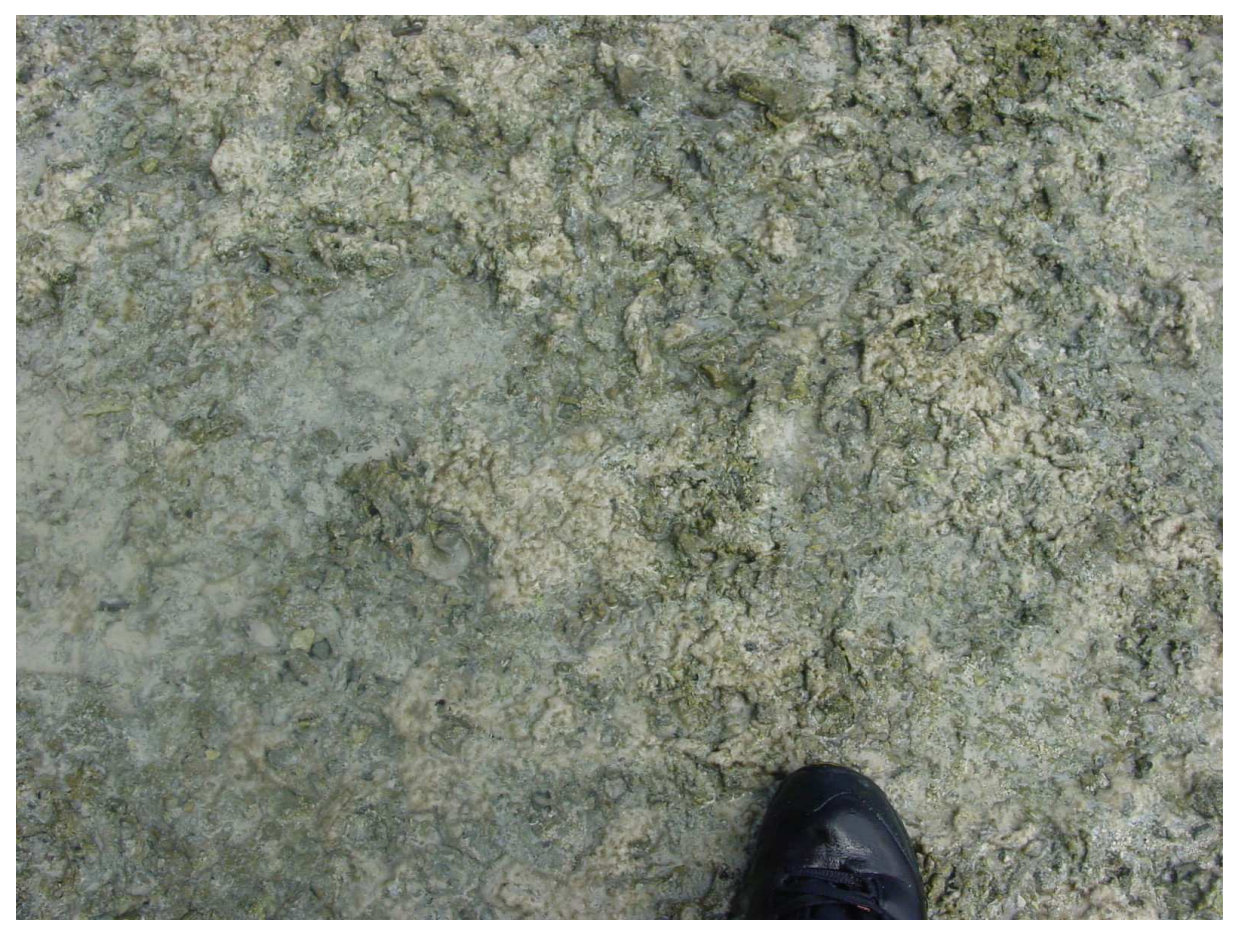

Fig 4.3 Typical reef pavement surface devoid of unconsolidated material.

\subsection{3 b. Ocean-facing beach}

Outer reef beaches bound the islands of Palmyra. Beaches vary in width but are typically several metres wide. In some areas this width is greatly reduced by strong longshore currents operating at high tide eroding and moving material along the island edges to areas of deposition and expansion. This is especially evident on the northern side of Cooper-Meng Island where material is being eroded (Fig 4.4) and transported westward along the coast, infilling embayment's (Fig 4.5) and eventually losing material off into the western terrace and lagoons (Collen et al. 2009). In places, hard beach-rock embankments occur that are relics of past high sea-level cemented reef pavement. In many places beaches appear to blanket and extend out over the hard reef pavement 
surface. Beaches are mainly medium to coarse sand sometimes with chunks of larger coral debris found lying on top. In high energy areas such as Barren Island where the wave energy is strong, coarse rubble composed of fragmented branching corals derived from the fore reef and reef crests occurs.

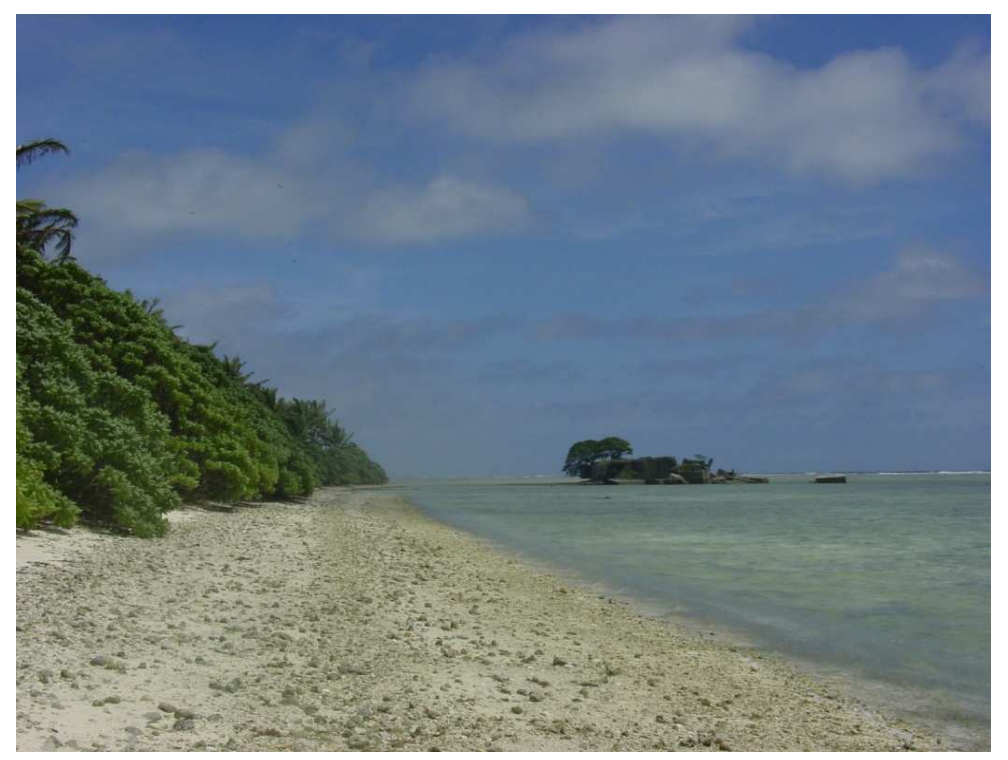

Fig 4.4 Looking west along the winnowing ocean facing beach on the northern side of Strawn peninsular. Larger coral debris is found scattered atop of the beach as finer sediment is being removed to the west. A channel has formed between the peninsula to the left and a World War Two gun emplacement to the right since 1979 (compare with Fig 4.2). 


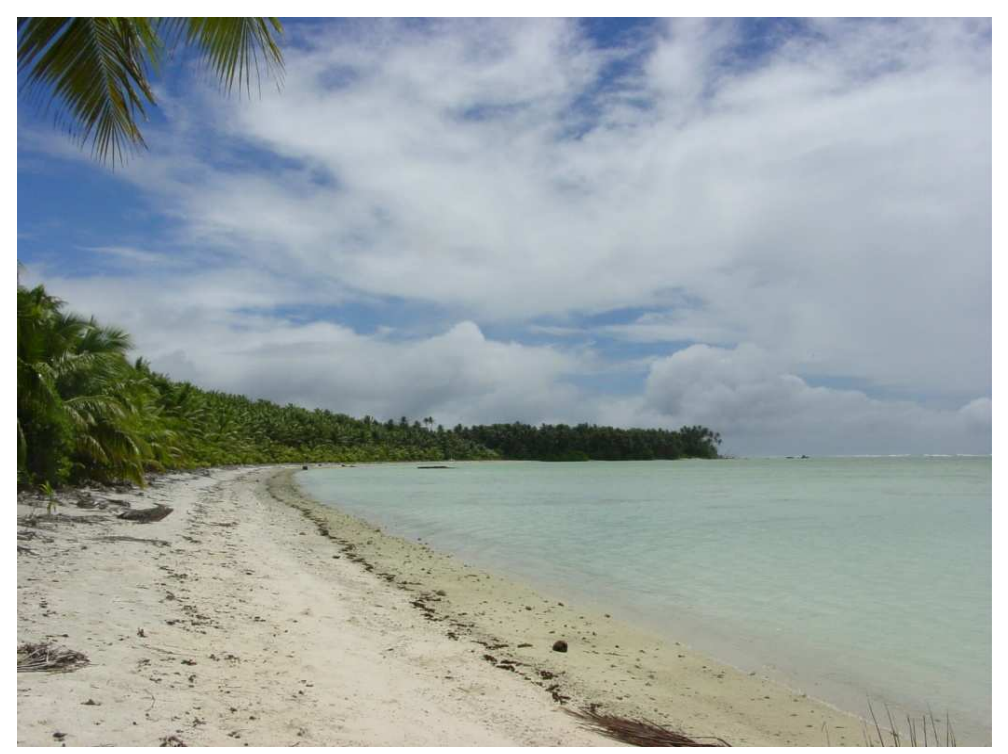

Fig 4.5 Looking west along accreting North Beach, northern side of Cooper-Meng Island.

\subsubsection{Lagoon inner reef flat}

The lagoon-side reef flat is an extensive area of reef pavement located on the inner side of Palmyra's islands. This zone is dominantly covered by sand, and mud aprons and sheets. These are probably no more then one or two metres in thickness, as earlier aerial photographs show much of these areas to be covered coral heads (Fig 4.8). A steep beach often grades directly into the aprons and banks up around the islands.

\subsection{4 a. Intertidal sand aprons and sheets}

Located behind and protected by Palmyra's islands are common, well developed sand aprons and sheets. These vary in width up to $300 \mathrm{~m}$ wide between inner islands and have areas of both muddier and sandier sediment depending on the local wave and current energy levels. Typically grainstones and rudstones grade to muddier packstone and wackestone sediment towards the lagoons from the islands. In areas of the inner reef where storm surge has pushed coarser material over the islands or through hoas (shallow passages) from the outer reef platform, gravel tongues occur spilling out over the reef flat. 
Water depths do not exceed $2 \mathrm{~m}$ at high tide, and many of the sand aprons and sheets are exposed at low tide. The sand apron is heavily burrowed with muddy sand hummocks and mounds (crab volcanoes) up to $12 \mathrm{~cm}$ high (Figure 4.6). The aprons and sheets are thought to be relatively thin deposits (up to several metres at maximum) that overlie older hardened cemented pavement and patch reefs.

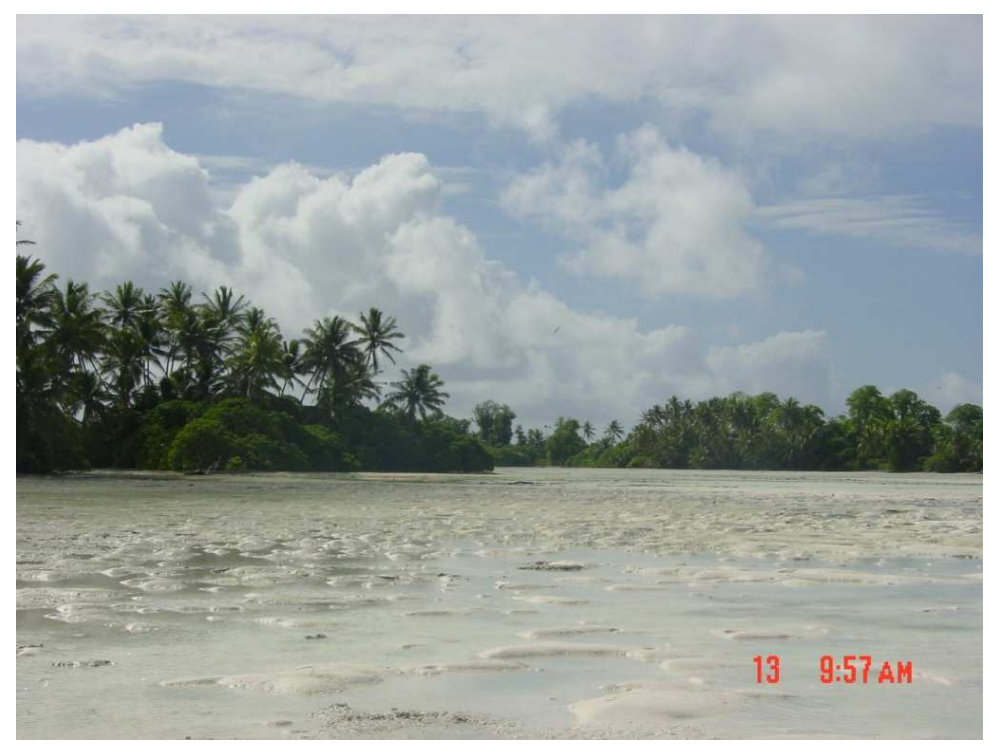

Fig 4.6 Inner reef flat intertidal sand aprons and sheets, looking west from Paradise Island towards Home Island. The sand aprons and sheets are heavily bioturbated by crustaceans and other organisms that form sediment mounds.

\subsection{4 b. Inner beach}

Inner lagoon beaches are mainly composed of medium to fine sands with patches of gravel, and are between one and five metres in width. Beaches appear in many places to grade from the islands directly into the extensive sand and mud aprons especially in the well protected leeward bays where it is difficult to distinguish the two. In some areas coarse sand and gravel rubble material can be seen extending out over the aprons or directly into the shallow lagoon. This material is derived from the islands and cays 
themselves, with many of the artificial islands consisting of material dredged from patch reefs once located in the inner atoll area as well as from the lagoon bottom.

\subsubsection{Lagoons}

Palmyra's lagoon zone is an area of comparatively shallow brackish water protected and separated from the deeper sea by the shallow or exposed islands and enclosing coralgal barrier reef rim. A number of environments exist within this protected enclosure.

\subsection{5 a. Shallow lagoons}

Palmyra Atoll has large areas of shallow lagoon with unconsolidated substrate material varying from muddy sands to gravel depending upon the energy acting upon that area. Generally, the material found within this zone is slightly gravely, muddy sand packstone grading into wackestone closer to the deep lagoon. The shallow lagoon zone encompasses the area from the low tide mark down to a depth of 5 metres. The substrate is heavily bioturbated by such organisms as crustaceans, worms and holothurians. Patches of coarser material were felt when dredging and in places clumps of living Halimeda were retrieved stuck to the outside of the dredge.

\subsection{5 b. Deep lagoons}

Palmyra exhibits an abnormally high proportion of deep lagoon zones for such a small atoll by area when compared with larger atolls from the tropical Pacific region. The deep lagoons are still largely surrounded by land and consist of a number of steep sided deep basins. Preliminary observations suggest that most water movement is to the west and restricted to the surface few metres. Consequently there is restricted circulation with low energy levels in the deeper water areas that act as a trap for fine sediment. The deep lagoon zone is defined here as that from $5 \mathrm{~m}$ water depth down to a depth of more than 40 $\mathrm{m}$ in the inner atoll. The deep lagoons generally have a mud or slightly sandy mud substrate. The seafloor was occasionally found to be rocky and the dredge sometimes 
became stuck. This could be either from old exposed pavement, the result of wartime dredging or dumping, or limestone exposed during the last low-stand and now covered by a very thin veneer of fine sediments. Investigations using CTD casts recording dissolved oxygen (Gardner et al. in prep) and from smelling recovered dredge material from these zones has shown that the deep lagoon areas of Palmyra are anoxic and producing hydrogen sulphide.

\subsection{5 c. Patch reefs / raised sand banks}

Patch reefs are common around the perimeters of Palmyra's lagoons but are not seen in the centres. They stand several metres above the surrounding seafloor, which is usually coralalgal sand. Massive Porites coral is the dominant species of patch reef-forming coral found. Their alignment is predominantly north-south but some patch reefs align east-west in East Lagoon extending out into the centre of the lagoon from its western limits. The patch reefs located in the lagoons occur as drowned Porites heads and can be seen exposed aerially up to $28 \mathrm{~cm}$ above the low tide mark. This exposure is thought to have been caused by the lowering of lagoon water level when a channel was blasted through the south-western reef flat in 1940 (Woodbury 1946). Many of the interior patch reefs have been infilled by coralagal sand aprons and sheets. A large area of living patch reef exists outside the lagoon interiors between Barren Island and East Island where a new fourth lagoon is being surrounded by islets (Fig 4.7). The interior patch reefs have been heavily utilized for the construction of causeways linking the main islands to one another. This can be especially seen in the North-South Causeway separating the central and eastern lagoons where the construction activity removed much patch reef material and piled it up upon the natural shallow reef flat. (Fig 4.8) 


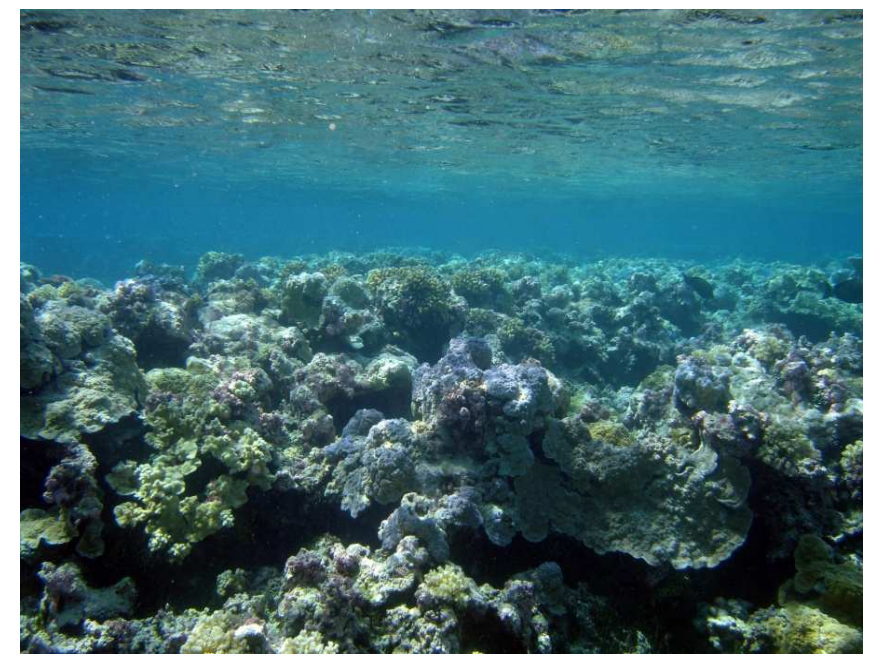

Fig 4.7 Living patch reef in the area between Barren Island and East Island known as the Coral Gardens at low tide.

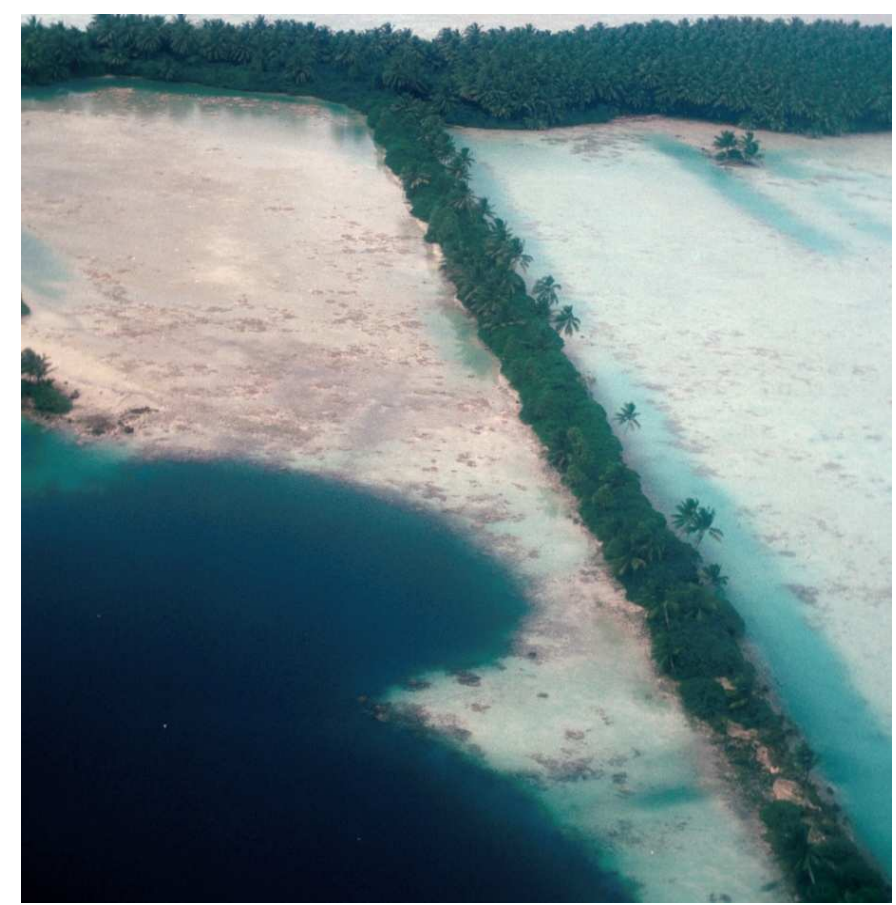

Fig 4.8 Aerial view of northern part of the North-South Causeway between Center and East lagoons looking north, taken in 1979. Patch reef material has been removed from a 
strip along the right side of the causeway as the building material. A break in the causeway now exists where the vegetation is least at the bottom right of the causeway in this photo. The extensive patch reef heads to the left of the causeway have now been largely infilled and covered with coralalgal sand sheets. Photo courtesy of J. Maragos.

\subsection{5 d. Blue holes}

Palmyra has several blue holes, most notably Turtle Pool (Fig 4.9) and the two small lagoons located at the north-west of West Lagoon (Map Appendix F). They are a submarine caves or sinkholes and are roughly circular in shape, steep-walled depressions and named for their dramatic contrast between the dark blue, deep waters of their depths and the lighter blue of the surrounding shallow lagoon areas around them (Guilcher 1988). Palmyra's blue holes are small in comparison to those found on other carbonate platforms, such as the Great Blue Hole on the coast of Belize dropping down to 150 metres. Palmyra's blue holes are muddy bottomed, range in depth from 30 to 40 metres, have poor water circulation and were shown to be anoxic at depth (Gaedner et al. in prep).

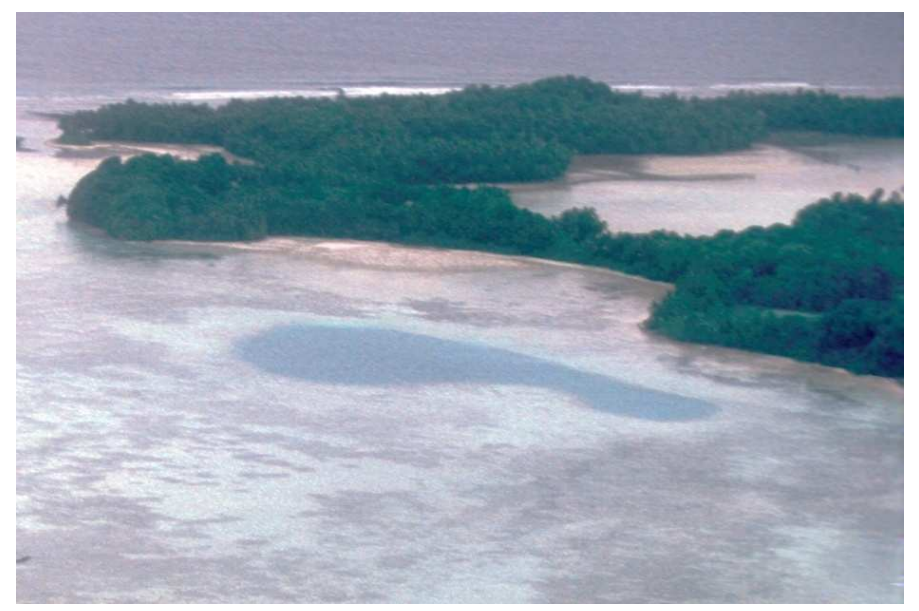

Fig 4.9 Aerial photograph taken in 1979 looking southwest of Turtle Pool, a blue hole located east of East Island. A channel now exists through the narrowest section of vegetated land in this photo. Photo courtesy of J. Maragos. 


\subsubsection{Reef islands}

Several types of islands are present on Palmyra Atoll. They account for a combined area of $2.5 \mathrm{sq} \mathrm{km}$ of land (Fig 1.2) (Collen et al. 2009), and have an average elevation of only 2 metres above sea level. Most islands are heavily vegetated by thick tropical rainforest species and are home to a number of large land crustaceans and to vast tropical seabird colonies (Flint 1992, USFWS 2001). Because the atoll was highly modified during World War two by airbase construction, the islands of Palmyra are both natural and artificial, and it is hard to distinguish the two in some places due to the dense vegetation cover. The artificial islands are the result of dredging the lagoon floor, patch reefs and reef pavement, and are therefore a mixture of many types and sizes of sediments. This is especially evident in some places of active erosion such as the northern side of the North Fighter Strip in Centre Lagoon where different layers of sediments are being eroded at different rates due to the nature of sediment available for use during reclamation and construction (Fig 4.10). The islands are littered with the remains of wartime buildings and defence emplacements; the largest island now called Cooper-Meng also has a sizable freshwater pond that is home to freshwater eels (Handler et al. 2006). The pre-1940 barrier islands and those that have developed since 1945 by break down of the artificial land form crescentic segments separated by hoas (shallow passages) that allow coarser sediment to be washed in and form deltas on the inner reef flat (Fig 4.11)

Palmyra has heavy rain fall (445 $\mathrm{cm}$ per year) and a well developed ground water lens rising to about 1 metre below the ground surface on the reef islands. This lens has not been studied, although fresh water has been observed rising from the sea floor after heavy rain several $\mathrm{km}$ west of the land on the Western Terrace (J.P.A. Gardner pers comm. 2006). This may possibly indicate a fresh water flow and pathway to outer atoll zones. 


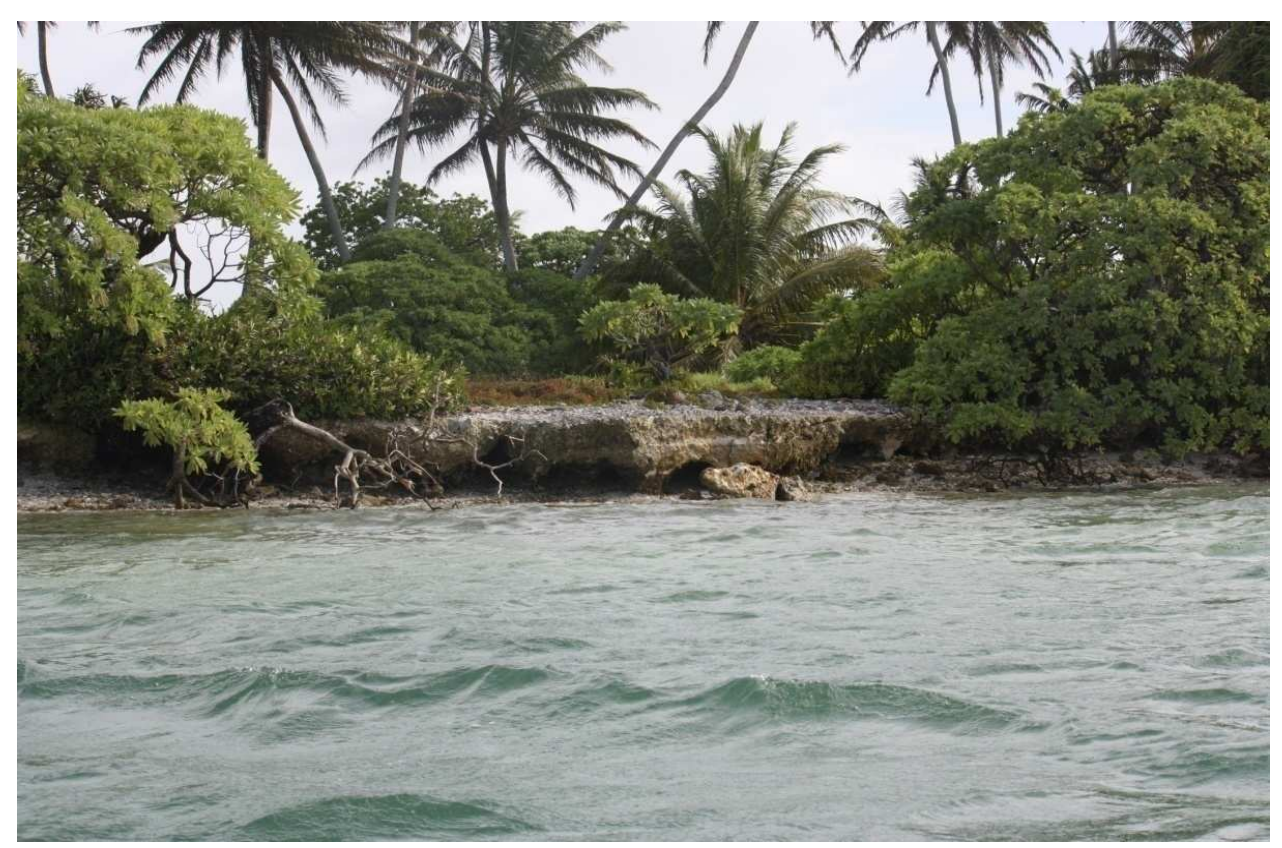

Fig 4.10 North Fighter Strip (Fig 1.2) is eroding showing layering of different grain sizes, undercutting and cliffing, and a coarse rubble beach. 


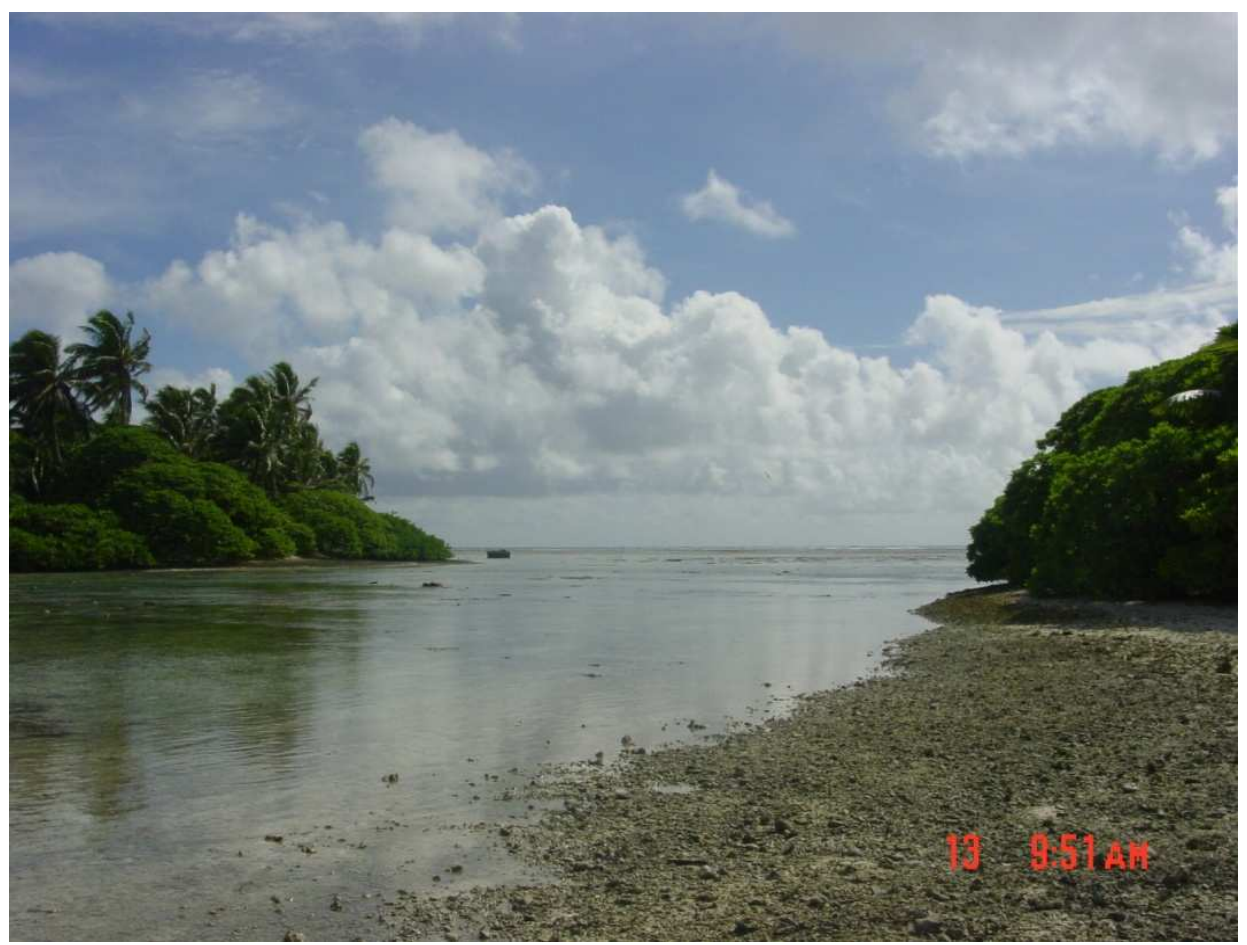

Fig 4.11 View north at low tide through the passageway between Quail and Aviation islands towards the ocean. A delta of coarser rubble material is being washed into and across the inner reef pavement and can be seen in the lower right hand corner.

Note: environments are a complex mixture and as a result the following maps are generalized. Larger copies of environment maps can be found in Appendix G 
Fig 4.12 Environment zone map of West Lagoon

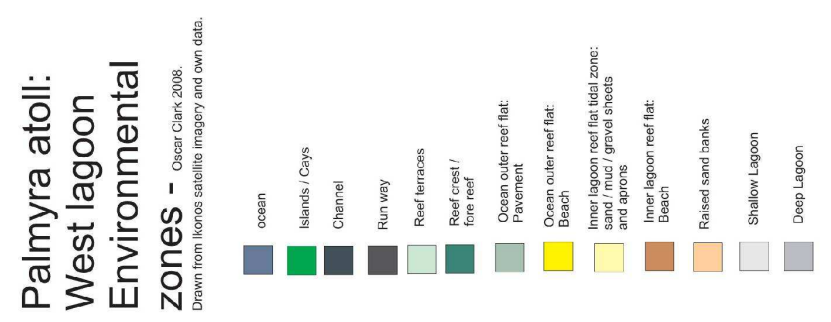

|

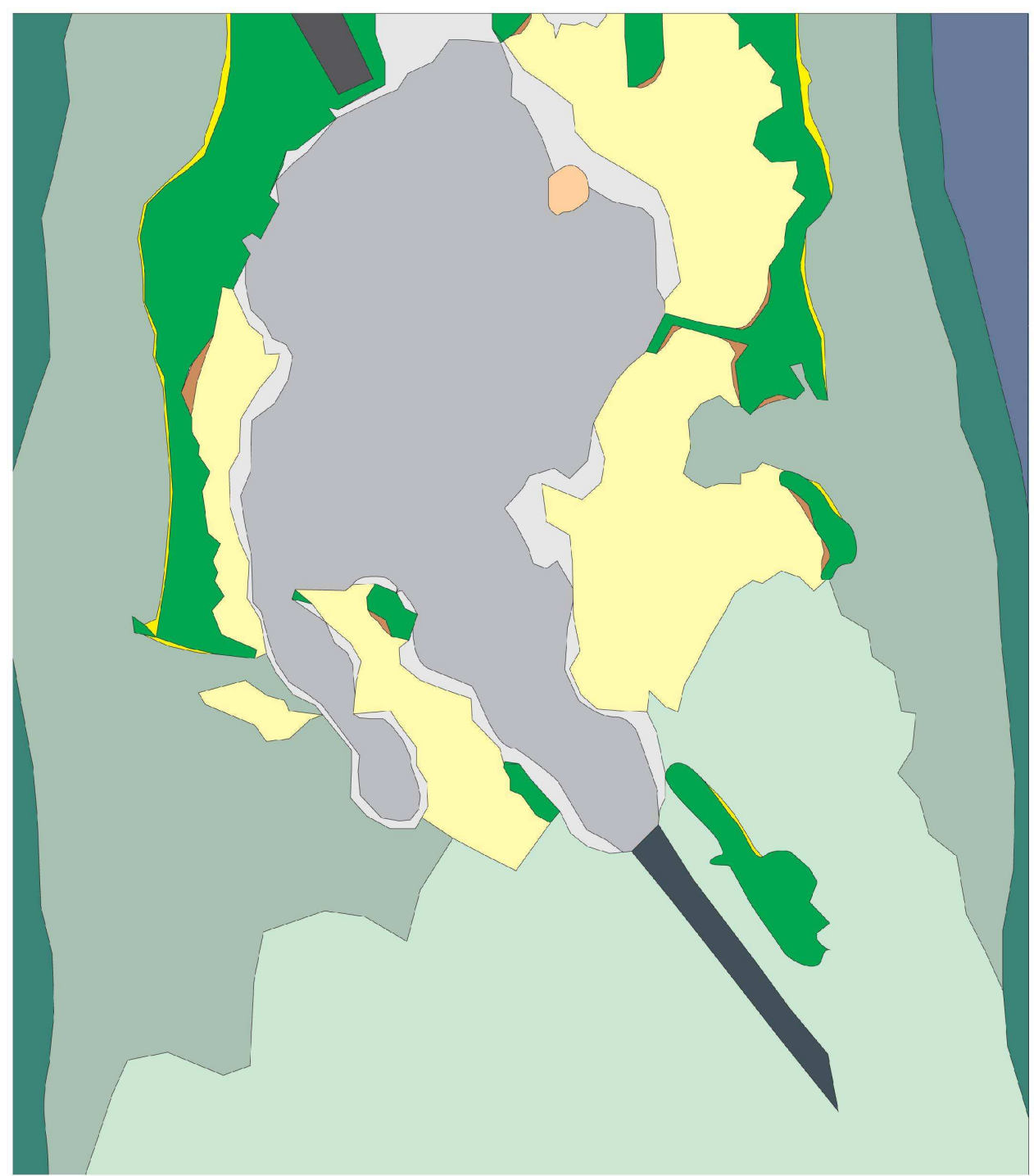


Fig 4.13 Environment zone map of Center Lagoon

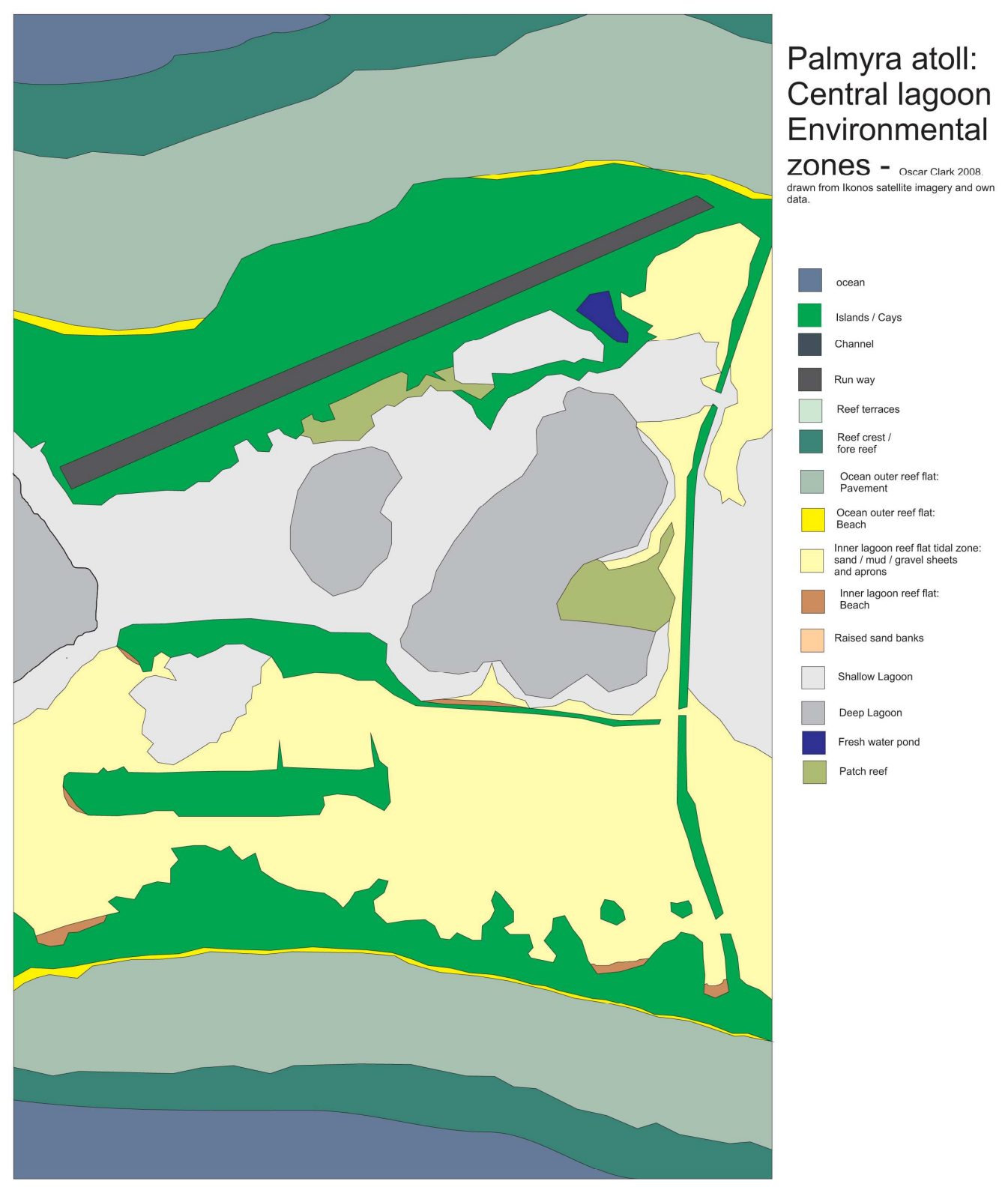


Fig 4.14 Environment zone map of East Lagoon
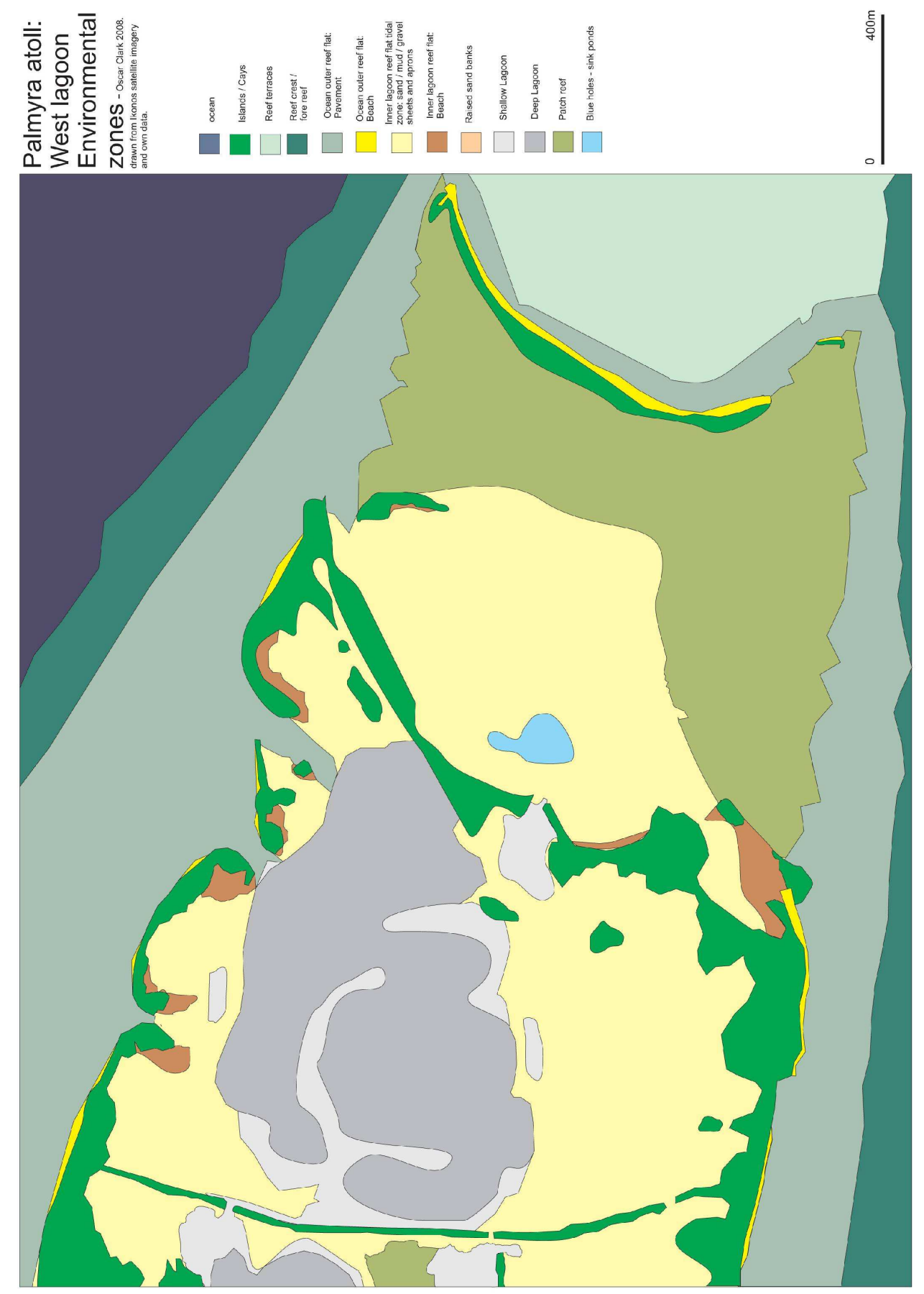


\subsection{Lithofacies descriptions: composition, texture and distribution}

Facies were defined, mapped (Fig 4.20, 4.21, 4.22, Appendix H) and interpreted on a purely qualitative basis, based usually on the presence of one or more significant features. Interpretation is a subjective exercise, involving the selection of important features and giving lesser weight to unimportant ones. The following properties were taken into consideration: texture, composition, sedimentary structures and digenetic features where possible.

The depth and turbidity of the water precluded direct observation of the deep lagoon floor by diving, and hence descriptions of lithofacies here are based on the analysis of material collected by dredging. However where possible actual physical descriptions and observations of the substrate were incorporated, mostly for the adjacent shallow tidal areas and beaches. Bathymetric maps and an IKONOS (2000) satellite image were used to extrapolate the identified lithofacies to give full maps of the sediment distribution.

Distinctive compositions diagnostic for any particular environment were not identified. Compositions appeared to be very similar from one environment to another (Fig 5.2, Section 5.) and so this parameter bore the least weight when distinguishing the sedimentary facies of Palmyra. Textural classification and depositional texture from sampled sediments showed the clearest variation between environments and therefore the lithofacies distinguished are identified primarily on these. 
Sediment lithofacies were categorized on the basis of composition, textural classification (Folk 1974, modified by Blair et al. 1999) and depositional texture (Dunham 1962 modified by Embry et al. 1972). The following six sedimentary facies have been identified:

Peloidal mud lithofacies

Muddy sand lithofacies

Coralagal sand lithofacies

Rubble facies

Cemented pavement and beachrock lithofacies

Living reef facies

Table 4.1 Classification of limestone according to depositional textures (Dunham 1962 modified by Embry et al. 1972)

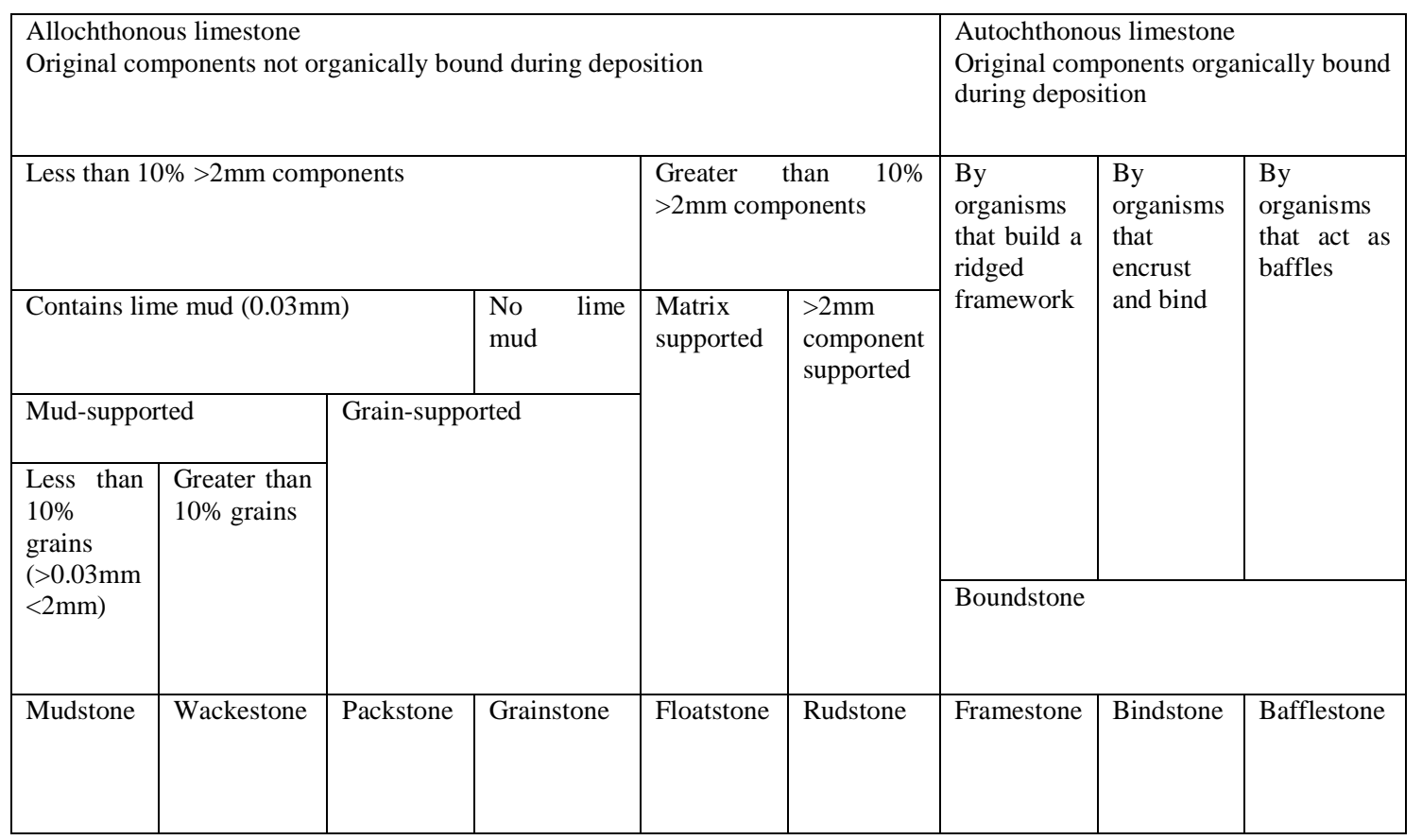




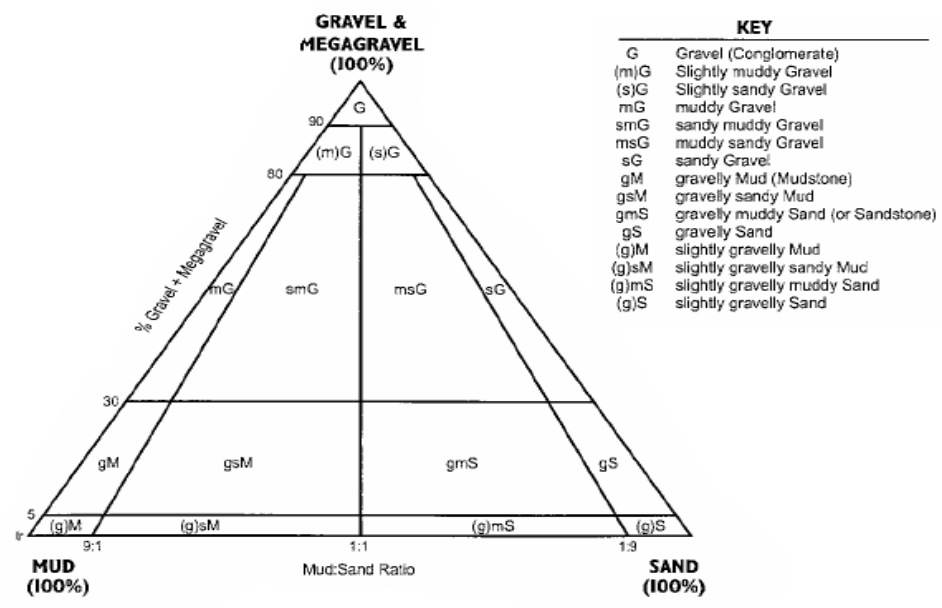

Fig 4.15 Folk's (1974) textural classification with modifications by Blair and Mc Pherson (1999).

\subsubsection{Peloidal mud lithofacies}

The peloidal mud facies is found in areas of low energy predominantly in the deep lagoons of Palmyra Atoll. This facies encompasses the range of sediment textures from mud, slightly gravely mud, sandy mud, slightly gravely sandy mud and gravely sand mud (Folk's textural classification). The mean grain size is silt (Appendix B) and on average $70 \%$ or more of the sediment is silt or finer. This facies type is characterized by the abundance of peloids, the majority of which are of fecal and pseudofecal origin. The most common are ellipsoidal, hardened fecal pellets with diameters of approximately 250 $400 \mu \mathrm{m}$ (medium sand). Recognizable skeletal fragments occur within these, but the abundance of these recognizable skeletal fragments is moderate to low and much of the material is too small to identify (See section 6.1).

The material coarser than $0.25 \mathrm{~mm}$ is composed of dominantly coral and red algae, followed by molluscan fragments and Halimeda plates, with lesser components from crustaceans and foraminifera. The highest percentage of foraminifera and of "Other" material (in particular organic wastes and woody material) contributing to the sediment is 
found in this facies. The lowest percentage of echinoid remains contributing to the sediment is found in this facies. The percentage of the mud fraction was observed to increase with water depth within the deeper parts of lagoons (see Chapter 5, Fig 5.11, 5.17). Mudstones are the most common depositional textures with lesser wackestone, and sediments are either poorly sorted or very poorly sorted.

\subsubsection{Muddy sand lithofacies}

This facies represents the transition zone between the coarser sand lithofacies of the reef flats and the muddy lithofacies of the deep lagoon environments and forms an almost continuous rim separating the two. It corresponds approximately with the shallow lagoon zone between 0 and $7.5 \mathrm{~m}$ water depth and represents the coarser material that is washed into the lagoons and settles rapidly due to its greater mass. The boundaries of this lithofacies are gradational and considerable overlaps exist between the sand and mud lithofacies, especially in areas of steep bathymetric changes where debris tongues of this material reach down into deeper water. This facies is characterized by muddy sand, slightly gravely muddy sand and gravely muddy sand (Folk's textural classification). Wackestones are the most common depositional texture with lesser amounts of packstones. Sediment composition differs from that of the mud lithofacies in that it does not show as high organic content or the presence of peloids.

\subsubsection{Coralalgal sand lithofacies}

The coralalgal sand facies is found in areas of moderate energy and composition is dominated by coral and red algae, then molluscan and Halimeda fragments with fewer components of crustaceans and echinoids along with skeletal debris from many other organisms. This facies is characterised by poorly sorted sand to gravely sand. It is the most abundant facies seen on the atoll (covering more than $45 \%$ ) and is found on the interior platform sand aprons (Fig 4.16), sheets and beaches, in the shallow lagoon and in lesser amounts in the sand lenses that blanket the outer reef pavement. The depositional 
texture is usually a grainstone with some packstones and floatstones depending on the energy regime.

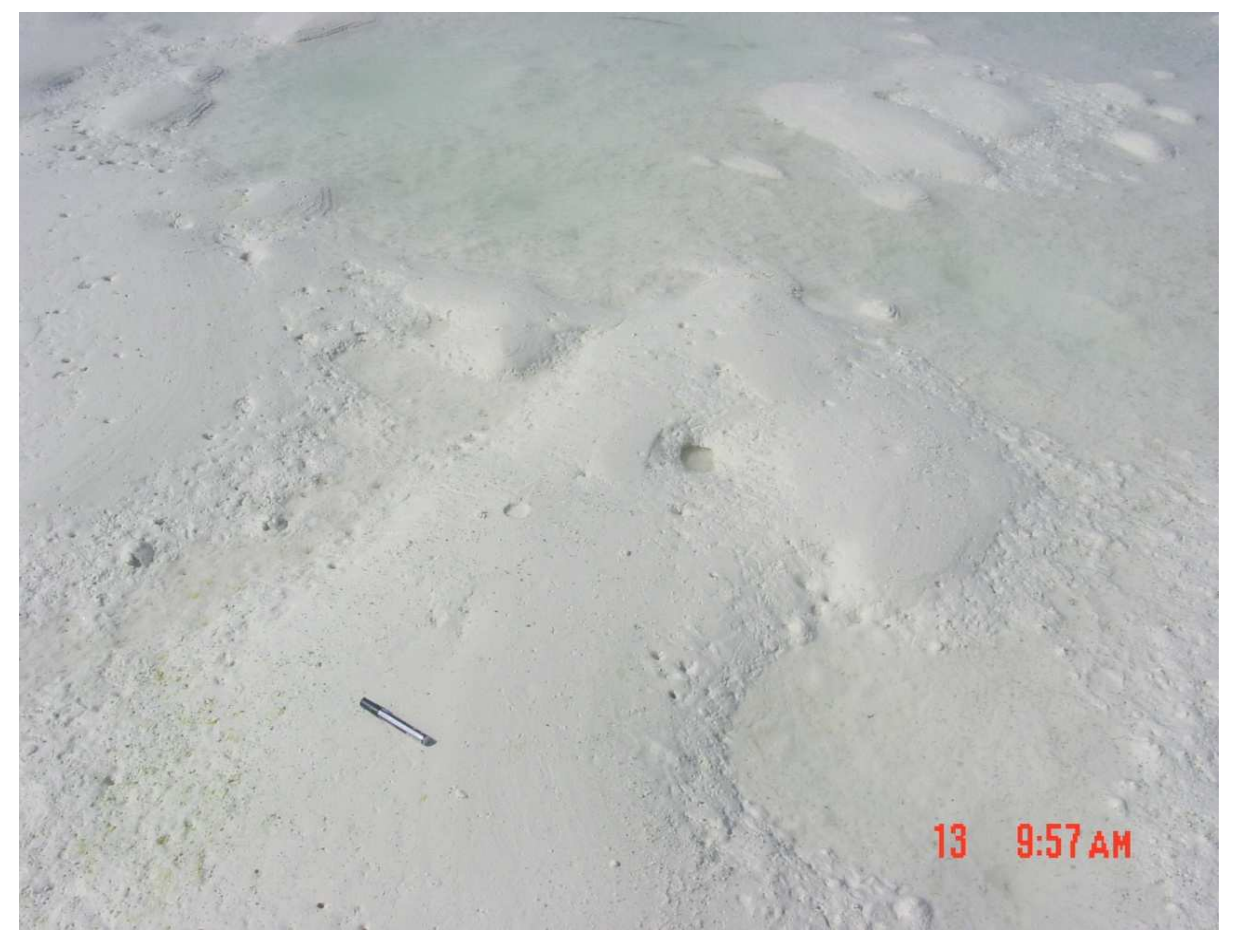

Fig 4.16 Coralalgal sand facies from interior reef flat sand sheets

\subsubsection{Rubble lithofacies}

The rubble facies is characterized by generally gravel up to cobble sized, moderately sorted, randomly-aligned, angular sub-rounded coral and algal clasts (Fig 4.17). The depositional texture is a rudstone or floatstone. The predominant clasts are branching Acropora sourced from the fore reef slope and reef crest. Much of the material is algalencrusted, heavily bioeroded and bleached white. The rubble facies is the result of high energy wave action and is found on the ocean facing beaches and as moving sheets on the outer reef pavement. This facies usually forms only a surface veneer overlying sand-sized sediments. A well developed rubble facies beach can be seen on the eastern side of Barren Island where strong easterly waves reach shore. Where active deposition is not occurring, 
such as behind the beach crest on Barren Island, the rubble facies beaches are grey in colour and often show clast dissolution. Here, clasts appear smooth underneath and jagged on the exposed side, due to the weathering action of rain (Fig 4.18).

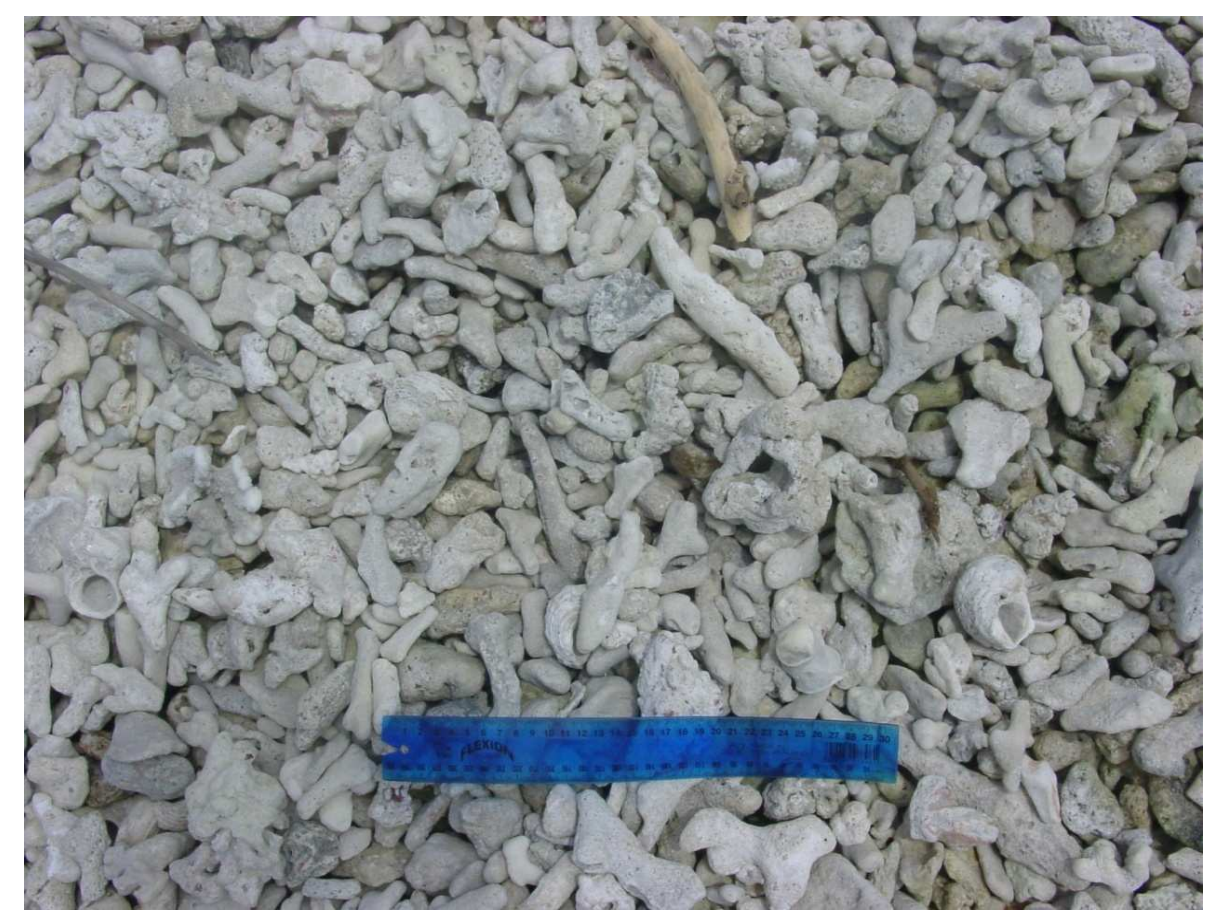

Fig 4.17 Typical rubble facies material forming deposits on Barren Island. Ruler is $30 \mathrm{~cm}$ long 


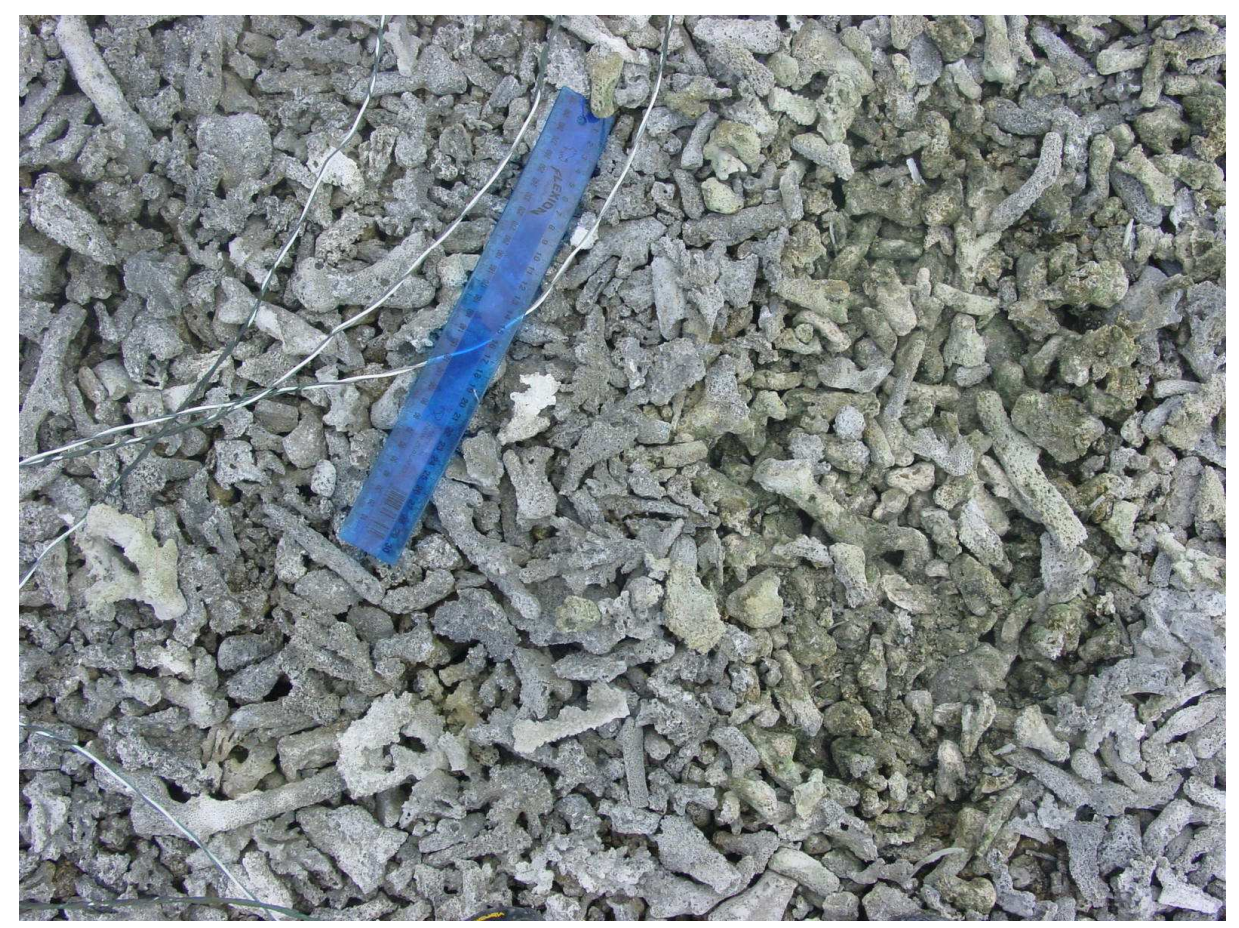

Fig 4.18 Weathered rubble facies on western side of Barren Island showing clast dissolution and darkening. Ruler is $30 \mathrm{~cm}$ long.

\subsubsection{Cemented pavement and beachrock lithofacies}

Exposed beachrock occurs on beaches as a series seaward-dipping strata (Fig 4.19) these extend out across to form the tidal outer reef pavement. It is a hard consolidated rock comprised of rounded cemented corals, molluscs and algae. Composition was observed to be highly variable: $1-7 \mathrm{~cm}$ branching fragments of Acropora are dominant components in beachrocks found on southern side of Paradise Island (Fig 4.20) and in other areas giant clams (Tridacna) dominate. Visual grain components range between 1 and $170 \mathrm{~cm}$ in size and appear cemented together. The beachrock is heavily weathered at the rock-sea interface, where dissolution of binding grains and cement is occurring. Aragonite has been found to be the primary cement on other Pacific atolls (Guilcher 1988), but the beach rocks have not been studied at Palmyra. The origin of beach rock remains largely a matter of discussion (Wiens 1959, Guilcher 1988) and there have been many papers 
published on the theory of its origins. It is not clear whether the stratification existed as beach layering prior to the consolidation, or whether it develops during the hardening (Wiens 1959, Guilcher 1988). The beachrock may be remnants of either Pleistocene or early Holocene structure from a period when the local sea level was somewhat higher. It is most likely the remnants of reef growth 2000 years ago when sea level was estimated to be $1-1.5 \mathrm{~m}$ higher then present, as suggested for nearby Tarawa Atoll, Kiribati (Schofield 1977 in Marshall et al. 1984). Precise dating is needed to determine the correct ages and history of formation of these deposits.

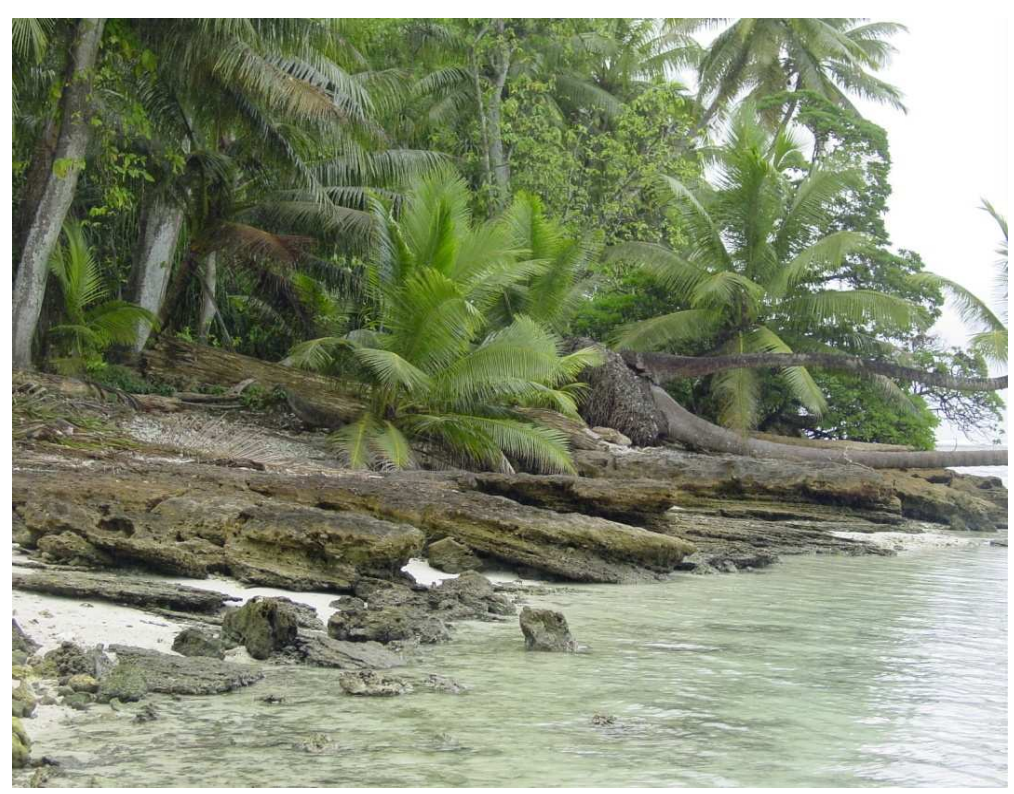

Fig 4.19 Stratified seaward sloping beachrock, southern coast of Paradise Island 


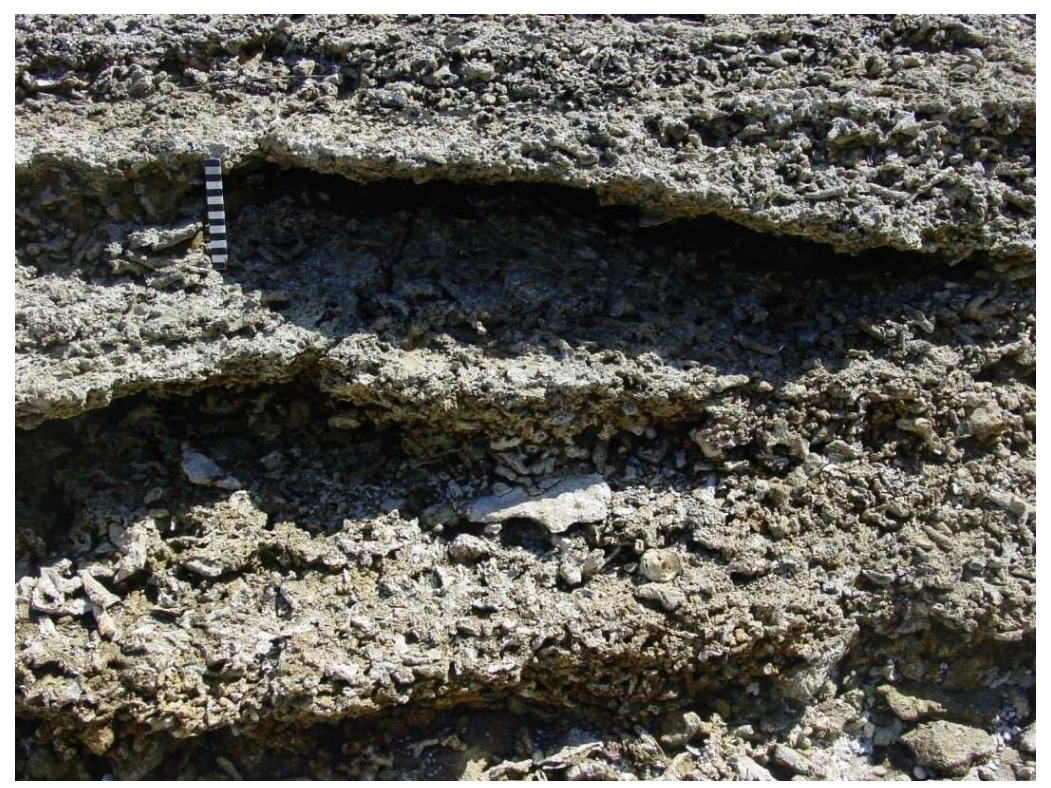

Fig 4.20 Typical beachrock showing stratification, southern coast of Paradise Island Indicator denotes $10 \mathrm{~cm}$.

\subsubsection{Living reef lithofacies}

This facies is characterized by active reef growth, found on the fore reef, reef crest, reef terrace and patch reefs (Fig 4.6). Coral, algae and many other species are present here. Unconsolidated sediment is normally very sparse and only found in thin patches in depressions between the living heads of coral. The sediment is coarse grained, moderately sorted sand, comprised of coral fragments and Halimeda plates with lesser amounts of other skeletal debris with little or no mud fraction-sized components. The depositional texture of the sediment is a rudstone. 
Fig 4.21 Facies distribution map of West Lagoon

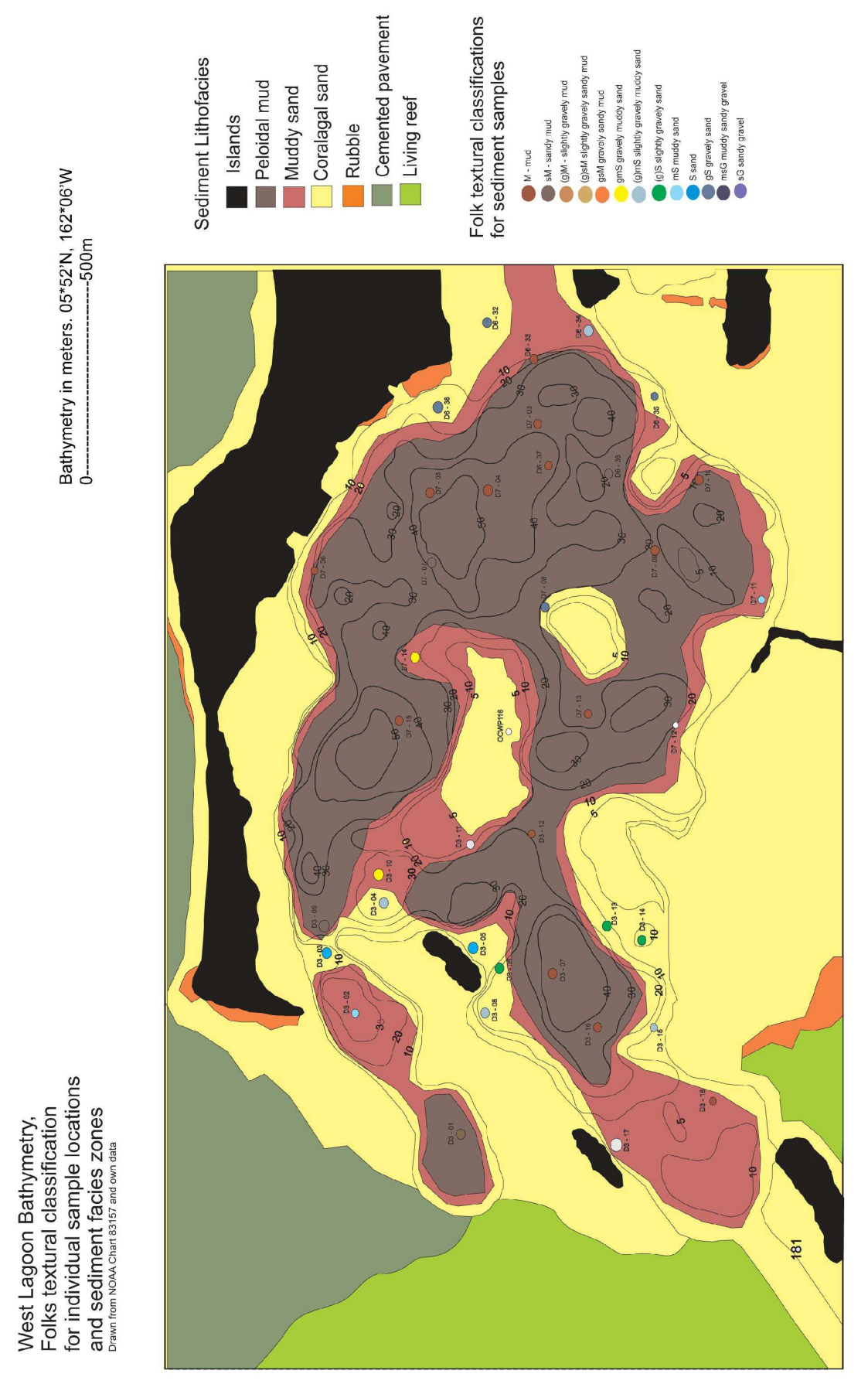


Fig 4.22 Facies distribution map of Center Lagoon

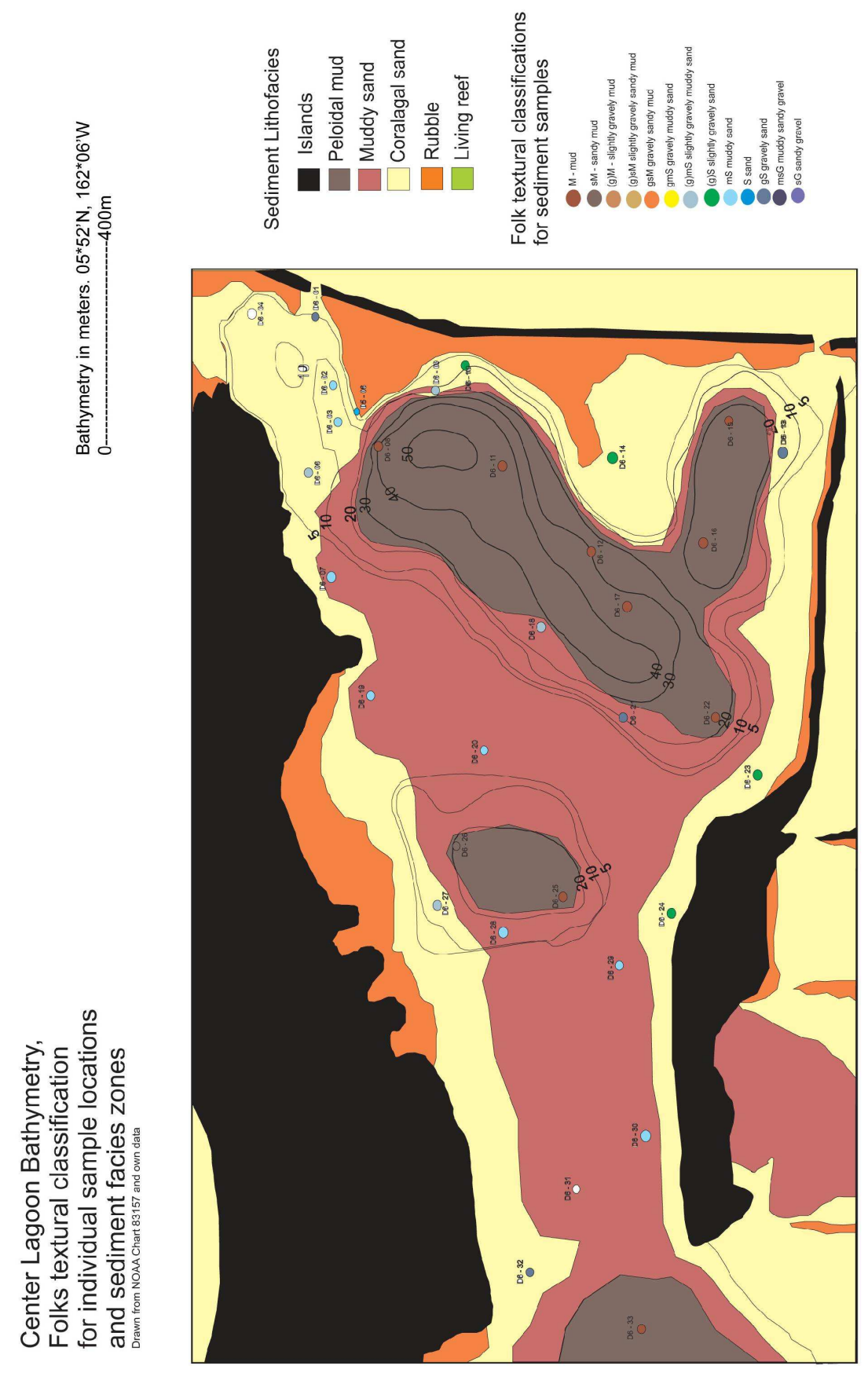


Fig 4.23 Facies distribution map of East Lagoon

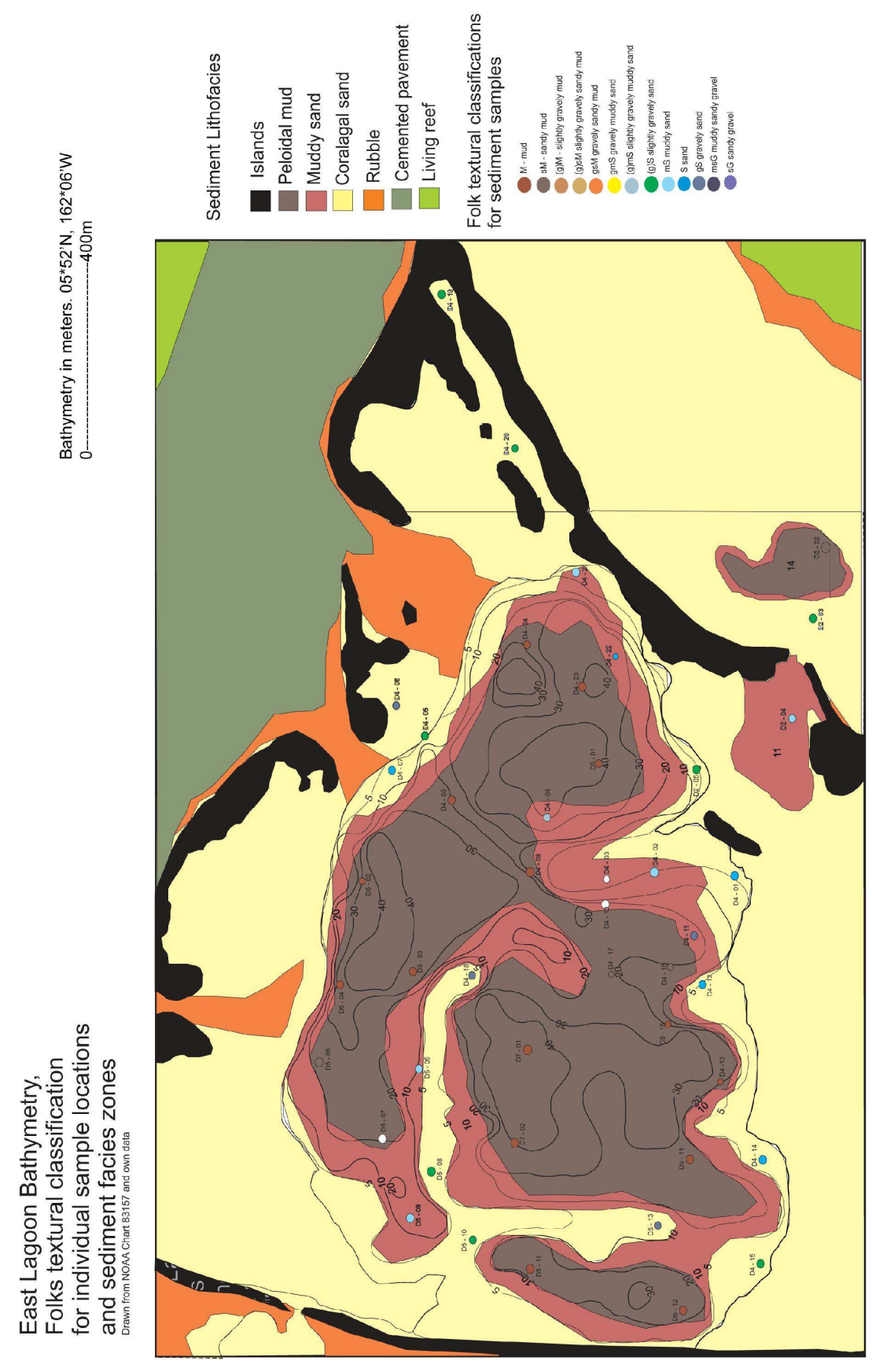


Note: larger copies all presented maps are located in Appendix $G, H$ and $I$ at the end of thesis and are available upon request from the author. 


\section{Chapter 5: Sedimentology, processes and products}

\subsection{Sediment composition}

Compositional analysis was performed on 22 processed sediment samples collected from the interior of Palmyra Atoll (Table 5.1, Appendix D). All sediments sampled are composed of carbonate components derived from on or near the atoll. Sediments accumulating are either clearly of skeletal origin (mainly particles of sand-size and larger), or are fine sediments derived from the breakdown of the skeletal material.

Fig 5.1 shows the average percentage of contribution per component for 22 samples analysed, Table 5.1 displays the percentage each sub category contributed on average. Seven main categories of clasts were identified in the granule and finer fractions, these are;

Coral and red algae fragments

Molluscs

Calcareous algae

Foraminifera

Crustacea

Echinoids

Other

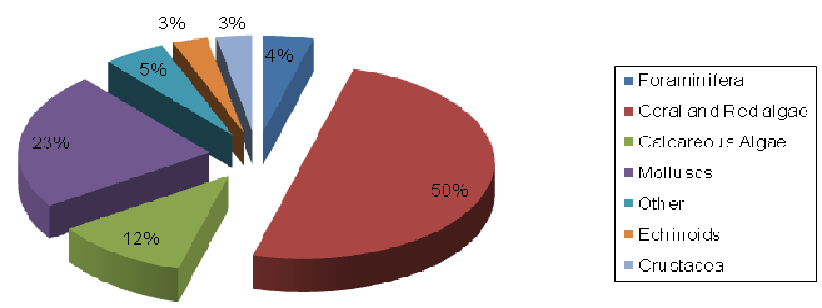

Fig 5.1 Proportion of the major sediment components identified in 22 samples from Palmyra Atoll 
Table 5.1 Compositional categories identified during counting of the gravel and sandsized fractions for 22 sediment samples from the lagoons and interior tidal areas of Palmyra Atoll (Appendix D). The percentages shown are the averages for all analysed samples (22 in total)

\begin{tabular}{|l|l|l|l|}
\hline \multirow{4}{*}{ Component } & \multicolumn{2}{|l|}{ Group } \\
\hline \multirow{5}{*}{ Totals }
\end{tabular}




\subsubsection{Coral and red algae fragments}

Coral-algal fragments are the dominant component of all samples from Palmyra Atoll and contributed on average about $50 \%$ of each sample analysed (Fig 5.1, 5.2, Table 5.1). Most of the coral is probably sourced from the fore reef, reef crest and outer reef flat, patch reefs within the lagoons and by reworking of dredged island sediments. Coral fragments vary in size from boulder-sized microatolls to mud-size fragments. Sand-sized coral clasts are angular to sub-angular and usually spherical in shape. Coral and calcareous red algae were considered together due to the optical difficulties of differentiating algae and coral, and because of the encrusting nature of algae over the exterior and penetrating the interior of coral fragments. Geochemical studies by Morris (1998) and Atkinson (1999) of the usually Mg-rich calcite contents of various clasts showed that, from this technique, calcareous red algae content of Fijian reef flat samples ranged from 20-40\% and Mg-poor coral ranged from $25-45 \%$, compared to the dominantly coral with negligible red algal composition initially determined by purely optical means.

\subsubsection{Molluses}

Molluscs were the second largest constituent analysed, with an average contribution of 23.2\% per sample (Fig 5.1, 5.2, Table 5.1). Many different species of molluscs exist on Palmyra Atoll, ranging in size from microscopic to the giant clam, Tridacna maxima that grows to more than $50 \mathrm{~cm}$. Bivalves were observed more frequently than gastropods in the fractions analysed (Fig 5.2). Molluscs were typically abraded and broken, especially the bivalves, but small gastropods appeared to be more resistant and showed less breakage. 


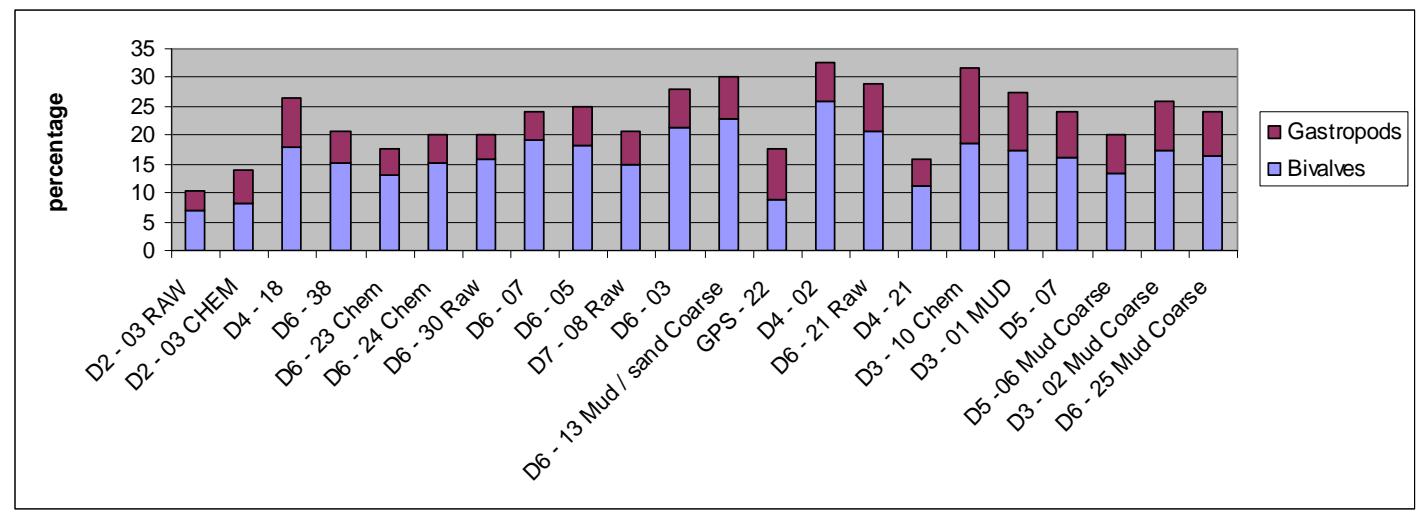

Fig 5.2 Molluscan composition percentage for 22 samples analysed. Water depth for samples increases from left to right.

\subsubsection{Calcareous green algae}

These fragments are derived from the green calcareous algae Halimeda spp. and are the third largest constituent to the sediment with an average contribution of $11.5 \%$ per sample (Fig 5.1, 5.2, Table 5.1). The plant Halimeda has many small oval, platy and irregular green segments with aragonite skeletons that attach to each other by uncalcified nodes in decreasing size. Halimeda grows prolifically and the segments are continuously breaking off from the tips. The organic part of each segment degrades after death while the platy calcareous skeleton is left, initially as gravel-sized sediment. The skeletal plates are low density and porous, and disintegrate easily to directly form a fine silt. Plates were observed to vary in size from more than $2 \mathrm{~cm}$ to only a few $\mathrm{mm}$ in width, and observations of them in the smaller fractions were difficult because of their optical similarity to both coral and red algae.

\subsubsection{Foraminifera}

Foraminifera had an average contribution of $3 \%$ per sample. Several large species of each of the suborders Rotaliina, Miliolina and Textulariina are present (Fig 5.3, 5.4, Table 5.1) and are illustrated in Plates 5.1 and 5.2. Foraminifera were observed throughout the atoll 
sediments with minor variation in abundances between sample sites (Fig 5.4, Appendix D). Shallow and deep lagoons show approximately the same total abundances of foraminifera across the three main lagoons. The highest abundance of foraminifera at 12.0 $\%$ was observed in sample D3 - 02, from a blue hole located at the northwest of West Lagoon (Fig 5.4). Here, sediment is being washed around the western end of Strawn Peninsula and across the reef pavement that surrounds the blue hole. This outer reef material may be the reason the abundance is higher as foraminifera may be being washed in from the ocean reef flat or possibly open water, rather than sourced from the lagoon itself. The lowest abundance of $0.19 \%$ was recorded in sample D4-02, a sample from the edge of the inner reef flat and the shallow lagoon, located at the southern extent of East Lagoon, immediately west of East Island. This location is well protected from the outer reef and offshore waters. Marginopora vertebralis is the most abundant of the larger foraminifera found on Palmyra Atoll (Fig 5.3, 5.4). The two Amphistegina species A. lessonii and A. lobifera combined are the second most abundant constituents. A. lobifera was observed throughout all environments and locations on Palmyra, while A. lessonii was restricted to samples from East and Center lagoons (Fig 5.4). Other species of large foraminifera were rare (about $0.01 \%$ ).

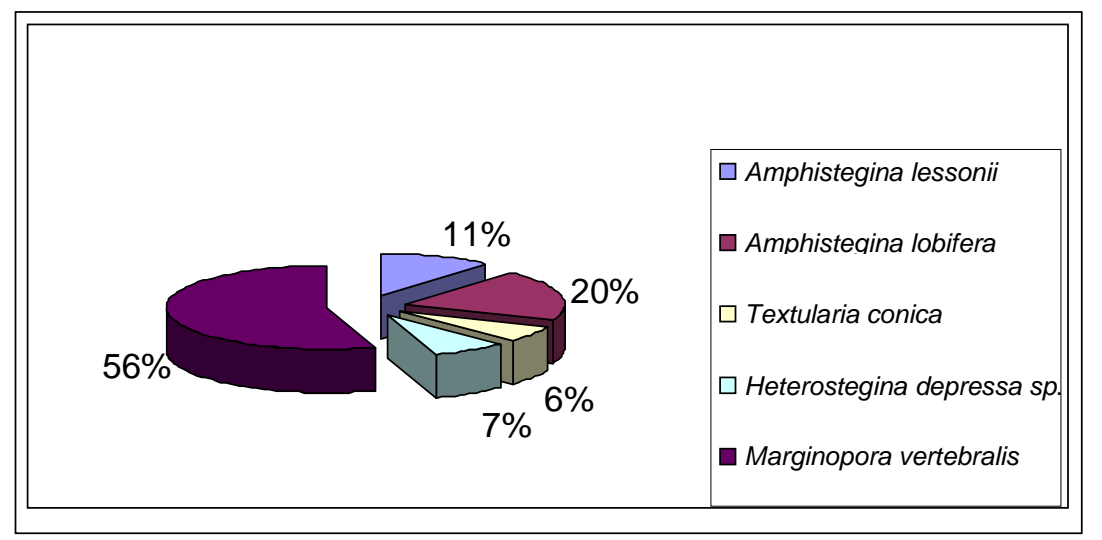

Fig 5.3 Percentage of species of total foraminifera counted from 22 samples on Palmyra Atoll 


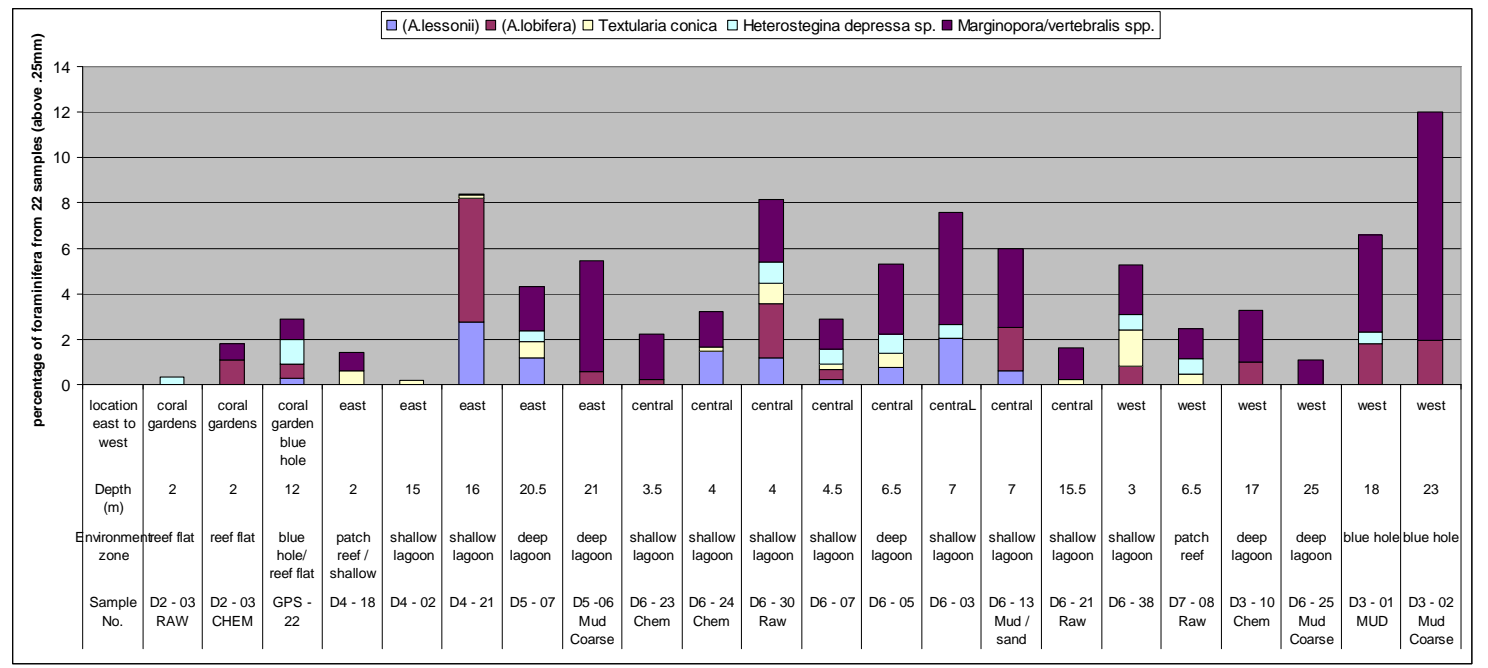

Fig 5.4 Foraminiferal composition for 22 samples analysed. Samples are arranged from east to west and in decreasing water depth for each lagoon. 
Plate 5.1 
Plate 5.2 


\subsubsection{Crustacea}

The crustacean category consists of both shell fragments, including plates and claws, and also ostracods. The average combined total contribution per sample was $3.1 \%$ (Fig 5.1, 5.5, Table 5.1); of which crustacean fragments are the most dominant constituent except for sample D3- 02. The latter is from a blue hole to the northwest of West Lagoon, a sample that also exhibits abnormally high amounts of foraminifera believed to be washed in from offshore and the outer reef (Fig 5.4). Crustaceans were found in all samples. The lowest contribution to sediment was observed from sample D2 - 03 recovered from the Coral Gardens, a living patch reef area located east of East Lagoon (Fig. 5.5). Only ostracod shells, with their calcite mineralization compared to the protein of other crustacean shells, are likely to be preserved in sediment over the longer term.

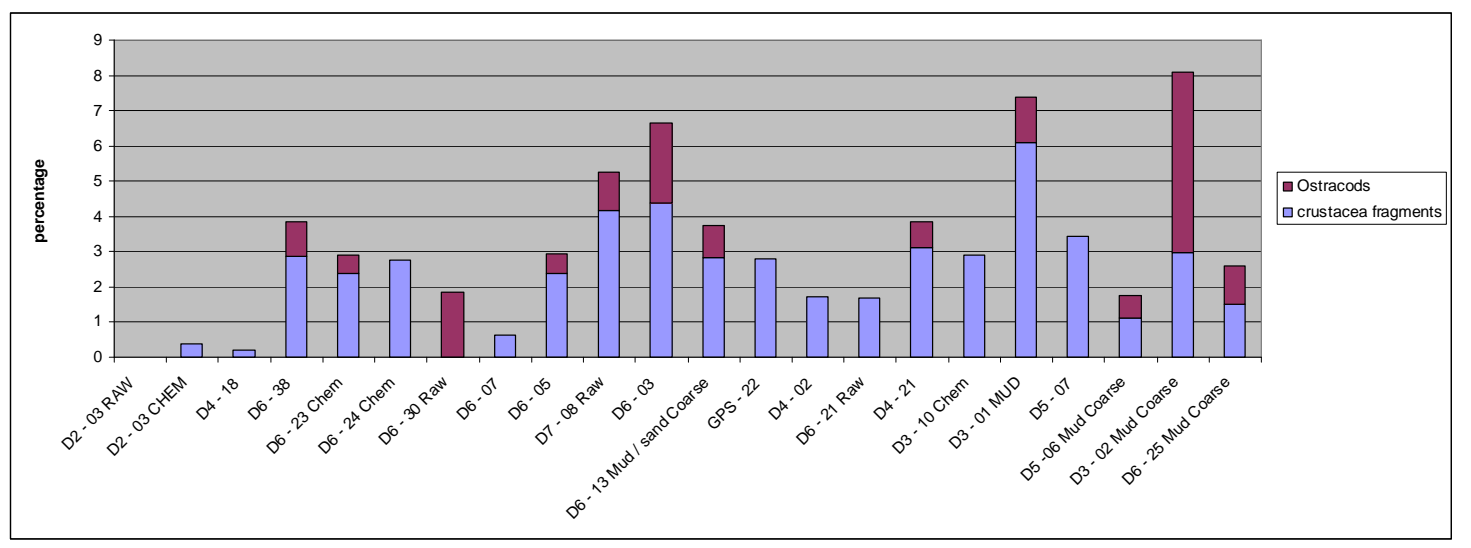

Fig 5.5 Crustacean composition of 22 samples analysed. Water depth of samples increases from left to right.

\subsubsection{Echinoids}

The echinoid category consists of both fragments of plates and of the movable outer spines. Echinoids had an average contribution of $3 \%$ per sample (Fig 5.1, 5.6, Table 5.1); of which spine fragments are the most dominant constituent throughout (Fig 5.6). Spines 
and plates were observed in every size fraction and in a variety of colours. Most spines were fragmented; they occur in all samples except for the very deepest and finest mud sample D6 - 25 from a deep anoxic compartmentalized depression in Center Lagoon. These results suggest that echinoid growth is restricted to shallow water depths, most likely on the reef flats and shallow lagoon areas where amount of suspended sediment in the water column is lower and dissolved oxygen levels are higher.

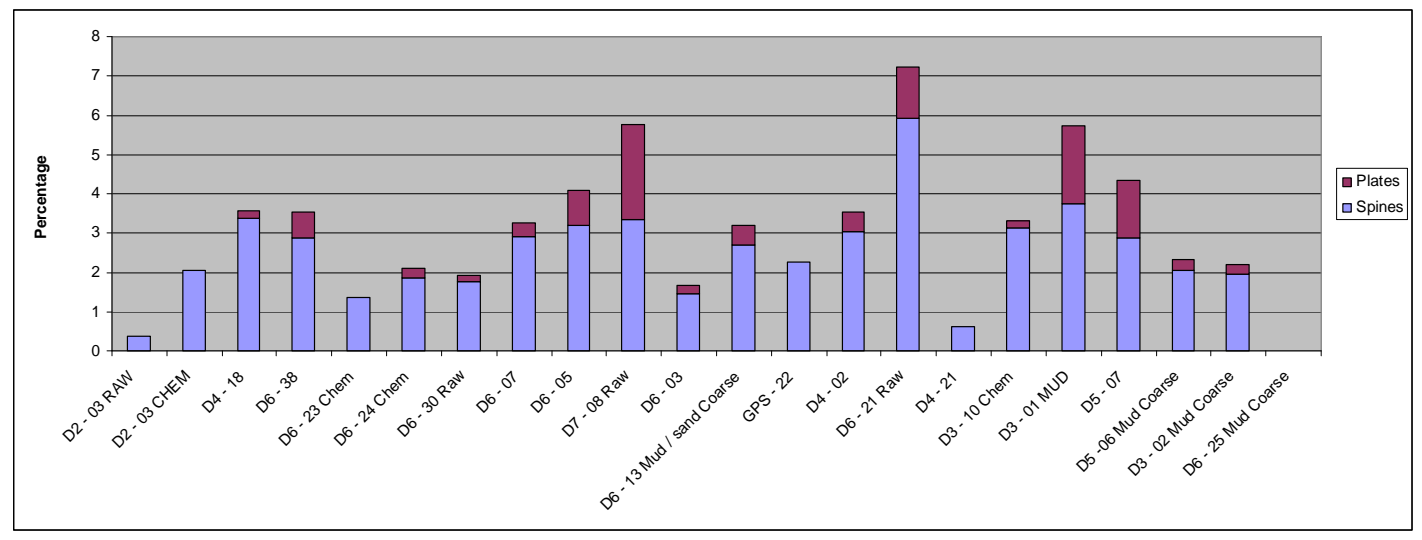

Fig 5.6 Contribution of echinoid clasts to the 22 samples analysed. Water depth of samples increases from left to right.

\subsubsection{Other}

This category contains the sponge spicules, organic material and wood, bryozoans, worm tubes and unidentifiable grains. These were included in the counting but were not sufficiently abundant to be considered here as individual categories. The "Other" total had an average contribution of $4.1 \%$ per sample (Fig 5.1, 5.2, Table 5.1). Organic material and unidentifiable grains increased greatly in the finer muddy samples analysed. Sponge spicules were the rarest component and were found only in the $0.125 \mathrm{~mm}$ fraction of 3 samples (Fig 5.7). 


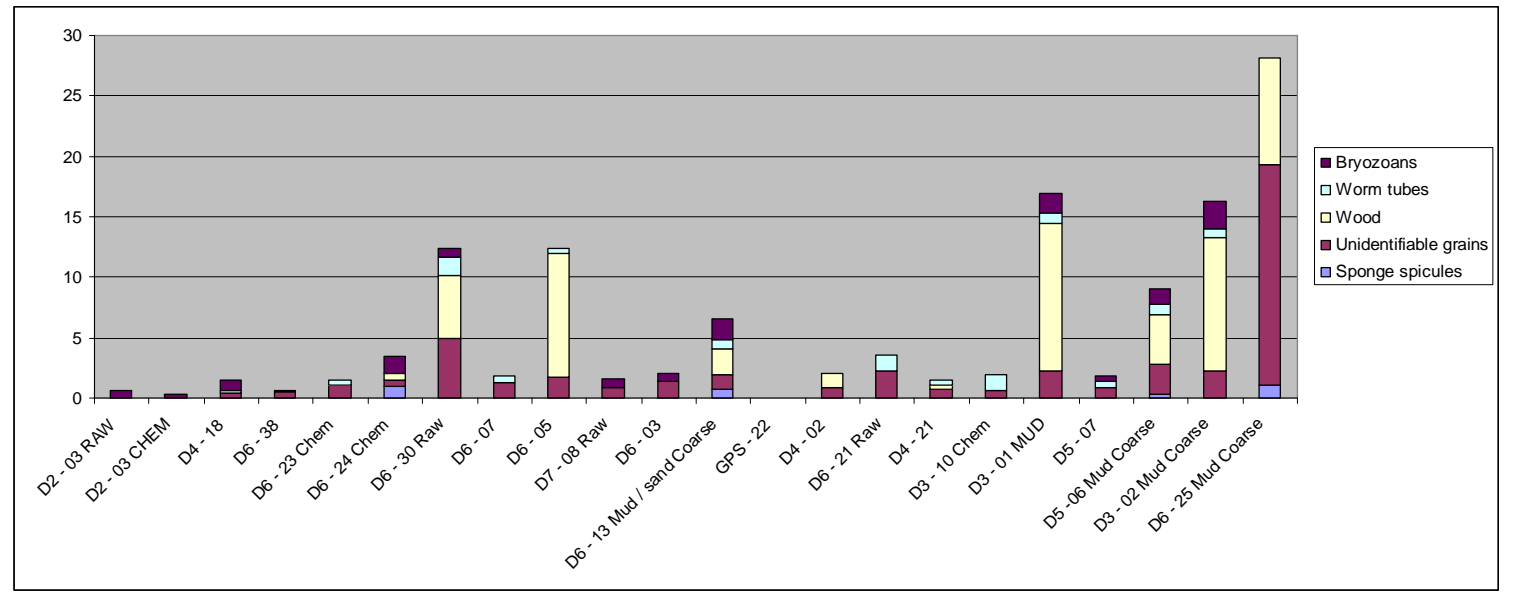

Fig 5.7 Composition of the "Other" component for the 22 samples analysed. The water depth for samples increases towards the right with the mud samples showing an increase in organic material and unidentifiable grains.

\subsubsection{Discussion of sediment composition}

Distinctive compositions diagnostic for any particular environment were not identified, and compositions appeared to be very similar from one environment to another (Fig 5.8) with the exception of the blue holes north-west of West Lagoon. This probably indicates a homogenization of all sediments related to the small size of the atoll, whereby all the source areas contain similar material and the only variable is grain size. Although there is a possibility that clear variations may not be apparent due to the array of sampling. 


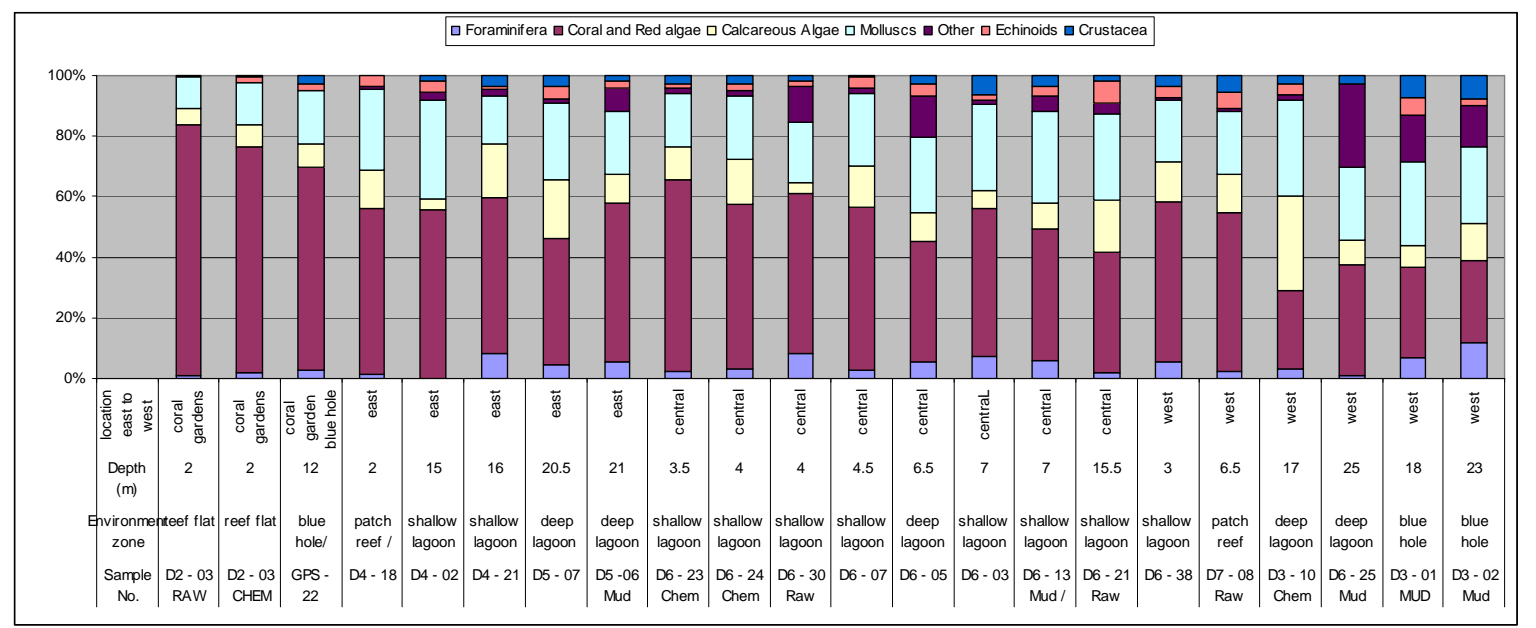

Fig 5.8 Summary representation of the average compositions of six major sediment components for 22 samples from the lagoons and interior tidal areas of Palmyra Atoll. Water depths for samples increase from left to right. A larger version of this figure is in Appendix D.

\subsubsection{Total organic carbon content}

An estimation of the total organic carbon content was made for 25 sand samples. Results were obtained by using process method 2 (Section 3.2.2) for dominantly sand-sized samples with removal of organic material using a hydrogen peroxide wash. Results were calculated by subtracting the weight of chemically washed and re-dried samples from the initial dry weight of the same samples before processing began. Table 5.2 shows the loss of weight recorded during this process. Almost all samples were weighed initially to 30 grams and the average loss was about .05 of a gram or an average of $2.09 \%$ loss. Fig 5.9 shows a comparison of the percentage of weight lost when compared with water depth. No clear correlation of organic carbon content to water depth can be distinguished but these data are only for sand samples as mud samples were difficult to test (See section 3.3.1). However, similar values have been recorded in mud samples from Palmyra (J.P. Gardner pers comm. 2008); however, it is likely that the type of organic material varies 
from location to location. More investigation is needed to quantify the percentage of organic material being associated with carbonate sediments from Palmyra atoll.

Table 5.2 Loss of weight recorded for organic removal process

\begin{tabular}{|c|c|c|c|c|}
\hline Sample number & $\begin{array}{l}\text { Dry weight } \\
\text { before } g\end{array}$ & $\begin{array}{l}\text { Loss from } \\
\text { organic } \\
\text { removal } \\
\text { process g }\end{array}$ & $\begin{array}{l}\text { Percentage of } \\
\text { loss }\end{array}$ & $\begin{array}{l}\text { Depth in m } \\
\text { of sample } \\
\text { recovery }\end{array}$ \\
\hline D2 - 01 & 30.91 & 0.7 & 2.26 & 2 \\
\hline D2 - 02 & 30.61 & 0.42 & 1.37 & 15 \\
\hline D2 - 03 CHEM & 31.35 & 0.09 & 0.29 & 2 \\
\hline D2 -05 & 30.13 & 0.36 & 1.19 & 2 \\
\hline D2 - 07 & 30.24 & 0.56 & 1.86 & 3 \\
\hline D3 - 05 & 30.40 & 0.41 & 1.35 & 8 \\
\hline D3 - 10 & 30.02 & 1.44 & 4.80 & 7.5 \\
\hline D3 - 13 & 30.76 & 0.12 & 0.39 & 17 \\
\hline D3 - 14 & 30.38 & 0.40 & 1.32 & 8 \\
\hline D4 - 01 & 30.64 & 0.22 & 0.72 & 4.4 \\
\hline D4 - 19 & 30.15 & 0.32 & 1.06 & 2 \\
\hline D4 - 21 & 30.48 & 1.24 & 4.07 & 0.5 \\
\hline D4 - 22 & 30.43 & 1.01 & 3.31 & 16 \\
\hline D5 - 05 & 30.96 & 0.56 & 1.81 & 12 \\
\hline D5 - 08 & 30.85 & 0.05 & 0.17 & 19 \\
\hline D5 - 13 & 30.76 & 0.03 & 0.09 & 2.5 \\
\hline D6 - 01 & 30.08 & 0.98 & 3.26 & 6 \\
\hline D6 - 05 & 31.12 & 0.1 & 0.32 & 11 \\
\hline D6 - 10 & 30.59 & 0.08 & 0.27 & 6.2 \\
\hline D6 -20 & 30.76 & 0.21 & 0.68 & 8.3 \\
\hline D6 - 29 & 30.57 & 0.05 & 0.16 & 3.5 \\
\hline D12 - 01 & 30.80 & 1.24 & 4.06 & 19.5 \\
\hline D12 - 02 & 30.8 & 0.76 & 2.47 & 0.5 \\
\hline GPS - 23 & 30.68 & 0.4 & 1.30 & 6 \\
\hline GPS 119 OC & 30.55 & 3.55 & 11.62 & 0 \\
\hline
\end{tabular}




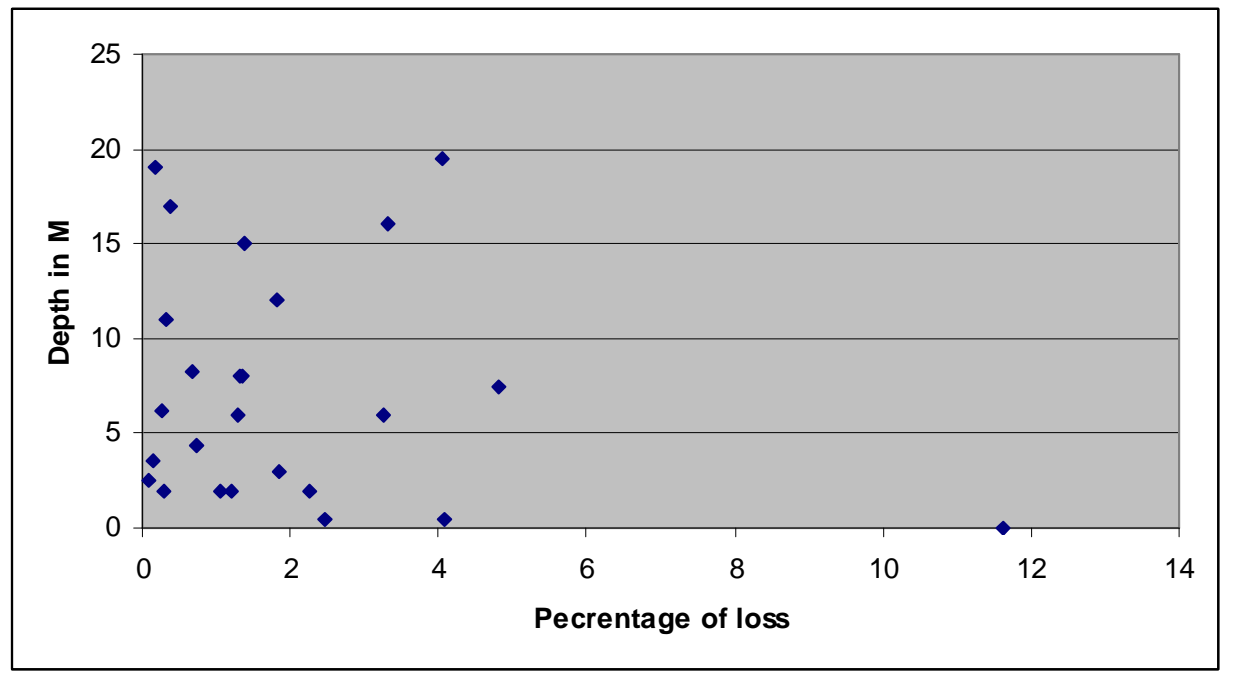

Fig 5.9 Depth in $\mathrm{m}$ of sample recovery compared to percentage of loss from chemical organic removal process

\subsection{Sediment source and erosion processes}

Palmyra Atoll is an organo-sedimentary structure where sediments accumulating are of skeletal origin, either clearly sand-sized or larger (Section 5.1 sediment composition) or are a fine sediment derived from the breakdown of the skeletal material. There is a continual source of material by normal mechanical erosion and by biological processes both direct and indirect and this material is then either settling in situ or being transported across the atoll by currents or biota. The accumulating sediments are derived from the reworking of dredged material used to artificially construct some islands or by the growth and decay of biota living on or near the atoll itself. Most of this accumulating material is probably sourced from the fore reef, reef crest and the reef flats with other amounts sourced from reworking of previous sediment deposits and from patch reefs within the lagoons.

The amount of sediment produced by growth and decay is constrained by the biological potential of the reef organisms (Tucker and Wright 1990) and, as outlined in section 
1.4.1, reef organism growth is dependant on a number of factors such as sunlight, temperature, salinity, turbidity, water circulation and level of nutrients among others. There are currently no data available on the growth and calcification rates of the calcareous biota of Palmyra Atoll, nor are there any data on the amount of material being supplied by reworking and erosion of material dredged during the modification of the atoll in World War Two.

The major atoll reef growth and sediment production is by primary frame building scleractinian corals and crustose coralline algae (Section 5.1.1). The hermatypic (reefbuilding) scleratinians contain symbiotic algae (zooanthellae), and thus are limited by plant photosynthesis to well-lit, shallow waters less than $100 \mathrm{~m}$ deep and mainly under 20 m (Tucker and Wright 1990). On Palmyra scleratinian growth is dominant on the fore reef, reef crest and patch reef areas (living reef facies). Other calcareous forms encrust these frame units and bind them together. These consist of crustose coralline algae, serpulids, bryozoans, soft corals, boring foraminifers and vermetid gastropods. These also occur in cavities within the reef. The skeletons of other calcareous organisms are direct sediment contributors, such as bivalves, gastropods, echinoids, crustacean, planktonic foraminifera and sessile epibenthic organisms such as the calcareous alga Halimeda. Almost all of the reef biota contributing to the sediment budget have calcareous skeletons, although some such as sponges contribute small amounts of siliceous material.

Many organisms indirectly contribute to the sediment accumulation by bioeroding. Bioerosion may be as important as mechanical erosion and works with it to produce unconsolidated sediment on Palmyra Atoll. There are many different types of bioeroders present on Palmyra. These have not been studied specifically for Palmyra Atoll, but have been studied in detail on other tropical reefs. Bioerosion can occur on many different scales and involve numerous species from microscopic bacteria to macroscopic mollusc and fish. The term "bioerosion" includes endolithic and epilithic borings, scrapings, and raspings and the ingestion of sediments that occur on many different scales (Warme 1975, Guilcher 1988). These produce different clast sizes depending on the type of erosion and 
the size of the organism eroding. Bioerosion has been assigned to four different groups according to their primary mode of erosion (Table 5.3), each of which is discussed below: Table 5.3 Different types of bioeroders that affect tropical carbonates, categorised by their primary modes of erosion. Assembled and adapted from Milliman (1974) and Hopley (1982) by Atkinson (1999). A tick indicates that that kind of biota performs that type of bioerosion, a cross indicates that it does not

\begin{tabular}{|l|l|l|l|l|}
\hline Biota & Borers & Predators & Grazers & Browsers \\
\hline Algae & $\sqrt{ }$ & $\mathrm{X}$ & $\mathrm{X}$ & $\mathrm{X}$ \\
\hline Asteroids & $\mathrm{X}$ & $\sqrt{ }$ & $\mathrm{X}$ & $\mathrm{X}$ \\
\hline Bacteria & $\sqrt{ }$ & $\mathrm{X}$ & $\mathrm{X}$ & $\mathrm{X}$ \\
\hline Bryozoans & $\sqrt{ }$ & $\mathrm{X}$ & $\mathrm{X}$ & $\mathrm{X}$ \\
\hline Crustacean & $\sqrt{ }$ & $\sqrt{ }$ & $\mathrm{X}$ & $\sqrt{ }$ \\
\hline Echinoids & $\sqrt{ }$ & $\mathrm{X}$ & $\sqrt{ }$ & $\mathrm{X}$ \\
\hline Fish & $\mathrm{X}$ & $\sqrt{ }$ & $\mathrm{V}$ & $\mathrm{X}$ \\
\hline Fungi & $\sqrt{\mathrm{X}}$ & $\sqrt{ }$ & $\mathrm{X}$ & $\sqrt{ }$ \\
\hline Holothurians & $\mathrm{X}$ & $\sqrt{ }$ & $\mathrm{X}$ & $\mathrm{X}$ \\
\hline Mollusc & $\sqrt{ }$ & $\sqrt{ }$ & $\sqrt{ }$ & $\sqrt{ }$ \\
\hline Polychaetes & $\sqrt{ }$ & $\mathrm{X}$ & $\mathrm{X}$ & $\sqrt{ }$ \\
\hline Sponges & $\sqrt{ }$ & & $\mathrm{X}$ & $\mathrm{X}$ \\
\hline
\end{tabular}

\subsubsection{Borers}

The boring activity of both macroborers and microendolithic organisms represent a major destructive process affecting sediment preservation within reef environments (Perry 1998). Macroborers include the destructive bivalve mollusc Lithophaga and Magilopsis, the barnacle Lithotrya, sipunculid and polychaete worms such as Christmas tree worms and feather duster worms who bore into coral skeletons. Microendolithic organisms include cyanobacteria, chlorophytes, rhodophytes, the boring sponge Cliona and fungi. Some species of foraminifera are also known to bore into sediment. Most borings are made to primarily provide a protective living environment rather than to directly provide nutrition; for example, some endolithic algae are forced to penetrate deeper into the rock as they are rasped by chitons and other browsing molluscs (Guilcher 1988). In places coarse sediments consist entirely of unbroken coral colonies such as the boulders formed close to the outermost beaches during storm events (Cobb et al. 2003). Massive framework-building organisms such as the scleratinian corals, calcareous algae and mollusc shells, have a dense durable internal architecture. The breakdown of these 
massive skeletons is less by mechanical abrasion than by biogenic erosion, or by breakdown following biological weakening of the skeleton (Stoddart 1969). Borings can affect both living and dead material. Borings become more prevalent and much greatly progressed after the death of the organism being attacked. Microboring has been implicated as the main cause of micritization that occurs to grains (Scoffin 1987, Kennedy A 2004).

\subsubsection{Predators}

Predators are primarily carnivores that actively seek out a food source. Many carnivorous fish feed on other fish, but certain specialized forms such as butterfly fishes and parrot fish use chisel-like teeth to feed directly on the tips of predominantly branching corals (Stoddart 1969). The fish grind the exoskeleton of the coral to get the algae within its cells, and excrete sand and silt-sized. A single parrotfish can produce about five tons of sand per year (Glynn 1972). In addition to fish, crustaceans, gastropods, and asteroids are known predators of living corals (Stoddart 1969, Glynn 1972). Acanthaster planci (the crown-of-thorns sea star) is a well-known predator of coral polyps in other Indo-Pacific reef systems. Large numbers of these sea stars can devastate reefs, leaving behind only the calcium carbonate skeletons which are then more easily attacked by boring organisms.

\subsubsection{Grazers}

Grazers feed by scraping or rasping food from the surface of the substrate usually with the purpose of ingesting algae. There is considerable evidence of the geological effects of grazing by surgeonfish (Acanthuridae) and parrotfish (Scaridae) in shallow near shore areas, where the rock surface is often covered with rasp-marks (Stoddart 1969, Glynn 1972). The material they defecate is sand and silt-sized sediment. Other grazing bioeroders such as echinoids are also important sediment producers, both directly by providing their own skeletal parts and indirectly by producing material while feeding on algae (Bak et al. 1975). A study of Diadema antillarum on a fringing reef in Barbados found that they were capable of producing 97 tonnes per hectare per year of 
unconsolidated, mainly silt-sized sediment (Hunter 1977). A similar study in on the coral reefs of Curapao and Bonaire (Netherlands Antilles) showed Diadema antillarum to be a major coral predator and, in areas with high coral cover, up to $8.2 \%$ of the Diadema population (with a density of 8.5 animals $/ \mathrm{m}^{2}$ ) was feeding on living coral surfaces at night (Bak et al. 1975). Grazers may play an important role in reef dynamics and coral colonization, as the removal of grazing herbivores such as Diadema antillarum by a hurricane from a fringing reef in Jamaica resulted in the failure of the reef to recover as non-calcareous algae and alien species were then able to flourish at the expense of the coral (Perry 1996)

\subsubsection{Browsers}

Browsers are biota that ingests sediment in order to extract nutrients from the associated algae and detritus. Holothurians (sea cucumbers) are one browsing that has been observed in large concentrations on the reef flats of Palmyra, especially on the extensive tidal sand sheets and shallow lagoon zones located behind and between the short fighter strips in the Central Lagoon area (Fig 5.10). These bottom feeders ingest large quantities of sediment, and they have been implicated as potentially major modifiers of sediment elsewhere (Bonham and Held 1963). Observations of Holothuria atra at Rongelap Atoll, Marshall Islands showed an ingestion rate of $1 \mathrm{~g}$ dry weight of sediment in 5-10 minutes, and Bonham and Held (1963) calculated a total sediment ingestion by two species at Rongelap of $2.4 \times 10^{\wedge} 8 \mathrm{~kg}$./year. Whether the sediment is affected by passage through the gut of holothurians is debatable (Stoddart 1969). The $\mathrm{pH}$ values of less then 7.0 (acidic) that have been found in their stomachs are low enough to cause dissolution of calcium carbonate (e.g. Bonham and Held 1963), although even delicate skeletal materials are apparently not affected (Trefz 1958 in Stoddart 1969). Holothurians may also organically bind sediment into faecal pellets. 


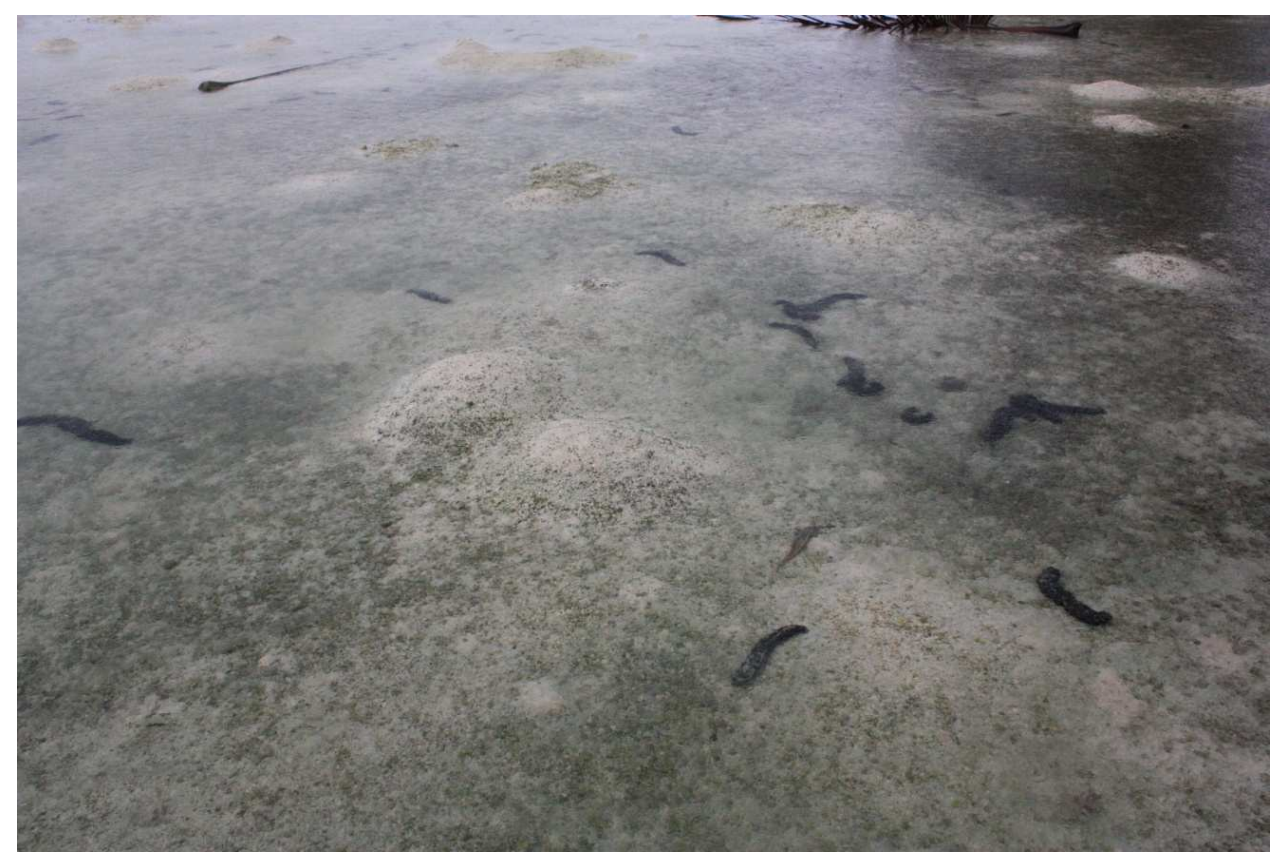

Fig 5.10 Photo of abundant holothurians Holothuria sp. living in shallow water near South Fighter Strip on Palmyra Atoll (Fig 1.2)

\subsubsection{Further effects of organisms on sediments; Encrustation and bioturbation}

Once skeletal material is contributed to the sediment budget it is still affected by the ongoing activities of benthic organisms and the processes that have been discussed above still operate. The activities of organisms can bind sediment, modify sediment deposition rate (See chapter 6), and encrust grains and the substrate. Blue and green coralline algae and bryozoans are among the more important encrusting biota. Continued attack and boring of grains helps to assist in the continual breakdown to finer sediments. Reworking and the destruction of depositional structures readily occurs, and this is particularly evident on the tidal interior reef flat zones where bioturbation by crustaceans and worms leaves the substrate covered in large mounds and depressions (Fig 4.6). Organisms can also assist in the transport of sediment across an atoll (Emery 1956). 


\subsection{Grain size and sorting}

The following descriptions relate to the grainsize analyses and statistical calculations for 51 samples that were selected as representative of the lagoon, tidal and beach environments (Appendices A, B, C). Sediments from Palmyra Atoll range in size from boulder to silt, with most of those analysed being dominated by sand-sized particles and the reminder being mainly finer sediment. Visual estimates of the fraction of coarser clasts were made in the field. The results of the analyses show that the grainsize of sediments from Palmyra grades from the coarsest rubble material located at the reef crest towards finer material within the interior of the atoll in its lagoons where silt prevails.

\subsubsection{Measurement of average grain size}

Folk's (1974) graphic mean (MZ) was considered to be the best determinant of overall size and is calculated using the formula:

$M_{z}=(\phi 16+\phi 50+\phi 84) / 3$

The graphic means for all analysed samples are shown in Appendix B. These were used as a parameter in classifying the sediments from Palmyra. The overall mean of the graphic means of the samples was $2.58 \mathrm{~mm}$ (fine sand). Ten samples were silt, 3 very fine sand, 14 fine sand, 17 medium sand, 6 coarse sand and 1 sample was very coarse sand. When graphic mean grain size is compared to the water depth for the sample, a clear trend of grain size fining with increasing water depth is apparent (Fig 5.11). 


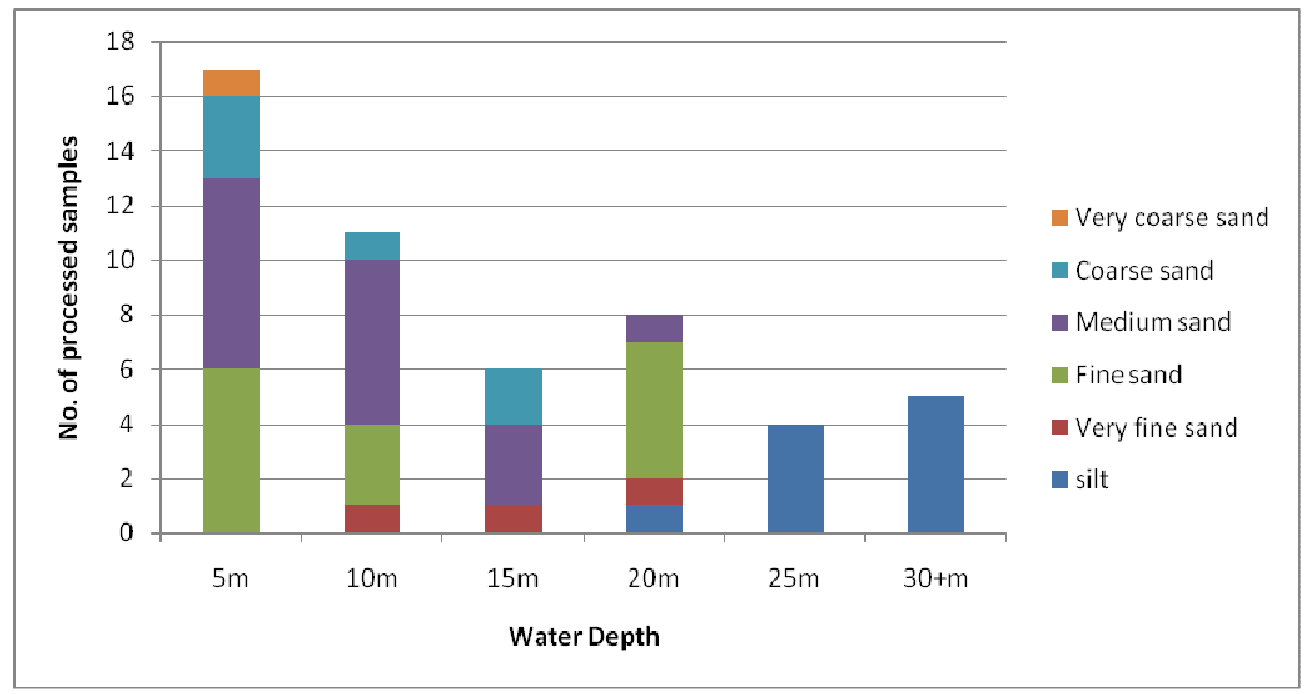

Fig 5.11 Graphic mean grain size of samples plotted against water depth $(\mathrm{n}=51)$

\subsubsection{Sorting}

Folk's (1974) inclusive graphic standard deviation was used as a measure of sorting and is given by the formula:

$$
\frac{\phi 84-\phi 16}{4}+\frac{\phi 95-\phi 5}{6.6}
$$

This formula includes $90 \%$ of the distribution and was considered the best overall approximation measure of sorting from the three standard deviations calculated. The other standard deviations calculated were the moment measures method and Inman's methods (Appendix B, C). The following classification parameters for sorting were used (Folk 1974):

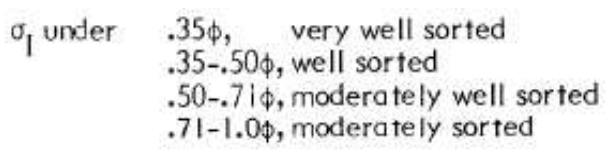

\author{
1.0-2.0\$, poorly sorted \\ $2.0-4.0 \phi$, very poorly sorted \\ over $4.0 \phi$, extremely poorly sorted
}


Results showed that, overall, the sediment samples analyzed were poorly sorted. One sample was extremely poorly sorted, 5 samples were very poorly sorted, 39 samples were poorly sorted, 5 samples were moderately sorted and 1 sample was well sorted. No samples were recorded as being moderately well sorted or very well sorted (Fig 5.12).

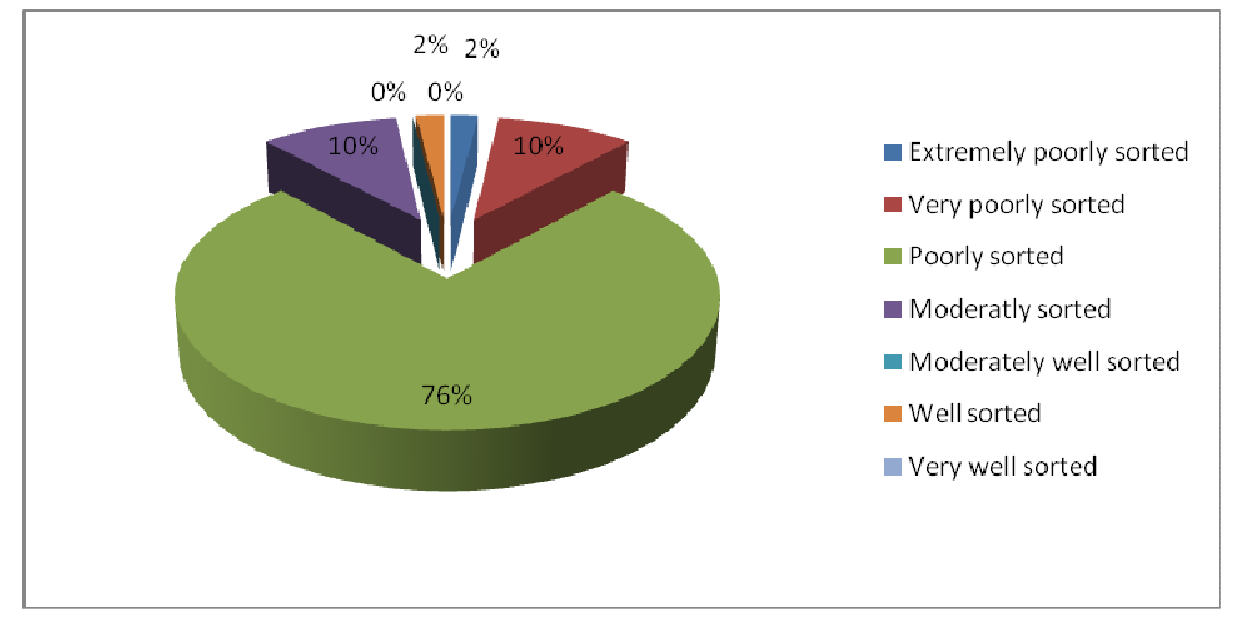

Fig 5.12 Percentage diagram of sorting of 51 samples from the Palmyra Atoll interior

Results show that the sampled sediments of the lagoons and interior tidal flats of Palmyra Atoll are predominantly poorly sorted. This pattern of sorting was thought to reflect a similarity in the hydrodynamic energy regime operating and influencing sediments within the interior of the atoll. However, hydrodynamic energy regimes have been observed to differ considerably from one location to another. For example, the breaks in the causeways have very strong tidal current forcing when compared to the sheltered tidal sand sheets on the interior reef flats. This infers that hydrodynamic energy is not the only factor influencing sorting distributions.

\subsubsection{Measures of skewness}

Skewness measures the degree of asymmetry as well as the "sign" that indicates whether a curve has an asymmetrical tail on the left (a finer positive (+) value) or the right (a coarser negative (-) value) of the grain size frequency distribution curve. Both Inman's 
and Folk's methods for calculating skewness were investigated, and Folk's Inclusive Graphic Skewness method was selected as the best measure of skewness to use because it determines the skewness of the "tails" of the curve, not just the central portion, and the "tails" are where the most critical differences between these samples lie. Furthermore it is geometrically independent of the sorting of the sample, as in the skewness formula a measure of phi spread occurs both in numerator and denominator (Folk 1974). The formula used to calculate inclusive graphic skewness is (Folk 1974):

$\frac{\phi 16+\phi 84-2 \phi 50}{2(\phi 84-\phi 16)}+\frac{\phi 5+\phi 95-2 \phi 50}{2(\phi 95-\phi 5)}$.

The following parameters of skewness were used to classify the processed sample (Folk 1974):

+1.00 to +.30 , strongly fine-skewed; +.30 to +.10 , fine-skewed; +.10 to -.10 , nearsymmetrical, -.10 to -..30, coarse-skewed; and -.30 to -1.00 , strongly coarse-skewed. The absolute mathematical limits of the measure are +1.00 to -1.00 , and few curves have $\mathrm{Sk}_{\mathrm{I}}$ values beyond +.80 and -.80 .

Folk's method showed more variation in the degree of skewness of the Palmyra atoll samples (Appendix A, B), but the degree of skewness appeared to visually compare better with the obtained histograms (Appendix C). 5 samples were strongly coarse-skewed, 16 were coarse-skewed, 15 samples were nearly symmetrical, 11 samples were fine-skewed and 4 samples were strongly fine skewed. Fig 5.13 shows these results as a percentage.

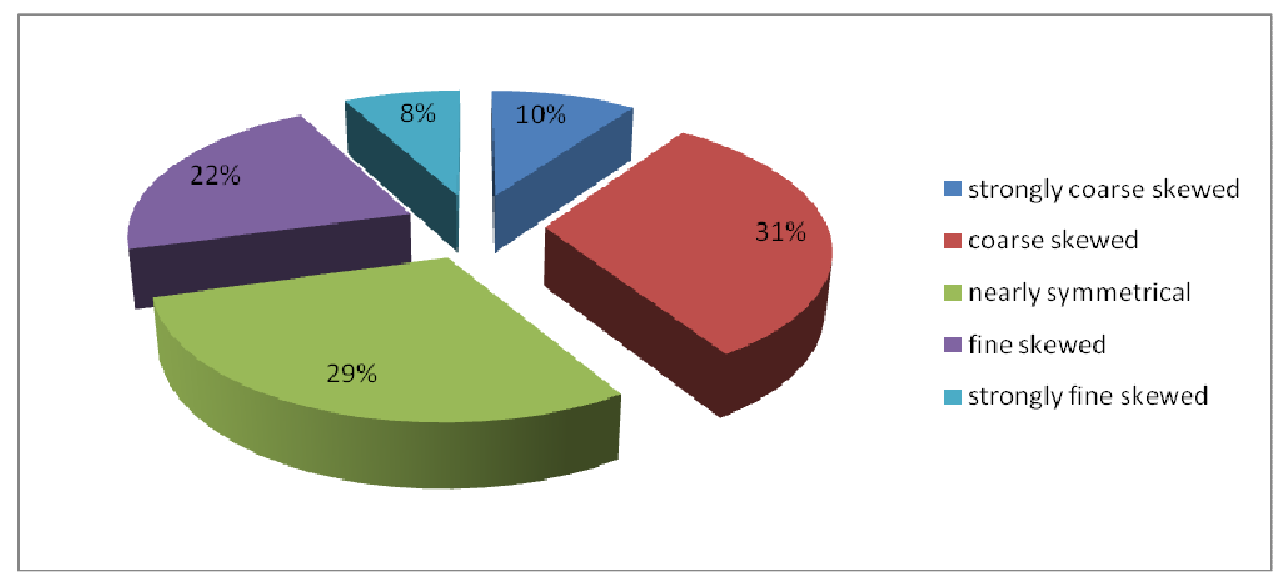

Fig 5.13 Percentage diagram of skewness of 51 samples from the Palmyra Atoll interior 


\subsubsection{Textural classification}

Blair et al.'s (1999) modification of Folk's (1974) method for determining textural classification (Fig 4.15) was applied to the calculated grain size data for the processed samples from Palmyra's lagoons (Appendix B). The remaining unprocessed samples were given a textural classification by visual comparison with each other. The mapped results of this are in Appendix I. Folk's (1974) classification was used in the determination of the lithofacies boundaries shown in section 4.8 .

\subsubsection{Depositional texture}

Embry et al.'s (1972) modified method for determining depositional texture from Dunham's (1962) original method (Table 4.1) was also applied to the calculated grain size data (Appendix B). The mapped results of this are in Appendix J. This classification was also used in the determination of the lithofacies boundaries shown in section 4.8.

\subsubsection{Roundness}

The roundness of grains in these sediments is a function of grain composition, grain size, type of transport process and distance of transport (Folk 1962, Boggs 2001). For example, hard resistant grains such as fragments of Acropora branches are abraded less readily than are weaker grains such as Halimeda plates. Further, fecal and pseudofecal pellets are already rounded when formed, and some grains such as some foraminifera may already be rounded when alive (Folk 1962). These factors make it difficult to relate the observed roundness to any specific process in a shallow carbonate depositional setting. 


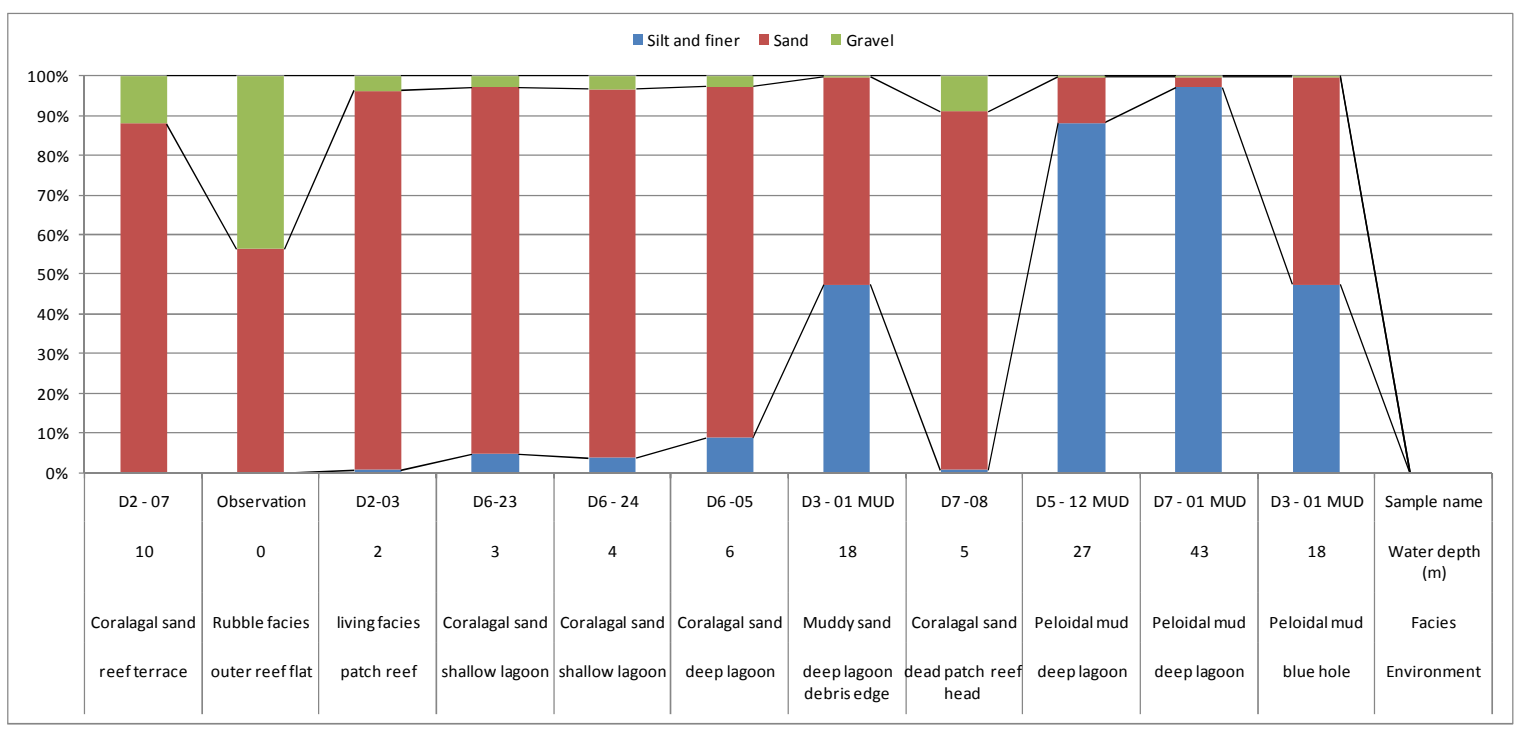

Fig 5.14 Generalized transect of Palmyra from crest to lagoon comparing gravel, sand, silt and finer sized sediments. Environmental zones and facies are also shown.

\subsubsection{Discussion of grainsize characteristics}

Most of the sampled sediments are poorly sorted and are nearly symmetrical in their grain size distribution (Appendix B, C). Grainsize variation indicates a trend of decreasing grainsize from the shallow crest and outer reef towards the interior of the atoll and into the deep lagoons (Fig 5.11, 5.14). The variations in grainsize seen are generally consistent and form concentric zones of sedimentary facies (Figs 4.21, 4.22, 4.23).

The grainsize and textural classification are thought to be determined by the distance of transport to the point of deposition from the sediment source, and this distance travelled directly reflects the hydrodynamic conditions and energy levels operating (Boggs 2001). In the case of Palmyra, this would reflect the decreasing energy levels towards its interior.

However, there are other factors to consider and a second school of thought (Wien 1959, Folk 1974, Hopley 1982, Stodart 1988, Tucker and Wright 1990) believes that in general on reefs, because of irregular topography and the influence of benthic organisms, size, 
shape and sorting in sediments depend more on the skeletal characteristics or architecture of constituent organisms than on the hydrodynamic energy of waves and currents. This is because different grains disintegrate in different ways and have different hydrodynamic behaviours and different threshold velocities for movement. For example, Halimeda plates decay at a faster rate than the more resistant fragments of the coral Acropora (Tucker and Wright 1990). Similarly, a smooth and rounded Amphistegina test is likely to be transported more readily than a blocky fragment of coral. Furthermore, if the sediment is deposited close to its source with little transport occurring it will be texturally immature and hence sorting will be more dependant on the skeletal characteristics than on the hydrodynamic conditions (Hopley 1982). Poor sorting may in fact reflect high biological activity in addition to hydrodynamic forces. The specific grain bulk densities determined by the specific gravity of the particular carbonate mineral used by an organism combined with its skeletal micro-architecture were not studied but could be another important factor controlling the type of transport and end member textural characteristics. Furthermore, grains are subject to the ongoing processes of bioerosion from source through to deposition and this will be in part affecting the grain size distribution observed (Section 5.2). Highly detailed and specific investigations would be required to quantify the importance of each process.

\subsection{Sediment movement}

Sediment movement studies for Palmyra Atoll are still very much in their infancy and the necessary data are not yet available. The primary mechanism of sediment movement across Palmyra Atoll is thought to be by wave and tidally-induced currents (hydrodynamic forcing). The wave transport processes are episodic and are determined by the strength of the prevailing winds and/or swell directions, with larger material or material from greater depths only being able to be moved during storms rather than under normal background conditions. The overall direction of wave-influenced transport is from east to west, both long-shore and through the lagoons (Cobb et al. 2003, Maragos 2008, Collen et al. 2009). These currents and waves are generated by the predominant east to 
west trade winds, although the wind direction occasionally reverses and comes from a westerly direction (Barkley 1962).

Once sediment is entrained, the physical transport of grains across the atoll will occur as either bedload transport (traction and saltation) or suspended load transports (Boggs 2001). Transport is initiated when the velocity of the water becomes greater than the threshold velocity of the grains and therefore the type of movement is dictated by the difference between these two factors, with suspension being more evident in smaller grains (Briggs 1977, Orme 1977, Boggs 2001). Some material is then deposited as sand on shallow flats, some is deposited in the deep lagoons and much is thought to be carried beyond the island into the deep ocean.

On the outer reef flat of Palmyra, ocean swell causing surf waves dominates, with wave energy being greatest on the windward reef crest. The reef crest is a major modifier of the ocean's wave energy as it abruptly stops the onward progression of the wave, completely eliminating the wave form within a metre or so of the crest zone. Studies in the Cocos (Keeling) Islands (Kench 1996, Kench 1997, Kench 1998) show that $70-99 \%$ of the wave energy is dissipated here and that the high energy results in the highest transport mobility, resulting in little sediment being deposited on the reef crest. The remaining wave energy is dissipated across the reef platform, resulting in the lag of coarse rubble sediment deposits found on the outer reef. Wave energy dissipation across the outer reef pavement is most extreme as water approaches the high tide mark over a tidal cycle. Therefore the ability to transport sediment by wave energy is dependent on how much energy penetrates to the interior of the atoll through reef channels.

Because of the protective barrier of islets and reef pavement, sediment movement in the interior is influenced more by local wind-generated waves, currents and tidal movement than by the stronger oceanic wave energy affecting the outer reef. This is thought to be reflected in the similar level of poor sorting of most of the interior sediments. Field observations from the deep lagoons of Palmyra indicate that the water column has in places considerable suspended silt and clay-sized material. In the deep lagoons, CTD 
casts show turbid water forms a layer at depth (Fig 2.1, Gardner pers. comm. 2008) The deep high turbidity zone occurs at the same depths as the layer of anoxic water, although the relationship is not clear as of yet (see section 2.2.2). Suspended sediment collectors have been deployed more recently in June 2008 in Palmyra's lagoons and the results of this study are pending (J.D. Collen pers. comm. July 2008).

Reef biota may also be affective sediment transporters. Emery (1956) believed fish may be as important in the sediment budget of coral reefs and may rival waves and currents as transporting and trituration agents. The analysis of the gut contents of scarids from Johnston Island (north of Palmyra) and of surgeonfish, triggerfish and pufferfish from Palmyra show a dominance of coralline algae (45-90\%, but absent in two cases), followed by fine debris (10-70\%, but absent in the puffers), coral (0-60\%) and shells (0-40\%). Halimeda and foraminifera were insignificant (Emery, 1956). Ault (2007) studied the gut contents of 160 bonefish from various localities on Palmyra, the results of which showed that $66(41 \%)$ were empty at the time. Crabs, mainly ghost crabs (Macrophthalmus spp.), made up $33 \%$ of the total weight and $41 \%$ of the total volume of prey consumed by bone fish. Acorn worms (sipunculids) accounted for $29 \%$ of both weight and prey consumed. The remainder of the prey items consisted of various crustaceans and polychaete worms, with a few small fishes and one terrestrial beetle. Coral rubble comprised $19 \%$ of the weight and $9 \%$ of the volume of stomach contents. These two studies show that fish can ingest large quantities of sand-sized particles and this may reflect the larger grain size fraction material seen associated with the very deepest and finest samples from Palmyra, where fish feeding on the reef flats at high tide are defecating coarser material as they later pass across the lagoons.

Sediment movement patterns have historically been different. Water movement patterns, which affect sediment movement, were changed during and by the modification of the islets during World War Two. Some of the effects of this are discussed in section 2.5.2 of this thesis. The full impact of this operation on the atoll is currently unknown; however, it is likely it had a significant impact on the grainsize and facies distribution within the 
interior of the atoll, especially in West Lagoon where the majority of the dredging took place.

\subsubsection{Sedimentary structures and other evidence of sediment movement}

The well sorted rubble facies found on the outer reef beaches, in particular on Barren Island, and the outer reef pavement as rubble lenses reflect a winnowing of the finer sediments, although in the outer beach zone moderately to poorly sorted sand-sized sediments were typically found only a few $\mathrm{cm}$ below a rubble veneer. The lag rubble is mostly composed of broken Acropora branches and reflects the high energy occurring in these areas both during storm activity and under normal strong easterly trade wind condition. In places of intensified energy the rubble has been built up into ridges that have a maximum height of 2 metres with steep $40^{\circ}$ slopes on the side of prevailing energy. The storm beach ridge seen on Barren Island is a good example of this, here material is been constantly thrown up towards the west by the strong easterly swells, on to the ridge and the island is steadily growing in an easterly direction (Fig 5.15). 


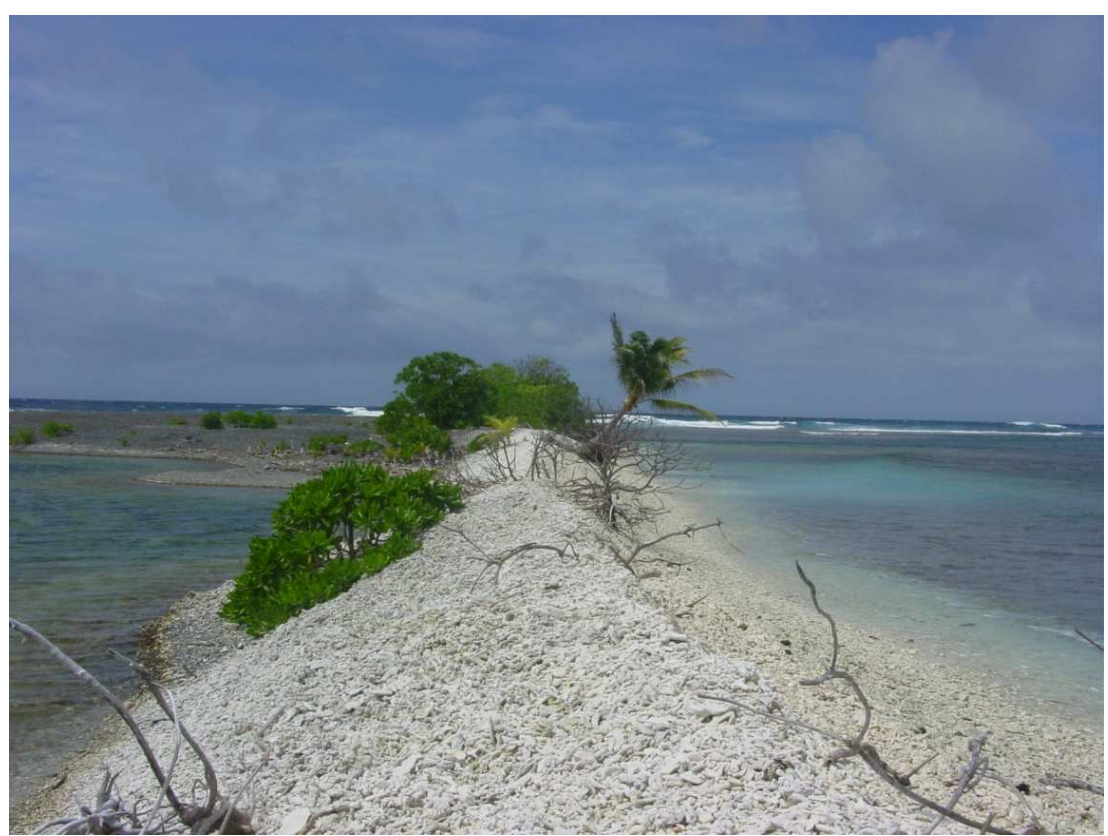

Fig 5.15 Storm ridge forming Barren Island. The ocean and prevailing swell is to the right of the ridge with Coral Gardens, a living patch reef facies, located in sheltered water to the left. The dark material that can be seen at the base of the ridge on the left side is deeply stained, implying that the ridge is a relatively stable structure.

Strong currents are causing a winnowing of fine sediment to occur within the passage ways from the outer reef to the inner reef flats between fringing islands. Here, fine material is being entrained and removed and a coarse rubble debris delta can be seen spreading in from the outer reef flat across the inner reef flat (Fig 4.11). As mentioned, in some cases where the inner reef flat is not very wide debris fans of relatively coarse sediments are observed flowing down from the reef flats and shallow lagoon zones into the deeper lagoon mud zones. Debris fans occur elsewhere where bathymetry changes quickly. An attempt was made to examine a debris flow into the deep lagoons from the shallow lagoons and inner reef flat of Central Lagoon and a test dive was undertaken to $30 \mathrm{~m}$ water depth on the eastern limits of central lagoon near the cut in the causeway. The depth and turbidity made it difficult to see the debris fans in detail but a short core sample was retrieved from the steep slope face and this is currently being processed and dated. 
Strong winnowing and scouring of the substrate by strong tidal currents that move water in a constant westward direction is clearly observed in the breaks in the causeway between Center and East lagoons. A preliminary water velocity of $0.1441 \mathrm{~m} / \mathrm{sec}$ was recorded in the northern most break in the cause way between Central and Eastern lagoons (Table 6.1) (Gardner pers comm. 2008).

Small scale ripples, flow marks and other sedimentary structures that occur on the sand sheet on the inner flats are constantly and quickly covered and reworked between every tidal cycle by heavy bioturbation from crustaceans and other organisms that burrow and create depressions and mud mounds (Fig 4.6, 5.16).
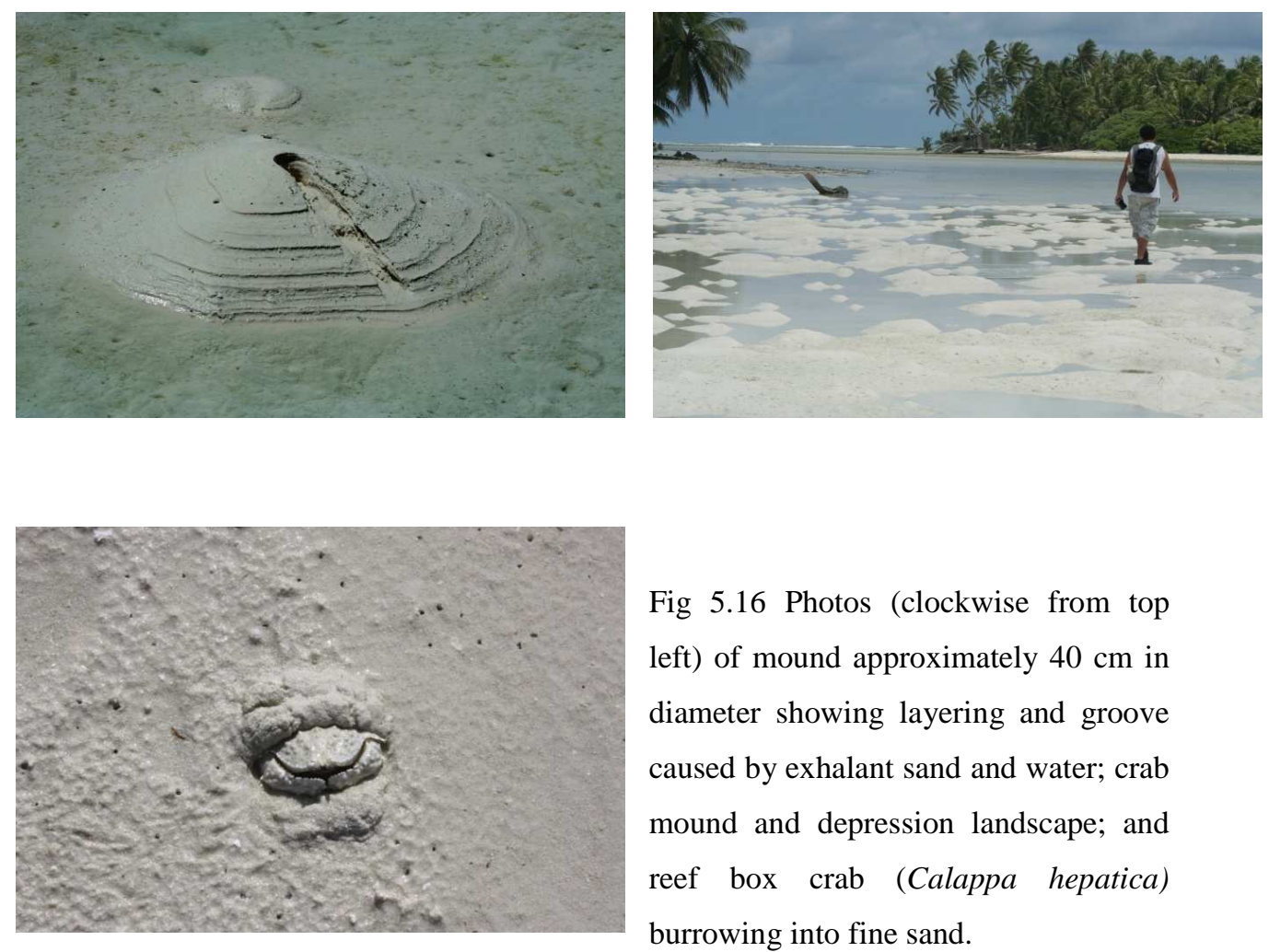

Fig 5.16 Photos (clockwise from top left) of mound approximately $40 \mathrm{~cm}$ in diameter showing layering and groove caused by exhalant sand and water; crab mound and depression landscape; and reef box crab (Calappa hepatica) burrowing into fine sand. 


\subsubsection{Image interpretation}

Historical aerial photos and figures have been compared with recent satellite images, photos and observations in an attempt to identify and quantify both indicators of sediment flow and the amount and distribution of sediment on Palmyra. It is apparent from comparing photos taken shortly after military occupation with present observations that there has been much sediment build-up over the interior patch reef areas (Fig 4.8). The outer island shorelines have changed considerably, and the predominant movement of sediment redistribution has been from east to west (Collen et al. 2009) (See section 2.5.3 shoreline changes). Collapsed bunkers present on the atoll ocean reef flat indicate erosion of the shorelines and a possible movement of sediment from the islands back into the reef flats and lagoon zones.

\subsection{Sedimentation rate}

Sedimentation rates for the various depocentres of Palmyra Atoll are unknown. The sediment-producing organisms on the atoll are primarily calcareous. The amount of carbonate production is highly dependent on the type of organisms and there is a high degree of global growth variability from 0.8 to $30.5 \mathrm{~kg} \mathrm{~m}^{2} /$ year (Hart and Kench 2007) with an average rate of growth for warm water carbonates of about $4.5 \mathrm{~kg} \mathrm{~m}^{2} /$ year (Rogers 1990, Scoffin 1987). It is important to note that different organisms produce at different rates and those different organisms inhabit different environments within a carbonate reef system. Furthermore, only a percentage of the material produced by an organism will actually be added to the accumulating sediments on the atoll, and an unknown percentage of the material will be removed into deeper water. The overall general trend in productivity of sediment producing organisms is thought to follow the same pattern as other atolls and decreases from the living reef crest towards the interior of the atoll.

Measurement of sedimentation rates from Palmyra Atoll would require either $(a)$ detailed measuring of sediment accumulation over a period of years; or $(b)$ by deducing mean rates of growth from geological evidence, especially borehole data 


\subsection{Chemical alteration of sediment}

Chemical alteration of grains and the cementation of carbonate grains have not been studied on Palmyra. However, by analogy with other studies it should be actively occurring primarily in the inter-tidal and supra-tidal area through the precipitation of aragonite, calcite, micrite and Mg-calcite (Scoffin 1987, Guilcher 1988 and others). Cementation is most notable in the formation of exposed beachrock deposits that occur on the ocean facing reef pavement, island interface. Chemical alteration is often associated with boring of grains and processes such micritization are believed to weaken the internal structure of grains and promote further breakdown (Kennedy 2003)

\subsection{Correlation analysis}

Correlation analysis between the depth of water and the percentage of fine material for 51 samples (Fig 5.17) shows that water depth and fine fraction material are positively correlated and the proportion of fines in the sediment increases with decreasing water depth.

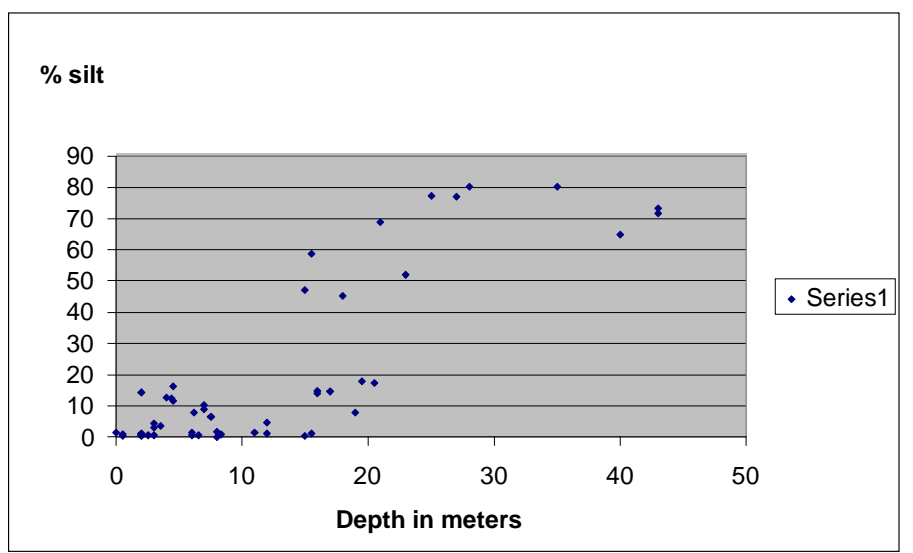

Fig 5.17 Comparison of water depth against percentage of fines for 51 samples.

However, analysis shows that the sediment composition cannot be correlated with either depth or environmental parameters (Fig 5.8). 


\section{Chapter Six: Discussion}

Mapping, sampling, grainsize and compositional analysis of the recent sediments of Palmyra Atoll have shown a concentric pattern of sediments, morphology and environs in zones passing inwards from the high-energy fore reef and reef crest towards the lower energy deep lagoon zones. Palmyra is exposed to dominantly easterly trade wind and ocean swells which exert a strong control on the reef flat and lagoon hydrodynamics, and thus are a major control on the environmental and sediment zonations.

Six sedimentary environment zones and eight sub zones typical of tropical atoll reefs have been identified from fore reef to deep lagoon (Section 4.1, Fig 4.12, 4.13, 4.14). These have specific sets of sedimentary facies attributed to them; however facies can overlap and be found in more than one environ. Environment positions and zonation are controlled by the bathymetry, the level of exposure to hydrodynamic energy and by the communities of biota present, and the interactions between these.

Five distinctive lithofacies have been identified on the basis of textural classification, depositional texture, grain composition and distinctive lithological features (Section 4.8; Fig 4.21, 4.22, 4.23). Facies form concentric bands that approximately align with the environmental zones but also overlap them. The observed sediment zonations reflect a complex interaction between the supply and physical properties of the source material and the various processes which transport and degrade it. Surface sediment assemblages appear to be largely controlled by the hydrodynamics, position of environments and the water depth.

Compositional analysis of the gravel and sand fractions of samples taken from the interior of Palmyra showed that coral and calcareous red algae were the dominant constituents in all sediments and lithofacies present, contributing on average 50\% of the components. Mollusc were the second largest constituent and contributed on average $23 \%$ of the bulk, of which bivalves made up more than $70 \%$. The calcareous green algae Halimeda spp. were the third largest constituent with an average of $11 \%$. Decreasing in contribution, 
other material consisting mainly of organic debris, foraminifera, crustacean and echinoids made up the remainder of the sediments, each contributing $5 \%$ or less of the bulk composition. Indicative compositions diagnostic for any particular environment were not clearly identified, and compositions appeared to be very similar from one environment to another (Fig 5.2). This result may indicate either a homogenization of all sediments due to the small size of the atoll, whereby all the source areas contain similar material and the only variable is grain size, that clear variations may not be apparent due to the insufficient sampling or that reworking of sediments by military actions would have promoted a mixing of sediment types. The components are all of skeletal origin. This is the result of primarily carbonate organism growth and decay and the contribution both directly and indirectly by those organisms to the accumulating sediments.

The sediments of Palmyra Atoll range in size from boulder to mud-sized. Grainsize analysis of samples collected from the lagoons and reef flats of Palmyra showed that most sediments are poorly sorted and are nearly symmetrical in their grain size distribution (Appendices B, C). Most samples analysed were dominated by sand-sized particles, with the remainder of each sample being mainly finer sediments. This result is biased as the majority of sediment samples collected were of sand or mud and coarser material was not sampled quantitatively. The overall average grain size observed was fine sand. A trend in textural classification and grainsize distribution was apparent: sediments from Palmyra Atoll grade from the coarsest rubble material located at the reef crest towards finer material within the interior of the atoll where silt prevails in the deep lagoons (Fig 5.10, 5.13). The variations in grainsize seen are generally consistent and form concentric zones of sedimentary facies (Figs 4.21, 4.22, 4.23).

The grainsize and textural classification are partly determined by the distance travelled to the point of deposition from the sediment source, and this directly reflects the hydrodynamic conditions and energy levels operating (Boggs 2001, Folks 1974). However, particularly in atoll settings, the size, shape and sorting observed in sediments may depend more on the skeletal characteristics or architecture of constituent organisms than on the hydrodynamic energy of waves and currents. This is because different grains 
disintegrate in different ways and have different hydrodynamic behaviours and different threshold velocities (Swinchatt 1965, Folk 1974, Stoddart 1988, Hopley 1982, Tucker and Wright 1990). To what degree each of these factors contributes to the observed trends in grain size distribution is unknown and will require more detailed study.

There are numerous physical, biological, chemical and biochemical processes operating constantly to produce the accumulating sediments upon Palmyra Atoll. Material accumulating is mostly from living framework, epifaunal and infaunal sources on the fore reef, reef crest and reef flats and from the reworking of dredged material, with lesser amounts sourced from patch reefs within the interior of the lagoon. Sediments are being produced and reduced to smaller particles by the mechanical effects of abrasion and breakage caused by water turbulence due to currents and wave action, and by the biological processes of bioerosion from a range of organisms. As with mechanical erosion, bioerosion will be operating on a range of scales and be caused by a number of mechanisms. On the small scale, these processes include boring by micro-endolithic bluegreen algae, molluscs, foraminifera, sponges and polychaetes. These can significantly weaken the sediment structure leaving it vulnerable to physical breakage by waves. There is also breakdown of the reef framework on an intermediate scale by a number of reef biota that rasp and ingest sediment, including parrot fish, echinoids and holothurians (Stoddart 1969). Consumption of coral polyps by carnivorous biota both directly contributes sediment in the process but also leaves the carbonate skeletons open to the effects of a multitude of smaller bioeroders. Large clast sediment production is by storm activities and the affects of strong ocean swells upon the reef material. Climatic processes, including ENSO modify many environmental parameters (Cobb et al. 2003) this is thought to affect coral growth and sediment production both directly and indirectly. ENSO processes have been proven to be present in coral records from Palmyra dating back to as old as the tenth century and much variation in the strengths of these processes is evident (Cobb et al. 2003). This is a highly complicated system and at present no quantitative data is available on how the sedimentology of Palmyra is affected by such climatic processes. 
The patch reefs of the interior of Palmyra are believed not to be prolific contributors of sediment at present, because many of these are dead following modification to the three main lagoons during World War Two. Only now are small amounts of live coral returning to these areas (Maragos et al. b 2008). There is, however, presently an extensive zone of living patch reef separated from and east of East Lagoon known as the Coral Gardens. Coarser material being transported from this area into East Lagoon must be minor due to its rapid settling rate and material from here is unlikely to be entering the other two lagoons further west. The data collected suggest that the surrounding lagoonal areas (mainly reef flats) generally have similar component composition to the sampled patch reefs. This implies that examination of the lagoon sediments themselves will give little or no indication of the relative importance of lagoon patch reef versus surrounding framework suppliers.

Once sediment is produced it is thought to be entrained and moved primarily by hydrodynamic forcing (wave and tidally-induced currents). The wave transport processes are episodic and are dependent on the strength of the prevailing winds or swell directions, with larger material or material from greater depths only being able to be moved during storms rather than under normal conditions. The overall direction of wave influenced transport is from east to west, both long-shore and through the lagoons (Cobb et al. 2003, Maragos 2008, Collen et al. 2009). The currents and waves are generated by the predominant east to west trade winds. The wind direction can occasionally reverse and come from a westerly direction (Barkley 1962). Clear evidence of a predominant westward transport can be seen in the modification to ocean facing beaches since 1939 to present (Fig 2.6, 2.7, 2.8, 2.9) (Collen et al. 2009). Reef biota may also be effective sediment transporters (Emery 1956), especially fish whose gut contents show that they ingest large quantities of sand-sized particles whilst feeding (Emery 1956, Ault 2007), and are thought to transport and redistribute coarse grained sediments throughout the lagoons of Palmyra. There is a possibility of coarse sediments begin transported by rafting from vegetation, whereby sediment is trapped for a time in the physical structure of the vegetation. These may explain the coarse material seen associated with the very deepest and finest samples from Palmyra. 
Once skeletal material is contributed to the sediment budget it is still affected by ongoing mechanical and biological processes. Organisms can bind sediment together and may modify sediment deposition rates. Other organisms may encrust grains and the substrate, and continued attack and boring of grains helps to assist in the continual breakdown towards finer particles. Reworking and bioturbation will cause the destruction of depositional structures.

\subsection{Biological Control of control of sedimentation rate in deep lagoons}

Preliminary water current velocities recorded in the lagoons of Palmyra Atoll (J.P.A. Gardner pers. com. 2008) are sufficient to transport much of the silt-sized material being produced on Palmyra offshore before it can in the deeper parts of the lagoons. However, the deep lagoons of Palmyra have high fine fraction contents (average upwards of $70 \%$ silt and mud) and are categorized here as a peloidal mud facies. It is hypothesized that the high percentage of fine material found in the deep lagoons is controlled by the formation of pseudofecal and fecal pellets by planktonic organisms living in approximately the top 30 metres of water of the lagoons and tidal areas of Palmyra Atoll.

Pseudofecal and fecal pellets are a type of peloid, a predominantly sand grain that readily breaks down to mud size, composed of microcrystalline carbonate (Fig 6.1). In samples from the deeper lagoons, they are ellipsoidal grains, with long axes 1.3 times longer than their short axes on average, and appear to be fecal or pseudofecal in origin. Fecal pellets are an organism's excremental aggregate of silt and clay-sized particles, organic material and water. Pseudofecal pellets are similar in both form and composition, and are produced as a way of removing unsuitable or surplus food particles. Particles are wrapped in organic mucus and then expelled without having passed through the digestive tract. A variety of organisms produce ellipsoidal fecal and pseudofecal pellets, such as holothurians, copepods and holoplanktonic opisthobranch gastropods. 


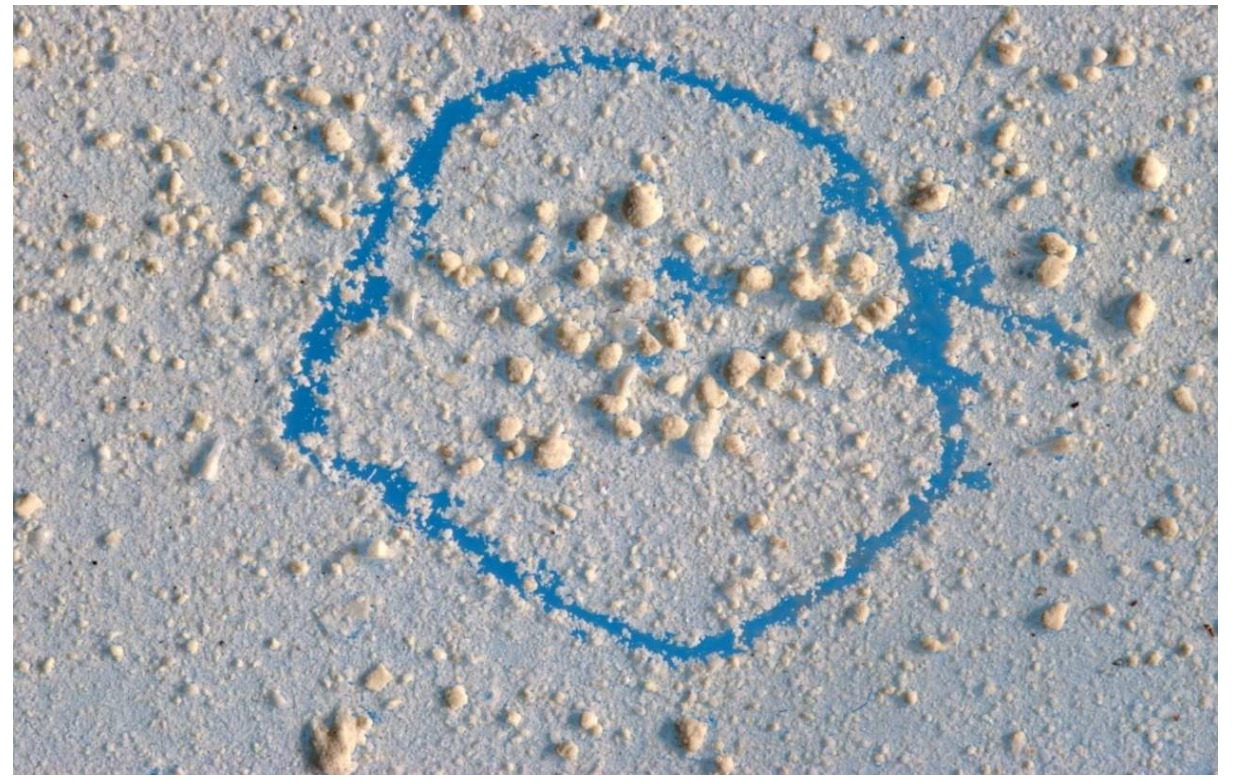

Fig 6.1 Typical pellets found in deep lagoon Peloidal mud. The outline circle shown in this photo is approximately $1.1 \mathrm{~cm}$ in diameter.

The importance of fecal and pseudofecal production to sedimentation has been demonstrated by a variety of authors (e.g. Wanless and Burton 1981, Schrader 1971, Uye and Kaname 1994). The size composition of the zooplankton community is an important parameter for the variation in the vertical flux of material via fecal pellets (Uye et al. 1994), as the pellets sink many times faster than the original particles used in their creation (the food source) (Schrader 1971). Therefore, because the settling rate has been increased, where horizontal water currents are significant less horizontal travel occurs before the material reaches the substrate. After the degradation of the organic material used to bind the pellet, the fine material is then added to the accumulating sediments. This is fine material that would not normally reach the substrate in an unbound state. Furthermore, Kench (1996) has shown that an ellipsoidal partial form, such as that of Comment [j5]: There are probably many pseudofecal and fecal pellets, will promote a more effective settling path though the water earlier references than Kench column. 
One of the organisms believed to be important to this process in the lagoons of Palmyra is the holoplanktonic opisthobranch gastropod Creseis virgula constrica (J.D. Collen pers comm. 2008) (Fig 6.2). C. v. constrica is a pteropod (a shelled pelagic mollusc of the suborder Thecosomata) (Bé et al. 1977). Abundances of up to 1600 pteropod shells per gram of dry sediment have been observed for samples from the deeper lagoons (Collen pers, comm. 2008). The pteropoda are thought to be most abundant at $20 \mathrm{~m}$ water depth in the Palmyra lagoons. Other important and abundant components of the plankton here that also produce fecal pellets are the copepod crustaceans. No data are available on the production rate of pseudofeces by the pteropoda and other organisms at Palmyra, although studies of the plankton are in progress (D. Garton pers. comm. 2008). However, a study by Hofmann et al. (1981) on the contribution of fecal pellets by copepods of the genus ParacaIanus from south-eastern shelf of the United States showed that the nauplii and adults could produce up to 50 pellets per day.

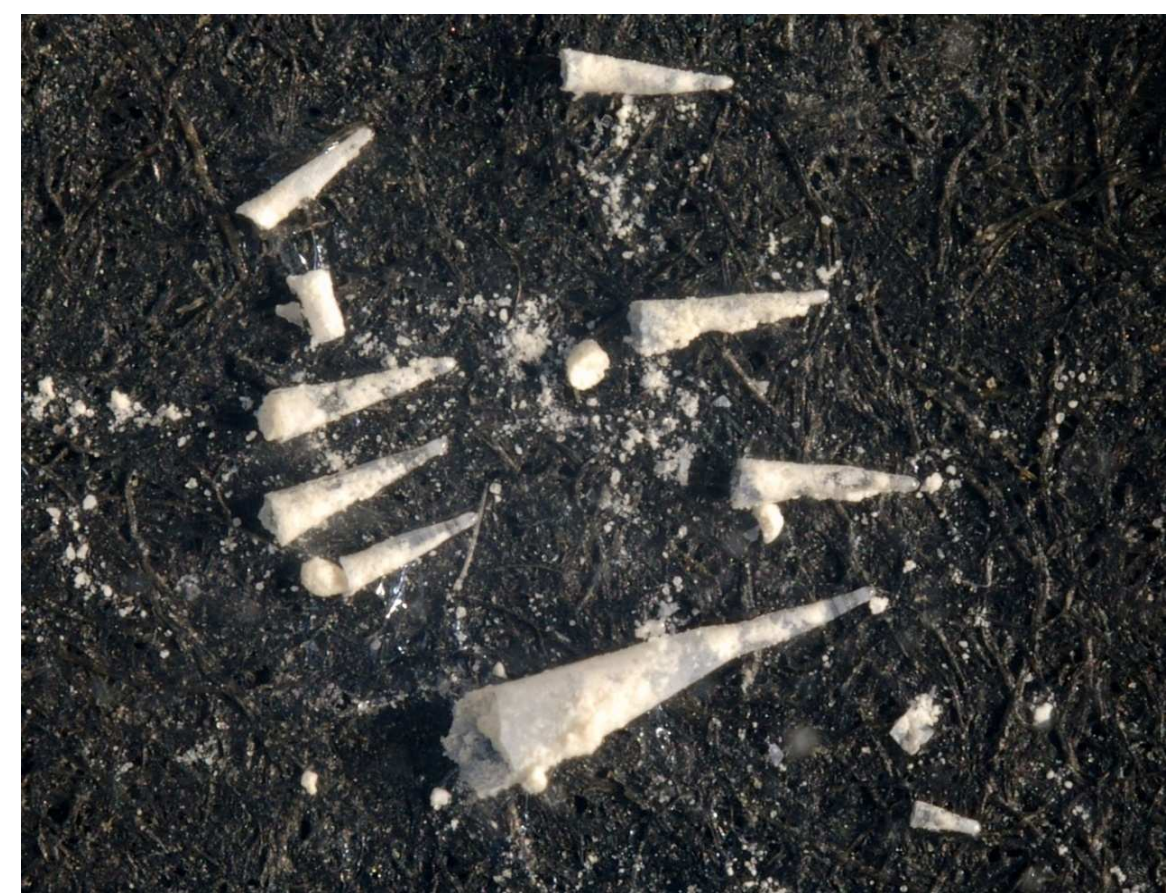

Fig 6.2 Photo of Creseis virgula constrica shells from the lagoon sediments. The largest shell is $8 \mathrm{~mm}$ in length. 
Binocular microscope studies of intact peloidal grains from a typical deep lagoon mud showed they had an average size of $220 \mu \mathrm{m}$ (Fig 7.1). An approximation of horizontal distance travelled compared to vertical distance sunk for three grain sizes $(63 \mu \mathrm{m}, 150 \mu \mathrm{m}$ and $220 \mu \mathrm{m}$ ) was made using the following parameters:

- Settling rates were obtained from www.filtration-and-separation.com (2008), which uses Heywood Tables for larger particles and Stokes' Law for small ones.

- Calcite has a density of $2.71 \mathrm{~g} / \mathrm{cm}^{3}$ and aragonite has a density of 2.83 $\mathrm{g} / \mathrm{cm}^{3}$ and, as there is no data on the bulk chemistry of the observed pellets, an average of the two of $2.77 \mathrm{~g} / \mathrm{cm}^{3}$ was used. It was further assumed that the pellets have a porosity of $30 \%$, giving an overall theoretical density of $1.939 \mathrm{~g} / \mathrm{cm}^{3}$.

- A fluid density of $1023 \mathrm{~kg} \mathrm{~m}^{3}$ and fluid viscosity of .001 Pas for sea water at $29^{\circ} \mathrm{C}$ temperature and $36 \quad$ PPM salinity (http://www.csgnetwork.com/h2odenscalc.html 2008).

- Seven current measurements were made at varying positions from the interior lagoons of Palmyra and at varying depths over a period of about 24 hours for each measurement at $10 \mathrm{sec}$ intervals (Table 6.1 summarises the obtained current meter data).

- A value for near surface water flow for the interior lagoons of 0.00751 $\mathrm{m} / \mathrm{sec}$ was assumed (see below).

Note: Because of the limited availability of instrumentation, measurements at each location were made by the same current meter and therefore measurements were made on different days and at different tidal conditions, during June 2008. Sites 1003 and 1002 are enclosed channels and are areas where current velocity is known to be high and site 1008 is from a reef flat channel environment between two fringing islands. Site 1007 is the only record for depths greater then $6 \mathrm{~m}$, and all others are from near surface 
positions. The low current velocity measured at site 1007 is comparable to the findings of Gardner et al. (in prep), who have shown that there is a stratification of turbidity below $30 \mathrm{~m}$ depth; this indicates that there is a reduction of the water movement below this depth and that once sediment has reached this depth it is likely to sink vertically. Sites 1006 and 1004 are considered to give the best representation of near surface water flow for the interior lagoons; an average of the two sites of $0.00751 \mathrm{~m} / \mathrm{sec}$ has been used as the best available representation of near-surface water flow occurring through the lagoons under normal background conditions. This number is very approximate; however, it is sufficient for the purposes of discussing likely sediment transport patterns

Table 6.1 Summary of current meter data for June 2008 (data supplied by J.P.A. Gardner pers comm. 2008)

\begin{tabular}{|c|c|c|c|c|}
\hline $\begin{array}{l}\text { Sample } \\
\text { name }\end{array}$ & $\begin{array}{l}\text { Location (See fig } \\
\text { 1.2, Appendix E) }\end{array}$ & Water depth & $\begin{array}{lr}\text { Average } & \text { mean } \\
\text { current } & \text { velocity for } \\
\text { period } & \text { recorded } \\
\text { excluding } & \text { current } \\
\text { direction } & \end{array}$ & $\begin{array}{l}\text { Start and finish time } \\
\text { and date of recording }\end{array}$ \\
\hline 1001 & $\begin{array}{l}\text { Deployment at } \\
\text { dolphins jetty } \\
\text { southern side of } \\
\text { Western lagoon }\end{array}$ & $\begin{array}{l}6 \mathrm{~m} \text { below } \\
\text { surface }\end{array}$ & $0.00746 \mathrm{~m} / \mathrm{sec}$ & $\begin{array}{l}17.32 .42(06 / 06 / 08) \\
13.46 .12(05 / 06 / 08)\end{array}$ \\
\hline 1002 & $\begin{array}{l}\text { Deployment at first } \\
\text { cut (Causeway) } \\
\text { between Centre and } \\
\text { East lagoons }\end{array}$ & $2-3 m$ & $0.1441 \mathrm{~m} / \mathrm{sec}$ & $\begin{array}{l}14.14 .38(06 / 06 / 08) \\
10.22 .08(05 / 06 / 08)\end{array}$ \\
\hline 1003 & $\begin{array}{l}\text { Deployment at Sand } \\
\text { Island }\end{array}$ & $\begin{array}{l}6 \mathrm{~m} \text { below } \\
\text { surface }\end{array}$ & $0.03182 \mathrm{~m} / \mathrm{sec}$ & $\begin{array}{l}14.51 .58(09 / 06 / 08) \\
11.05 .28(08 / 06 / 08)\end{array}$ \\
\hline 1004 & $\begin{array}{l}\text { Deployment at } \\
\text { Strawn Island }\end{array}$ & $\begin{array}{l}6 \mathrm{~m} \text { below } \\
\text { surface }\end{array}$ & $0.00902 \mathrm{~m} / \mathrm{sec}$ & $\begin{array}{l}15.12 .52(09 / 06 / 08) \\
11.26 .22(08 / 06 / 08)\end{array}$ \\
\hline 1006 & $\begin{array}{ll}\text { Deployment } & \text { in the } \\
\text { Western } & \text { lagoon } \\
\text { (wp234 } & \text { John } \\
\text { Collen) } & \end{array}$ & $\begin{array}{l}5-6 \mathrm{~m} \text { below } \\
\text { surface }\end{array}$ & $0.00599 \mathrm{~m} / \mathrm{sec}$ & $\begin{array}{l}16.47 .29(11 / 06 / 08) \\
13.00 .39(10 / 06 / 08)\end{array}$ \\
\hline 1007 & $\begin{array}{ll}\text { Deployment } & \text { in the } \\
\text { Western } & \text { lagoon } \\
\text { (wp225 } & \text { John } \\
\text { Collen) } & \end{array}$ & $\begin{array}{l}40 \mathrm{~m} \text { below } \\
\text { surface }\end{array}$ & $0.00116 \mathrm{~m} / \mathrm{sec}$ & $\begin{array}{l}09.10 .02(12 / 06 / 08) \\
05.23 .32(11 / 06 / 08)\end{array}$ \\
\hline 1008 & $\begin{array}{l}\text { Deployment } \\
\text { between quail and } \\
\text { aviation }\end{array}$ & at $6 \mathrm{~m}$ & $0.01053 \mathrm{~m} / \mathrm{sec}$ & $\begin{array}{l}13.16 .35(15 / 06 / 08) \\
09.30 .05(14 / 06 / 08)\end{array}$ \\
\hline
\end{tabular}




\subsubsection{Calculations}

The following calculations are for the time taken (and hence the horizontal distance travelled under the assumed current velocity) for particles of different grain size to settle to a depth of $30 \mathrm{~m}$. At this depth, it is assumed that further settling is in a purely vertical direction.

\section{For 63 micron clasts:}

- The settling rate is $0.002039 \mathrm{~m} / \mathrm{sec}=0.2039 \mathrm{~cm} / \mathrm{sec}$

- Time for particle to descend to a depth of $30 \mathrm{~m}(3000 \mathrm{~cm} / 0.2039 \mathrm{~cm} / \mathrm{sec})=$ 14711.94

- Horizontal distance that particle would travel in a $.751 \mathrm{~cm} / \mathrm{sec}$ current is (14 $711.94 \mathrm{sec} \times 0.751 \mathrm{~cm} / \mathrm{sec}$ ) $=11048.67 \mathrm{~cm}$

- $\quad 11048.67 \mathrm{~cm}=110.49 \mathrm{~m}$ horizontal distance travelled

- Result $=\mathbf{1 1 0 . 4 9} \mathrm{m}$ horizontal distance travelled for $30 \mathrm{~m}$ vertical descent

\section{For 150 microns clasts:}

- The settling rate is $0.009783 \mathrm{~m} / \mathrm{sec}=0.9783 \mathrm{~cm} / \mathrm{sec}$

- Time for particle to descend to a depth of $30 \mathrm{~m}(3000 \mathrm{~cm} / .9783 \mathrm{~cm} / \mathrm{sec})=3$ $066.54 \mathrm{sec}$

- Horizontal distance that particle would travel in a $.751 \mathrm{~cm} / \mathrm{sec}$ current is $(3$ $066.54 \mathrm{sec} \times 0.751 \mathrm{~cm} / \mathrm{sec})=2302.97 \mathrm{~cm}$

- $2302.97 \mathrm{~cm}=23.0297 \mathrm{~m}$ horizontal distance

- Result $=\mathbf{2 3 . 0 3} \mathbf{m}$ horizontal distance travelled for $30 \mathrm{~m}$ vertical descent

\section{For 220 microns clasts}

- The settling rate is $0.017762 \mathrm{~m} / \mathrm{sec}=1.7762 \mathrm{~cm} / \mathrm{sec}$

- Time for particle to descend to a depth of $30 \mathrm{~m}(3000 \mathrm{~cm} / 1.7762 \mathrm{~cm} / \mathrm{sec})=1$ $688.998 \mathrm{sec}$

- Horizontal distance that particle would travel in a $.751 \mathrm{~cm} / \mathrm{sec}$ current is (1 $688.998 \mathrm{sec} \times .751 \mathrm{~cm} / \mathrm{sec})=1268.438 \mathrm{~cm}$

- $\quad 1268.438 \mathrm{~cm}=12.68 \mathrm{~m}$ horizontal distance

- Result $=\mathbf{1 2 . 6 8} \mathrm{m}$ horizontal distance travelled for $30 \mathrm{~m}$ vertical descent 


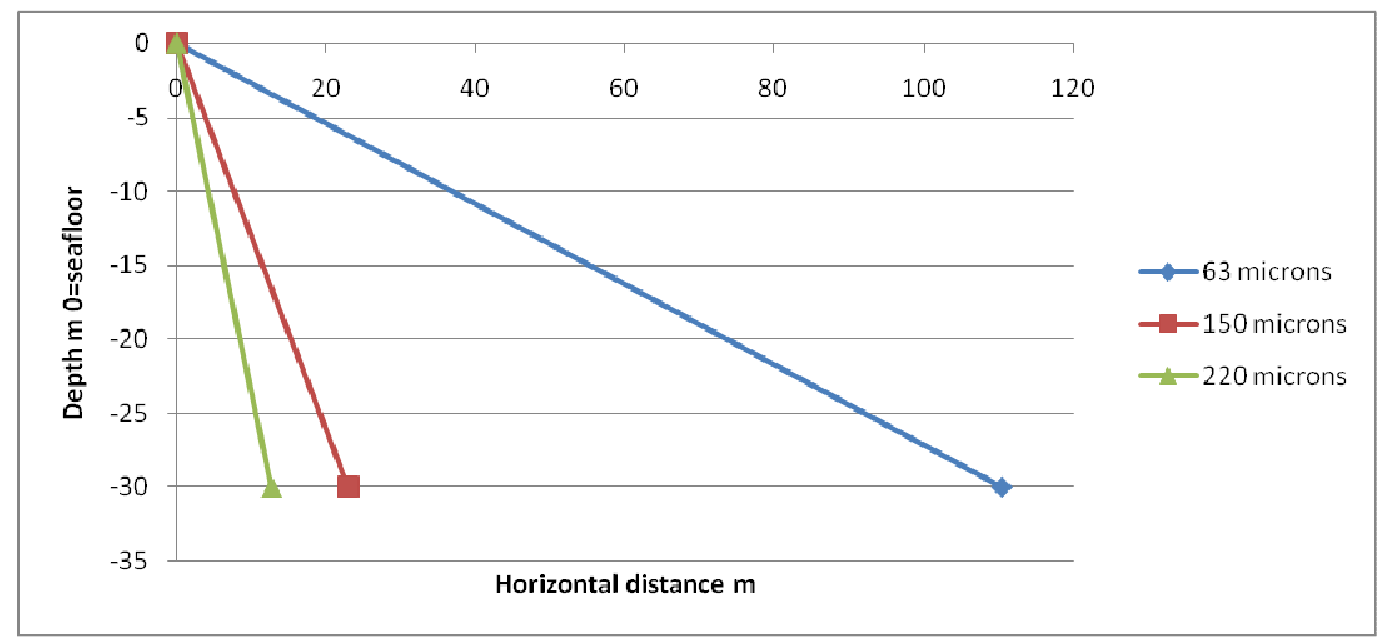

Fig 6.3 Hypothetical vector diagram of three particle sizes (not drawn to scale)

Note: Calculations do not take into account any variations of current velocity down to 30 metres depth. A true grain path would show particles decreasing in current velocity towards the still water zone.

The resulting calculation of horizontal distance travelled compared to sinking $30 \mathrm{~m}$ depth for clasts of $63 \mu \mathrm{m}, 150 \mu \mathrm{m}$ and $220 \mu \mathrm{m}$ sizes is shown in Fig 6.3. The results indicate that grains of 63 microns or less are likely to travel considerable distances, and may exit the lagoons before reaching the still water present below $30 \mathrm{~m}$ depth. The $220 \mu \mathrm{m}$ grains, however, are likely to reach this depth and then settle vertically to the bottom. It is important to note that this result does not take in to account the direction of current flow. Direction of current flow is likely to influence the overall horizontal distance travelled, for example if the current were to flow in one direction for a number of hours and the reverse direction the net horizontal transport would be less then if current direction was constant. However, the predominant overall current direction operating across Palmyra is in a westerly direction (see 2.2.1) (Maragos et al. A 2008)

The resultant settling rate of $0.018 \mathrm{~m}$ per sec (1 $534.64 \mathrm{~m}$ per day) for a $220 \mu \mathrm{m}$ pellet is comparable with the findings of Burland and Silver (1981) for laboratory investigations 
of the sinking rates from zooplankton salps and pteropods from the surface waters of the Californian current. They found that pellets from sank at rates up to 2700 and $1800 \mathrm{~m}$ per day, respectively.

\subsubsection{Implications of pellet formation}

Fecal pellets produced by aquatic organisms affect sedimentary processes in two ways. As fecal pellets are aggregates of particles, pellet sinking rates can be much greater than the rates of their smaller constituents (Haven et al. 1968, McCall 1979). Thus, pellets increase material fluxes through the water column by increasing sedimentation rates; this can also lead to the deposition of particles that, because of hydrodynamic or chemical characteristics, otherwise might not be deposited in a given environment (Haven et al. 1968, Silver et al. 1981). Shorter settling times provide for better chance of preservation and, incidentally, for less drift of suspended particles away from their place of origin. This means that the properties of surface water masses are more likely to be reflected in bottom sediments.

\subsection{Controls on the distribution of facies and environments by antecedent topography}

Ecological zonation is closely related to the sedimentary facies observed, and exerts some control over them. Ecological zonations may be partially explained by simple ecological controls, such as temperature, salinity, $\mathrm{pH}$, light penetration and turbidity (Section 1.4.1). The original distribution, shaping and growth of these environs, at least in their early stages, is most probably due to atoll morphology, in particular bathymetry and variation in exposure to waves and currents. Variation in bathymetry is most probably a consequence of differences in antecedent topographic features, which in turn may be explained by the karstic saucer theory of atoll origin (Hoffmeister and Ladd 1945, Wiens 1959, Purdy 1974, Guilcher 1988, Purdy 2005). "In summary, this theory states that the shape of atolls, and also of barrier reefs, derive from an antecedent, more or less horizontal, calcareous platform that emerged as a result of uplift or sea-level fall. Once 
emergent, the atoll became karstified by rainfall and percolating water, which produced landforms such as blue holes and gave it the shape of a saucer, with a central depression and a peripheral rim. Subsequent submergence of the platform structure resulted in a revival of coral growth, which buried the karstified limestone, and the annular rampart resulting from the karstification became the atoll rim. Thus the general shape of the atoll partly results from subaerial processes and not from peripheral reef building alone" (Guilcher 1988). Sea-level fall appears to be the influencing factor for Palmyra's modification. Fig 6.4 shows graphically how this theory results in the modification of atolls (Purdy 1974, Purdy and Winterer 2001). Subsequently, reef growth has continued and the resulting distribution of recent sediments is a combination of antecedent topographic features and the specific energy regime operating.

ATOLL
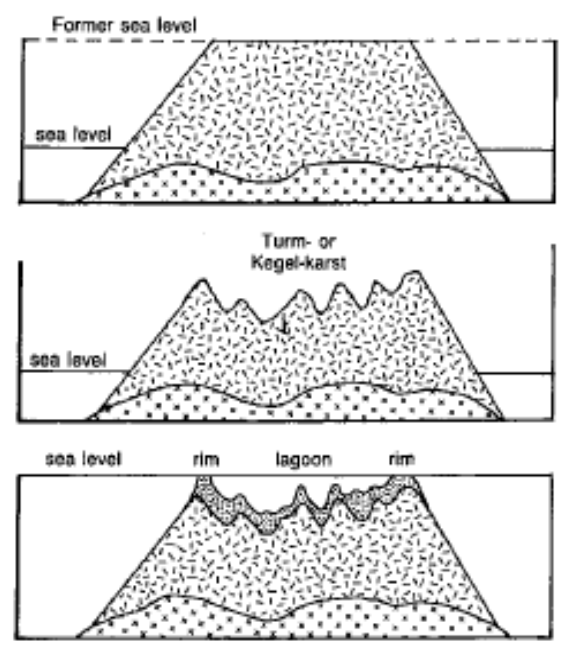

[.] basement imestono

Fig 6.4 Formation of atolls according to Purdy (1974), by Guilcher (1988)

Furthermore, the present day reef flats are thought to be a planation surface of hard cemented limestone that was probably formed at the present sea-level by erosion of a former higher reef accreted surface. This surface was most likely deposited during the early Holocene eustatic rise in sea level that was observed to form a mid Holocene 
highstand in relative sea level and similar surfaces on other Pacific islands (Hopley 1987, Dickinson 2004). The beachrock observed on the atoll was most likely deposited during this time of higher sea-level and has since become aerially exposed. This is the situation seen at Ebon Atoll (Weins 1959) and suggested for beachrock of Tarawa Atoll (Schofield 1977), both in the Marshall Islands.

The distribution of recent sediments has been also affected by the considerable anthropogenic modification to the morphology of the interior lagoons and surrounding islands during World War Two. Since that time, however, the atoll has largely been left to its own devices and natural processes have been operating largely unhindered by human intervention. This historical modification certainly affected the environmental zonation, facies and grainsize distributions, although the full extent of this is unknown. Variations in dredged material being dumped and compacted as fill layers (gravel, sand and clays) during construction of man-made features mean that ground properties vary considerably and are subsequently reacting differently to erosion (Collen et al. 2009). Dredging of the lagoons modified island and bathymetric profiles, making them steeper in contrast to more gently sloping natural shore profiles (Collen et al. 2009). At the present time, anthropogenic effects include pollutants from the settlement, shipwrecks, eroding military installations and from ocean-going floating debris, in particular plastics, which wash up on ocean-facing beaches of Palmyra.

\subsection{Comparison to other atolls and tropical carbonate systems}

Palmyra Atoll is unique and differs in several ways from other atolls of the Pacific and reef environments from other areas of the world where sedimentation has been examined. Most notably Palmyra Atoll, although once heavily modified, has had little human population or intervention on the island for the last 60 years and thus has been left largely to its own natural processes. As a result the atoll islands are heavily vegetated and populated with sea birds and the outer reefs are generally thriving. There has been no coastal protection program and the shorelines are modifying under natural conditions (Collen et al. 2009). 
Palmyra Atoll is small in size when compared to other atolls of the Pacific; as a result of the original size of the underlying volcanic structure. Palmyra is similar to many atolls in being asymmetrical, with differences between the windward and leeward sides. It is similar again to many other Pacific atolls in that the distribution of spur and grove systems is controlled by the dominant wind and swell direction. On Palmyra the spur and groves are found on the southern and northern sides of the atoll and are caused by the predominantly easterly and north-easterly prevailing winds and ocean currents that refract around both the elongated north and south sides of the atoll, generating alongshore currents that move westward (Barkley 1962, Maragos et al. A 2008). Palmyra has small lagoons that are deep, steep-sided and compartmentalized, in contrast to many atolls of the Pacific that have much larger and relatively shallow lagoons (such as Tarawa, Bikini, Rongerik and Funafuti atolls). Palmyra's morphology is thought to be a result of strong karstification of a small emergent island during previous sea-level falls caused by its location in the doldrums and the high annual rainfall that it receives each year due to this. At present Palmyra receives on average $445 \mathrm{~cm}$ of rain per year (Department of Interior 2008). The structure, especially the land areas and that of West and Center lagoons, has also been greatly affected by military dredging and construction during World War Two (Fig 2.5).

Comment [J6]: This is repetition of material in previous paragraph

The sediments and their distribution from the fore reef across the reef flats appear in the most part typical of tropical Pacific atoll systems. However, Palmyra differs in that it has very high percentages of fine material accumulating within its lagoons (upwards of $70 \%$ silt or finer). Data on lagoon floor sediments is available for Bikini, Rongelap, Rongerik, Raroia, Kapingamarangi, Ifaluk, Tarawa, Funafuti and from many barrier reef lagoon settings. Generally, mud values observed in other lagoon settings in the Pacific are low and the fine sediments are thought to be winnowed from the lagoon before settling offshore. Instead, usually either gravely sand coral debris-type facies (Namuka reef flat Fiji, Atkinson 1999; Lord Howe Island, Kennedy 2002; Middleton reef, Kennedy and Woddroffe 2004) or dominantly Halimeda debris (Bikini, Rongelap and Rongerik Atolls; Emery 1954, Suwarrow Atoll, northern Cook group, Tudhope et al. 1985, Funafuti Atoll, 
Collen and Garton 2004, Majuro Atoll, Smith and Collen 2006), or in some even deeper cases a foraminiferan-rich sand (Kapingamarangi Atoll (McKee et al. 1959) is present. In all these cases, silt-sized sediment abundance is less than $20 \%$ of the bulk. Calcium carbonate muddy bottomed lagoons have been found in deep enclosed basins at Addu and Diego Garcia Atoll in the Indian Ocean (Stoddart and Taylor 1971) and peloidal muds are common on isolated carbonate platforms from Belize-Yucatan system, Central America (Gischler 1999) and also common from the Florida shelf (Ginsburg 1956, Tucker and Wright 1990). Two unique examples of fine mud accumulation are seen on isolated areas of Tarawa Atoll, Gilbert Islands lagoon (between 6 and 10 depth) and in unusual abundance on Fanning Island lagoon; these accumulations, however, have been attributed to the high degree of protection given to the sediments from current winnowing, which in turn results from the near absence of deep channels connecting lagoon and ocean and the windbreak provided by the reef islands (Weber et al. 1972, Roy 1970). As discussed previously, the high abundance of fine material seen in the lagoons of Palmyra is thought to be a result of the natural deep enclosed bathymetry and the partial closing of the lagoons by military modification that both affect water circulation, together with the production of pellets by zooplankton.

In a number of deep lagoon localities (greater the $30 \mathrm{~m}$ ) the Peloidal mud sediments retrieved smelt strongly of hydrogen sulphide and suggested that the bottom waters were anoxic. In same locations that these sediments were retrieved, CTD casts reviled the presence of anoxic water above the substrate at depths greater then about $30 \mathrm{~m}$. This anoxic water was accompanied by increased turbidity. CTD casts were preformed the same time as this study in June 2007 and also in June 2008 (Gardner per. comm. 2008) (Section 2.2.2) (Fig 2.1). Further, water samples retrieved from deeper than $30 \mathrm{~m}$ during June 2008 were $\mathrm{H}_{2} \mathrm{~S}$ saturated (J.D. Collen, per. Comm. 2008). These results suggest a link is present between the depletion of oxygen, the level of turbidity and the level of organic material being supplied to the deep lagoon floor by means of feces and pseudofeces peloid production. Greater investigation is needed to quantify the relationship between these factors. 
Palmyra also differs from many other tropical carbonate systems in that it has no seagrass or mangrove zones. These are reef-associated communities of particular significance in other areas both as habitats and in terms of sediment accumulation and stabilization (Swinchatt 1965, Guilcher 1988, Tucker and Wright 1990, Morris 1998, Atkinson 1999).

The calcareous green alga Halimeda is a prolific producer of calcareous skeletal parts and on many atolls and reef systems is a dominant contributor to the sediments. Atkinson (1999) from Namuka reef flat, Suva, Fiji found that Halimeda on average contributed $38 \%$ of the sediment accumulating within the lagoons; others have found similar ranges from $20 \%$ to 40\% (Mopelia, Guilcher 1988, Rogerik and Rongelap atolls, Emery 1954, Isolated carbonate platforms in Belize-Yucatan system, Central America, Gischler et al. 1999). Halimeda is particularly prolific in deep water at 40-50m depth at Bikini Atoll where it accounts for over $70 \%$ of the bulk sediment (Emery 1954). Halimeda rich sediments are also seen forming a ring like pattern around the central area of Enewetak and Kapingamarangi (Guilcher 1988) and from Funafuti lagoon where they form thick beds (Collen pers. comm.). It is suspected that the low average abundances of Halimeda contributing to the accumulating sediments from the interior of Palmyra are in part a result of the lack of suitable substrate available and possibly the level of turbidity and suspended fine sediments observed in the water column within the lagoons. These would lower the level of light able to penetrate and reach the substrate that Halimeda would normally inhabit. The anoxia and high levels of $\mathrm{H}_{2} \mathrm{~S}$ appear significant in deeper water. A further reason may be the ease with which Halimeda segments are reduced to silt-sized fragments and finer, meaning that this material is either transported off the atoll or the degraded fine material is not then recognised during compositional analysis.

\subsection{Difficulties encountered and recommendations for future study}

Palmyra Atoll is a highly isolated location and as such there are many difficulties associated with the study of its recent sediments. Access to the atoll is by chartered flights from Hawai'i. Specific guidelines and conditions for entering and working within the refuge are in place. Studies of the geology and sediments of Palmyra present their own 
difficulties, as there is a lack of the long term records and observations that are needed to quantify many studies, furthermore only one visit was permitted and no chance to check details was available. Difficulties have been experienced in the processing of sediment recovered from Palmyra, in particular in dealing with the finest deep water mud samples and their inability to be fully disaggregated once dried. Long term water movement, climate and ecological studies are now beginning and will help in future sediment investigations and interpretations; unfortunately these and related studies important to understanding the sediment budget of Palmyra are currently proceeding and little material is published at present. A further step in improving the understanding of the sediments of Palmyra would come from detailed drilling and coring of the atoll. The data from this could be used to establish accurate ages and rates of sedimentation and evolution of sediments, previous sea level histories and ecological shifts among others.

\subsection{Summary and Conclusions}

\section{Facies mapping}

Six distinct sedimentary lithofacies have been identified within Palmyra Atoll lagoons and coastal fringes. These are the peloidal mud lithofacies, the muddy sand lithofacies, the coralagal sand lithofacies, the rubble lithofacies, cemented pavement and beachrock lithofacies, and the living reef facies. The most widespread facies identified within the study zone was the Coralalgal Sand Facies that covered approximately $45 \%$ of the study area.

\section{Environmental zones}

Six sedimentary and/or physiologic environmental zones and eight sub zones have been identified from Palmyra Atoll. These are the fore reef and crest, the eastern and western reef terraces, the ocean outer reef flat pavements and ocean-facing Beach, the lagoon inner reef flat intertidal sand aprons and sheets and lagoon beaches, the shallow and deep lagoons, patch reefs / sand banks and blue holes / ponds, and the reef islands zones. 


\section{Sedimentary processes}

The creation, movement and deposition of sediments upon Palmyra Atoll is by both physical as well as biological processes. Mechanical erosion is by current and wave forces. The predominant wave and current direction is from the east, caused by strong easterly trade winds and ocean currents. Tidal water movement is also important, and within the enclosed lagoon areas of Palmyra wave and current forcing is by local winds. The overall sediment movement is from east to west, both within the lagoons and across the reef flats. The biota may also be contributing to sediment movement. The biological processes operating serve to break down reef framework material and unconsolidated sediments at both microscopic and macroscopic scales, leaving material susceptible to further physical degradation. Biological activity in the form of bioturbation was observed to mix surfical sediments in many areas.

\section{Grain size distribution}

Sediments accumulating range in size from boulders to silt. This thesis focused on the sand and finer material from primarily the interior lagoons and tidal areas of Palmyra Atoll. Of the samples studied, the average sediments overall were of fine sand-size. Grainsize distribution was observed to grade from the coarsest, well sorted rubble material on the outer reef flat towards finer material within the deep lagoons of the atoll where silt-sized material prevailed. Material being generated by mechanical and biological processes and within the interior of Palmyra this material is predominantly sand or mud. The deep lagoons of Palmyra are particularly muddy and generally contain upwards of $70 \%$ silt or finer material. Most samples studied were poorly sorted and nearsymmetrical in their skewness distribution.

\section{Sedimentary composition}

The average bulk sediment is composed of six dominant categories: coral and red algae (50\%), molluscs (23\%), calcareous green algae, mostly Halimeda (11\%), foraminifera 
(4\%), echinoids (4\%) and crustaceans (4\%), and the remaining material (5\%) consisted mainly of organic or unidentified grains with very minor amounts of bryozoans, worm tubes and sponge spicules. All sediments of Palmyra Atoll are dominated by coral and calcareous red algal fragments, which make up about half of the sediment.

\section{Origin of sediments}

Sediments accumulating are clearly autochthonous in nature and sourced from the atoll. Sediments are either clearly skeletal (gravel and sand-sized) or finer material from the breakdown of skeletal components. Material is being sourced from living reefs and from the erosion and reworking of historical deposits. The recent material is being mainly sourced from the fore reef, crest and outer reef zones with lesser amount from patch reefs. Sediments are also being sourced by in situ growth of organisms living upon the accumulating sediments.

\section{Control of fine material in deep lagoons}

Binding of suspended sediments into pseudofecal and fecal pellets by large zooplankton is occurring within the lagoons of Palmyra, especially by the gastropod Creseis virgula constrica. Their skeletal remains are found in abundance in deep lagoon peloidal mud samples. Creseis has been implicated in the partial control of the sedimentation rate of fine material within the lagoons. Sediment samples from the deep lagoons predominantly contain more than $70 \%$ silt-sized or finer material.

\section{Control of distribution by antecedent topography}

Antecedent topographic features as the result of karstification during lowered past sealevels have resulted in the overall atoll shape seen today, that has since been modified and capped by the growth of Holocene reef material. The modern environments and sediments are now controlled by the interactions between the bathymetry, island morphology, hydrologic energy regime and biota associated with the atoll. 


\section{References}

Atkinson J., 1999. Recent carbonate sedimentation on Namuka reef flat, Suva, Fiji. Bsc Honours, Thesis Victoria University of Wellington

Atwater, T., J. Sclater, D. Sandwell, J. Severinghaus, and M.S. Marlow, 1993. Fracture zone traces across the North Pacific Cretaceous Quiet Zone and their tectonic implications. The Mesozoic Pacific: Geology, Tectonics and Volcanism, Geophys. Monograph, Vol. 77, Page 137-154

Ault J.S., 2007. Biology and management of the world Tarpon and Bonefish fisheries. Book; Published by CRC Press

Bak R.P.M., G.V. Eys, 1975. Predation of the sea urchin Diadema antillarum Philippi on living coral oecologia (Berl.). Springer-Voting, Vol. 20, Page 111--115

Barkley Richard A., 1962. Review of the oceanography of the Central Pacific ocean in the vicinity of the Line Islands. U. S. Bureau of commercial Fisheries, Biological Laboratory, Honolulu, Hawai'i.

Bé A.W.H., R.W. Gilmer. 1977. A zoogeographic and taxonomic review of euthecosomatous pteropoda. Oceanic Micropaleontology, Vol. 1, Page 733-808

Blair T.C., J.G. McPherson, 1999. Grainsize and textural classification of coarse sedimentary particles. Journal of Sedimentary Research, Vol. 69, Page 6-19

Boggs S.Jr., 2001. Principles of sedimentology and stratigraphy. 4th edition. Prentice Hall, Upper Saddle River, NJ. 662 pp

Bonham K., E.E. Held, 1963. Ecological observations on the sea cucumbers Holothuria atra and H. leucospilota at Rongelap Atoll, Marshal Islands. Pacif Science, Vol. 17, Page 305

Braithwaite C.J.R., L.F. Montaggioni， G.F. Camoin， H. Dalmasso， W.C. Dullo, A. Mangini, 2000. Origins and development of Holocene coral reefs: a revisited model based on reef boreholes in the Seychelles, Indian Ocean. International Journal of Earth Sciences, Vol. 89, Page 431-455

Bruland K. W., M. W. Silver, 1981. Sinking rates of fecal pellets from gelatinous zooplankton (Salps, Pteropods, Doliolids). Marine Biology, Vol. 63, Page 295 - 300

Carver R.E., 1980. Reducing sand sample volumes by spooning. Journal of Sedimentary Petrology, Vol. 51, Page 658 
Cobb K.M., C.D. Charles, H. Cheng, R.L. Edwards, 2003. El Nino/southern oscillation and tropical pacific climate during the last millennium. Nature, Vol. 424

Collen J. D., D.W. Garton, J.P.A. Gardner, 2009. Shoreline changes and sediment redistribution at Palmyra Atoll (Equatorial Pacific Ocean): 1874 - present, Journal of Coastal Research, (in press).

Davis A.S., L.B. Gray, D.A. Clague, and J.R. Hein, 2002. The Line islands revisited: New 40Ar/39Ar geochronological evidence for episodes of volcanism due to lithospheric extension. Geochem. Geophys. Geosyst. Vol. 3, Page 1018

Dawson, E.Y., A.A. Aleem and B.W. Halstead, 1955. Marine algae from Palmyra Island with special reference to the feeding habits and toxicology of reef fishes. Hancock Foundation Publication, Occ. Pap. 17

Dawson Y.E., 1959. Changes in Palmyra Atoll and its vegetation through the activities of man, 1913 - 1958. Pacific Naturalist, Vol. 1, Page 1 - 51

Dickinson W.R., 2004. Impacts of eustasy and hydro-isostasy on the evolution and landforms of Pacific atolls. Palaeogeography, Palaeoclimatology, Palaeoecology, Vol. 213, Page 251-269

Dunham R.J., 1962. Classification of carbonate rocks according to depositional texture. In: Ham (ed) Classification of Carbonate Rocks. Memoir 1, American Association of Petroleum Geologists, Page 108-121

Embry E.F.3 ${ }^{\text {rd }}$, J.E. Klovan, 1972. Absolute water depth limits of late Devonian paleoecological zones. Geol. Rundschau. Vol. 61, Fig. 5, Page 676

Emery K.O., J.I.Tracey Jr., H.S. Ladd, 1954. Geology of Bikini and nearby atolls; Bikini and Nearby Atolls: Part I, Geology. Geological Survey Professional Paper 260-A.

Emery K.O. 1956. Marine geology of Johnston Island and its surrounding shallows, central Pacific Ocean. GSA Bulletin, Vol. 67, Page 1505-1519

Ferguson, S., C. Musburger, P. Ayotte, T. Wass, B. Vargas-Angel, J. Maragos, S. Godwin, A. Tribollet, B. DeJoseph, A. Hall, M. Timmers, E. Coccagna, E. Dobbs, K. Hogrefe, D. Merritt, C. Young, K. Lino, E. Lundblad, J. Jones, J. Weiss, S. Charette, J. Bostick, 2006. Hi'ialakai HI0604 Cruise Report. NOAA Publication available at www.soest.hawaii.edu/pibhmc/.

Flint, E. 1992. Survey of the Terrestrial Biota of Palmyra Atoll: 18 February to 9 March 1992, Unpublished trip report, U.S. Fish and Wildlife Service, Page 19

Folk R.L., 1974. Petrology of sedimentary rocks. Book: University of Texas libraries, available free online at; www.lib.utexas.edu/geo/folkready/ 
Garcia, M.O., K.H. Park, G.T. Davis, H. Staudigel, and D.P. Mattey, 1983. Petrology and isotope geochemistry of lavas from the Line Islands Cahin, Central Pacific Basin. The Mesozoic Pacific: Geology, Tectonics and Volcanism, Geophys., Monogr. Ser, Vol. 77, Page 217-231

Gardner J.P.A, J.D. Collen, J. Allen, G. Dunbar, 2007. Palmyra Atoll research proposal, Victoria University of Wellington.

Gardner J.P.A., D.W. Garton, J.D. Collen, J. Allen, O.A. Clark, 2009. Pronounced dissolved oxygen stratification in a compartimentalized atoll lagoon system, (in preparation)

Gischler E., A.J. Lomando, 1999. Recent sedimentry facies of isolated carbonate platforms, Belize - Yucatan system, Central America. Journal of Sedimentry Research, Vol. 69, Page 747 - 763.

Glynn P.W., R.H. Stewart, J.E. McCosker, 1972. Pacific coral reefs of panamá: Structure, distribution and predators. International Journal of Earth Sciences, Vol. 61, Number 2

Guilcher A., 1988. Coral reef geomorphology, Book; John Wiley and Sons, Chichester

Haggerty, J.A., S.O. Schlanger, and I. Premoli-Silva, 1982. Late Cretaceous and Eocene volcanism in the southern Line Islands and implications for hotspot theory. Geology, Vol. 10, Page 433-437.

Hamann I.M., G.W. Boehlert, C.D. Wilson, 2004. Effects of steep topography on the flow and stratification near Palmyra Atoll. Ocean Dynammics, Vol 54, Page 460 - 473

Handler, A., J.A. Shelley, 2006. Anguilla marmorata (Giant Mottled Eel) discovered in a new location: natural range expansion or recent human introduction?. Pacific Science

Hart D.E., Kench P.S., 2007. Carbonate production of an emergent reef platform, Warraber Island, Torres Strait, Australia. Coral reefs, Vol. 26, Page 53-68

Haven D.S, R. Morales-Alamo, 1968. Occurrence and transport of faecal pellets in suspension in a tidal estuary. Sedimentary Geology, Vol. 2, Page 141-151

Hoffmeister J.E., H.S. Ladd, 1945. Solution effects on elevated limestone terraces. Geological Society of America Bulletin, Vol. 56, Page 809-818

Hopley J.W., 1982. The geomorphology of the Great Barrier Reef. Book: Published, Hardback, Cambridge University Press. 
Hunter I.G., 1977. Sediment production by Diadema antillarum on a Barbados fringing reef. Proc. 3 rd int. Symp. Coral Reefs

Ikonos satellite image, 2000. Of Palmyra Atoll, courtesy of the U.S. Fish and Wildlife Service and Space Imaging, Inc.

Kench P.S., R.F. McLean, 1996. Hydraulic characteristics of bioclastic deposits: new possibilities for environmental interpretation using settling velocity fractions. Sedimentology, Vol. 43, Page 561 - 570

Kench P.S., R.F. McLean, 1997. A comparison of settling and seive techniques for the analysis of bioclastic sediments. Sedimentry Geology, Vol. 109, Page $111-119$

Kench P.S., 1998. Hydrodynamic observations of the Cocos (Keeling) Island lagoon, Chapter 10.

Kennedy D.M., 2001. Surface lagoon sediemnts on Lord Howe Island, Tasman Sea. Journal of Coastal Research. Vol. 19, Page $57-63$

Kennedy D.M., C.D. Woodroffe, 2004. Carbonate sediments of Elizabeth and Middleton Reefs close to the southern limits of reef growth in the southwest Pacific. Australian Journal of Earth Sciences, Vol. 51, Page 847 - 857

AKennedy D. M., C. D. Woodroffe, 2004. Algal encrustation and the interpretation of radiocarbon dating of coral clasts. Coral reefs, Vol. 23, Page 509-513

Knowlton, N., and J. Jackson 2008. Shifting Baselines, Local Impacts, and Global Change on Coral Reefs. Plos. Biol. Vol. 6, Page 54

McCall P.L., 1979. The Effects of Deposit Feeding Oligochaetes on Particle Size and Settling Velocity of Lake Erie Sediments. Journal of Sedimentary Research, Vol. 49

Maragos J. E., 1993. Impact of costal construction on coral reefs in the U.S. Affiliated Pacific Islands. Coastal Management, Vol. 21, Page 235- 269

Maragos J.E., 1979. Palmyra. Appendix. Preliminary environmental survey and assessment. U.S. Army Corps of Engineers, Pacific Ocean Division, Ft Shafter, Hawaii, 31pages + Appendix

A Maragos J., J. Miller, J. Grove, E. DeMartini, A. Friedlander, S. Godwin, C. Musburger, M. Timmers, R. Tsuda, P. Vroom, E. Flint, E. Lundblad, J. Weiss, P. Ayotte, E. Sala, S. Sandin, S. McTee, T. Wass, R. Brainard, D. Obura, S. Furguson, B. Mundy, 2008. U.S. atolls and low reef islands in the Line and Phoenix Islands, Central Pacific Ocean, Chapter 15, Book: Coral reefs of the U.S.A. 2008. Edited by B.M. Riegl, R.E. Dodge. Published by Springer 
B Maragos J., Alan M. Friedlander, Scott Godwin, Craig Musburger, Roy Tsuda, Elizabeth Flint, Olga Pantos, Paula Ayotte, Enric Sala, Stuart Sandin, Sarah McTee, Daria Siciliano, David Obura, 2008. U.S. coral reefs in the Line and Phoenix Islands, Central Pacific Ocean: Status threats and significance, Chapter 16, Book: Coral reefs of the U.S.A. 2008. Edited by B.M. Riegl, R.E. Dodge. Published by Springer

Marshall J. F., G. Jacobson, 1984. Holocene growth of a mid-Pacific atoll: Tarawa, Kiribati. Coral Reefs, Vol. 4, Page $11-17$

McKee E.D., J. Chronic, E.B. Leopold, 1959. Sedimentary belts in lagoon of Kapingamarangi atoll. AAPG Bulletin, Vol. 3, Page 501-562

McKoy H., 2007. Carbonate sediment connectivity on coral reef platforms and its relation to the evolution of small sand islands: Mamanuca Island Group, Fiji. Msc Thesis Victoria University of Wellington

Milliman J.D., 1974. Marine carbonates. Recent sediemntry carbonates, Part 1. Springer Verlag., Page 375

Montaggioni L.F., 2005. History of Indo-Pacific coral reef systems since the last glaciation: Development patterns and controlling factors. Earth-Science Reviews, Vol. 71 , Page 1-75

Morris M., 1998. Applied sediemntology of the Nukubuco reef flat, Laucala Bay, Suva, Fiji. Bsc honours, Thesis Victoria University of Wellington

Moy C.M., G.O. Seltzer, D.T. Rodbell, D.M. Anderson, 2002. Variability of El Niño/Southern Oscillation activity at millennial timescales during the Holocene epoch. Nature, Vol. 420, Page 162-165

National Geographic, 2007. Web-document; The treasured islands of Palmyra 2001, http://ngm.nationalgeographic.com/ngm/0103/feature2/index.html

NOAA, 1944. Bathymetry map of Palmyra Atoll, Nautical chart No. 2 Panel E

NOAA, National Oceanic and Atmospheric Administration 2008. Online data base and research pages, www.noaa.gov

Palmyra Atoll Research Consortium, 2008. Online directory and research pages, http://www.palmyraresearch.org/about

Perry C.T., 1996. The Rapid Response of Reef Sediments to Changes in Community Composition: Implications for Time Averaging and Sediment Accumulation. Journal of Sedimentary Research, Vol. 66 
Perry C.T., 1998. Grain susceptibility to the effects of microboring: implications for the preservation of skeletal carbonates. Sedimentology, Vol. 45, Page 39-51

Purdy E.G., 1974. Karst-determined facies patterns in British Honduras: Holocene carbonate sedimentation model. AAPG Bulletin, Vol. 58, Page 825-855

Purdy E.G., E.L. Winterer, 2001. Origin of atoll lagoons. GSA Bulletin, Vol. 113, Page 837-854

Purdy E.G., E. Gischler, 2005. The transient nature of the empty bucket model of reef sedimentation. Sedimentary Geology, Vol. 175, Page 35-47

Radall, 1958. A review of ciguatera, tropical fish poisoning, with a tentative explanation of its cause.

Rao C.P., 1996. Modern carbonates, tropical, temperate, polar. Introduction to sedimentology and geochemistry. University of Tasmania, Page 206

Rock J.F., 1916. Palmyra Island with a description of its flora. Honolulu Star-Bulletin, Honolulu, Hawaii.

Roy K. J., 1970. Sedimentation and reef development in turbid-water areas of fanning lagoon. Bull. Amer. Assoc. Petrol. Geology. Vol. 54, Page 867

Rogers C.S., 1990. Responses of coral reefs and reef organisms to sedimentation. Marine ecology progress series, Vol. 62, Page 185-202

Sandin, S.A., Smith, J.E., DeMartini, E.E., Dinsdale, E.A., Donner, S.D., Friedlander, A.M., Konotchick, T., Malay, M., Maragos, J.E., Obura, D., Pantos, O., Paulay, G., Richie, M., Rohwer, F., Schroeder, R.E., Walsh, S., Jackson, J.B.C., Knowlton, N., Sala, E. 2008. Baselines and degradation of coral reefs in the northern Line Islands. PloS. Vol. 3, Page 1548

Schrader Hans -Joachim, 1971. Fecal pellets: Role in sedimentation of pelagic diatoms. Science, Vol. 174, Page 55 - 57

Schlanger, S.O., E.D. Jackson, R.E. Boyce, H.E. Cook, H.C. Jenkyns, D.A. Johnson, A.G. Kaneps, K.R. Kelts, E. Martini, C.L. McNulty, and E.L. Winterer, 1976. Initial Rep. Deep Sea Drilling Project 33

Schlanger, S.O., M.O. Garcia, B.H. Keating, J.J. Naughton, W.W. Sager, J.A. Haggerty, J. A. Philpotts, and R.A. Duncan, 1984. Geology and geochronology of the Line Islands. Journal Geophys. Res. 89 (11), Page 261-272

Schrader H.J., 1971. Fecal pellets: Role in sedimentation of pelagic diatoms. Science Vol. 174 
Scoffin T.P., 1987. An introduction to carbonate sediments and rocks. Book: Blackie, London

Smith, W.H.F., and D.T. Sandwell, 1997. Global sea floor topography from satellite altimetry and ship depth soundings. Science, Vol. 277, Page 1956-1962

Stoddart D. R., 1969. Ecology and morphology of recent coral reefs, Biological Review Vol. 44, Page 433 - 498

Stoddart D.R., J.D. Taylor, 1971. Geography and Ecology of Diego Garcia Atoll, Chagos Archipelago. Issued by the Smithsonian Institution

Swinchatt J.P. 1965. Signiface of constituent compostion, texture and skeletal breakdown in some recent carbonate sediments. Journal of Sediemntary Petrology, Vol. 35, Page 71-90

The Nature Conservancy, 2008. Palmyra Atoll facts page; http://www.nature.org/wherewework/asiapacific/palmyra/

Trenberth, K.E., 1997. The Definition of El Niño. Bulletin of the American Meteorological Society, Vol. 78, Page 2771-2777

Tucker M.E., V.P. Wright, 1990. Carbonate sedimentology. Book: Blackwell Scientific Publications.

Tudhope A.W., 1983. Processes of lagoonal sedimentation and patch reef development, Davis Reef, Great Barrier Reef of Australia. Thesis doctor of philosophy University of Edinburgh.

U.S. Department of the Interior, 2006. Office of Insular Affairs, 1849 C Street, N.W. Washington, DC 20240, Phone: (202) 208-6816, FAX: (202) 219-1989 http://www.doi.gov/oia/

USFWS. 2001. Environmental assessment: proposed Palmyra Atoll National Wildlife Refuge, Page 28

U.S. Fish and Wildlife, 2008. Web-document; http://www.fws.gov/pacificislands/wnwr/palmyranwr.html

Uye Shin-ichi, Kohei Kaname, 1994. Relationship between fecal pellet volume and body size for major zooplankters of the inland sea of Japan. Journal of Oceanography, Vol. 50, Page $43-49$

Vroom, P., M. Dailer, M. Timmers, J. Maragos, B. Vargas-Angel, C. Musburger, P. Ayotte, S. McTee, B. Richards, E. Keenan, S. Charette, A. Hall, J. Gove, K. Hogrefe, 
R. Hoeke, J. Jones, J. Miller, J. Chojnacki, L. Woodward, C. Eggleston, S. CooperAlletto, and R. Heikkenin, 2006. Hi 'ialakai HI0601 Cruise Report. NOAA Publication available at www.soest.hawaii.edu/pibhmc/.

Wanless H.R., E.A. Burton, 1981. Hydrodynamics of carbonate fecal pellets. Journal of Sedimentry Petrology, Vol. 51, Page 0027 -0036.

Weber Jon N., Peter M.J. Woodhead, 1972. Carbonate lagoon and beach sediments of Tarawa Atoll, Gilbert Islands. Smithsonian Institution, Atoll Research Bulletin, No. 157

Wiens H.J., 1959. Atoll development and morphology. Annals of the Association of American Geographers, Vol. 49, Page 31-54

Williams, G.J., Davy, S.K., and Aeby, G.S. 2007. Coral disease at Palmyra Atoll, a remote reef system in the Central Pacific. Coral Reefs DOI 10.1007

Woodbury D.O., 1946. Builders for Battle: How the Pacific Naval Air Bases Were Constructed. Book; Dutton and Company inc.

www.filtration-and-separation.com 2008. Online particle settling velocities calculator

www.csgnetwork.com/h2odenscalc.html 2008. Online fluid density and viscosity calculator.

Yu, X., M., McPhaden, 1999. Seasonal Variability in the Equatorial Pacific, Journal Phys. Oceanogr., Vol. 29, Page 925-947 